\title{
An Agent-Based Model to Support Negotiation-Based Order Acceptance in a Multi-Plant Enterprise
}

\section{Zahra Mobini Dehkordi}

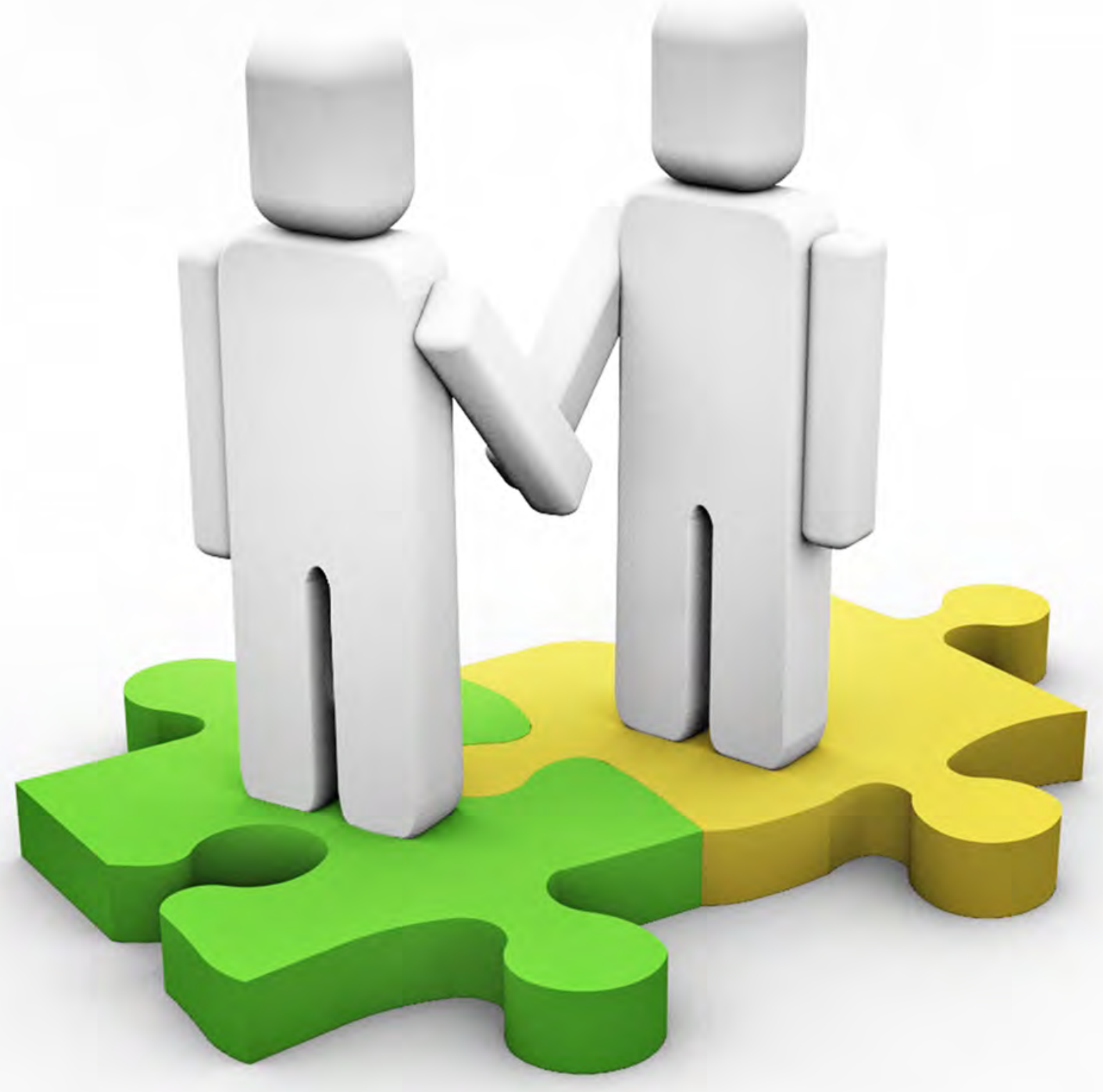





\title{
An Agent-Based Model to Support Negotiation-Based Order Acceptance in a Multi-Plant Enterprise
}

\author{
MASTER THESIS
}

\section{ZAHRA MOBINI DEHKORDI \\ 1542877}

\section{Graduation Committee:}

Prof.dr.ir M.P.C. Weijnen (Chair; Energy and Industry Section) dr.ir. Zofia Lukszo (First supervisor; Energy and Industry Section) Dr. Scott Cunningham (Second supervisor; Policy Analysis Section) ir. Behzad Behdani (Daily supervisor; Energy and Industry Section)

\author{
Program Master of Science in Engineering and Policy Analysis \\ Graduation October 2010 \\ Section Energy and Industry \\ Faculty Technology, Policy and Management \\ University Delft University of Technology
}

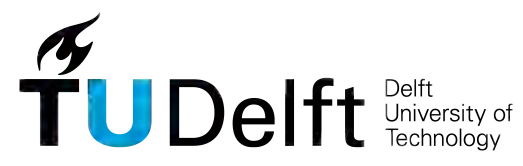





\section{Summary}

Order acceptance (OA) has a large influence on the performance of an enterprise. On the one hand, always accepting an order when capacity is available may restrict the system to accept more profitable orders in the future. On the other hand, rejecting too many orders leads to low capacity utilization and also has repercussions for future customer relations. In addition, accepting too many orders leads to an over-loaded production environment, where lead times increase and orders are delivered late. Most of these aspects of order acceptance decision-making can be handled by having proper negotiations with customers on order terms. However, this is a complex problem primarily because there are different actors who have various (conflicting) interests, needs and objectives. Accordingly, to provide insight for the decision makers in the firms in order to develop proper strategies for order acceptance, developing appropriate models seems necessary.

The objective in this research is to improve the order acceptance performance of a make-to-order multi-plant enterprise (MPE) by incorporating buyer-seller negotiations in its OA procedure with the main research question of "How can the buyer-seller negotiation process contribute to the improvement of order acceptance performance in the multi-plant enterprise?"

For this purpose, we have developed an agent-based model to support order acceptance decisions in a multi-plant enterprise particularly using different negotiation settings.

The research starts with literature review on order acceptance in general and negotiation in particular. A gap is identified in the OA literature: the major perspectives on the OA procedure rest on the underlying assumption that order terms are already determined which is not always tenable. In reality, order terms are usually specified by negotiation between the buyer and the seller and they are not predetermined. A negotiation-based order acceptance approach is consequently suggested in order to consider the whole activities in a negotiation process with three phases. The proposed process involves the initiation conditions for negotiation (pre-negotiation phase), the main interaction (negotiation phase) and the consequences of negotiation on the future decisions of the involved actors (post-negotiation phase). This negotiation process is a part of more general negotiation framework which is then extended into a negotiation ontology. The ontology introduces the main concepts and their relations in a negotiation problem. Next, the conceptualization of the order negotiation process in OA and the negotiation ontology are used in developing an agent-based model for buyer-seller negotiations in a case of multi-plant enterprise. The general assumptions and settings for model development are taken from a model have been presented by Behdani et al. (2010) for a lube oil multi-plant case study motivated by a real supply chain. In this research, the previous model is extended by incorporating negotiation between the 
enterprise and its customers on order terms. Finally, to illustrate the applicability of the developed model to support OA decision-making, some experiments are formulated (based on the most important related concepts in the literature) and implemented in the model. The experiments are used to evaluate the performance of several OA strategies and gain insight of the OA procedure in the MPE.

To sum-up, the main contribution of this work is to conceptualize and develop an agent-based model for the buyer-seller negotiation process incorporating all steps in the negotiations. The developed model and conceptualization presented in this work not only provide valuable insights into the nature of negotiation in a supply chain setting, but also, can support the OA decision makers to make better-informed decisions. Although, the model presented in this thesis is performed for a specific case description, the conceptualization and ontology presented are generic (there is no case-specific details) and they can be used not only for buyer-seller negotiations in other industrial settings but also for negotiation problems in other domains. Moreover, the agents developed in this research can also be reused in developing other models for some other industrial supply chains as described by van Dam (2009).

Keywords: Order acceptance, buyer-seller negotiation, agent-based modeling, multi-plant enterprise, supply chain. 


\section{Acknowledgement}

This document represents the throughputs of almost 7-month research for the master thesis project which concludes my studies in Engineering and Policy Analysis at Faculty of Technology, Policy and Management of Delft University of Technology.

This research was not possible without the help and support of some people who I would like to thank.

First, I would like to thank Professor. dr. ir. Margot Weijnen for her guidance. Next I would like to express my sincere thanks to dr. ir. Zofia Lukszo for keeping me pointed in the right direction throughout the research. I am also deeply grateful to Dr. Scott Cunninghum for his invaluable remarks during discussions we had.

I would like to extend my thanks to ir. Behzad Behdani who was of great help in conducting this research and dealing with the routines and challenges of a research work.

I am also grateful to the members of the energy and industry section whom I had the privilege to work with during the last few months. Their enthusiasm and dedication to their chosen field was always encouraging.

I would like to express my sincere thanks to a couple of friends who were always there for me especially at difficult times, particularly I would like to thank Amineh and Yashar, Nadjla, Shole, Raha, Tahereh, Yugi and Linneke for their precious friendship. This research would not have been possible without your support.

Last but not the least, I am deeply thankful for the love and support of my family without them I would not be able to pursue my goals.

Zahra Mobini Dehkordi

October 2010 


\section{Contents}

I Problem Exploration and Research Framework $\quad 1$

1 Introduction 2

1.1 Problem description . . . . . . . . . . . . . . . . . 2

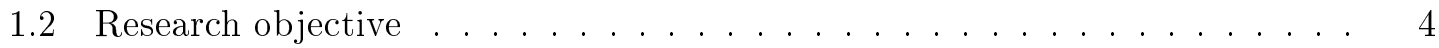

1.3 Research scope . . . . . . . . . . . . . . . . 5

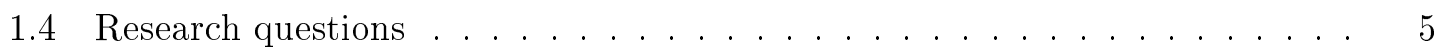

1.5 Research contribution ................... 6

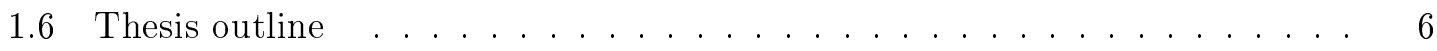

2 Negotiation in Order Acceptance $\quad 8$

2.1 Order acceptance basics . . . . . . . . . . . . . . . 8

2.1.1 Order acceptance background . . . . . . . . . . . . . . 9

2.1.1.1 Integration of sales and production activities . . . . . . 10

2.1.1.2 Order selectivity based on profit . . . . . . . . . . 11

2.1.1.3 Customer segmentation . . . . . . . . . . . . 12

2.1.1.4 Negotiation . . . . . . . . . . . . . . . . . 13

2.2 Negotiation basics . . . . . . . . . . . . . . . . . . 15

2.2.1 Negotiation in decision making . . . . . . . . . . . . . 15

2.2.2 Buyer-seller negotiation modeling background . . . . . . . . . . . . 16

2.2.2.1 Analytical models . . . . . . . . . . . . . 17

2.2.2.2 Simulation models . . . . . . . . . . . . . . 20

2.3 General framework for negotiation . . . . . . . . . . . . . . . 22

2.4 Chapter conclusion . . . . . . . . . . . . . . 26

3 Choice of Modeling Approach 28

3.1 System description . . . . . . . . . . . . . . . . . . . 28

3.2 System characteristics . . . . . . . . . . . . . . . . 30

3.3 Modeling approach for the MPE supply chain . . . . . . . . . . . . . . 34

3.4 Overview of some simulation paradigms . . . . . . . . . . . . . . . 35

3.4 .1 System Dynamics . . . . . . . . . . . . . . . 35

3.4 .2 Discrete Event . . . . . . . . . . . . . . . . . 36

3.4 .3 Agent Based . . . . . . . . . . . . . . . . . . . 37

3.5 Choice of agent-based modeling . . . . . . . . . . . . . . . . 38

3.6 Chapter conclusion . . . . . . . . . . . . . . . . . . 39 
II Development of the Negotiation Model in MPE

4 Agent-Based Model for Negotiation in MPE 42

4.1 Problem formulation . . . . . . . . . . . . . . . . . . . . . 42

4.2 System identification . . . . . . . . . . . . . . . . . . 42

4.3 Architectural design . . . . . . . . . . . . . . . . . . . 44

4.3.1 Negotiation Ontology . . . . . . . . . . . . . . . 44

4.3 .2 Agent architecture . . . . . . . . . . . . . . . . . 46

4.3.2.1 Seller Agent . . . . . . . . . . . . . . 46

4.3.2.2 Buyer Agent . . . . . . . . . . . . . . . . . . 49

4.3.2.3 Agent Interaction . . . . . . . . . . . . . . 51

4.4 Detailed design . . . . . . . . . . . . . . . . . . . . 59

4.5 Verification and validation . . . . . . . . . . . . . 63

4.5.1 Verification .................... 63

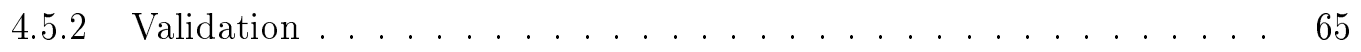

4.6 Chapter conclusion . . . . . . . . . . . . . . . 68

$\begin{array}{ll}\text { III Results and Reflections } & 70\end{array}$

5 Experimental Set-up and Simulation Results $\quad 71$

5.1 Model assumptions . . . . . . . . . . . . . . . . . . 71

5.2 Performance indicators . . . . . . . . . . . . . . . . . 73

5.3 Experimental set-up 1 :important OA viewpoints . . . . . . . . . . 73

5.3 .1 Base case . . . . . . . . . . . . . . . . 74

5.3 .2 Order selectivity . . . . . . . . . . . . . . 75

5.3 .3 Negotiation ......................... 75

5.3.4 Simulation results and discussion . . . . . . . . . . . . . 75

5.4 Experimental set-up 2: effect of demand load . . . . . . . . . . . . 78

5.5 Experimental set-up 3: different approaches in preparing the counter-offer . 79

5.5.1 Time-dependent concession ................. 80

5.5.2 Customer-dependent concession . . . . . . . . . . . . . . 80

5.6 Chapter conclusion . . . . . . . . . . . . . . . . . . . 81

6 Conclusion and Reflection $\quad 82$

6.1 Research overview . . . . . . . . . . . . . . . . . 82

6.2 Addressing research questions . . . . . . . . . . . . . . . . . 83

6.3 Research contribution . . . . . . . . . . . . . . . . 87

6.4 Recommendation for further research . . . . . . . . . . . . . . . 89

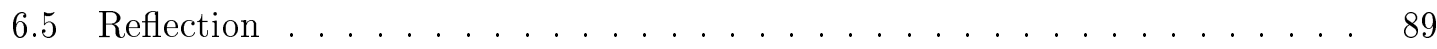

$\begin{array}{ll}\text { Bibliography } & 91\end{array}$

$\begin{array}{ll}\text { A Overview of the MPE Supply Chain } & 100\end{array}$

B Order Costs and Revenue 102 
C The Repast Model $\quad 106$ 


\section{List of Figures}

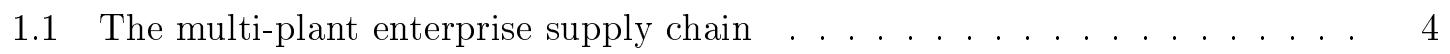

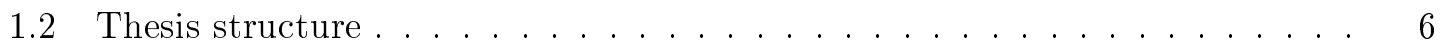

2.1 Negotiation based order acceptance approach . . . . . . . . . . . . . . . 14

2.2 Approaches in decision-making (Raiffa et al., 2002) . . . . . . . . . . . . 15

2.3 Negotiation Types (adapted from Wong and Fang (2010)) . . . . . . . . . . 17

2.4 Negotiation framework . . . . . . . . . . . . . . . . . . 23

2.5 Downhill evaluation function for price . . . . . . . . . . . . 25

3.1 The multi-plant enterprise operations, adapted from Behdani et al. (2010) . 29

3.2 Social and physical sub-systems in the MPE supply chain (simplified version) 31

3.3 The multi-level system of MPE supply chain . . . . . . . . . . . . . . 32

3.4 A discrete event model: products storage and transport . . . . . . . . . . 37

4.1 The interface of GSD and customers in order acceptance . . . . . . . . . . 43

4.2 Type of negotiation in this research . . . . . . . . . . . . . . . . . . 44

4.3 Simplified version of the negotiation ontology . . . . . . . . . . . . . . 45

4.4 The seller state transition diagram . . . . . . . . . . . . . . . . . 47

4.5 The buyer state transition diagram . . . . . . . . . . . . . . 50

4.6 Negotiation phases . . . . . . . . . . . . . . . . . . . 51

4.7 Seller pre-negotiation phase . . . . . . . . . . . . . 52

4.8 Offer preparation procedure . . . . . . . . . . . . 55

4.9 The agents' interaction diagram (three negotiation phases, decisions and

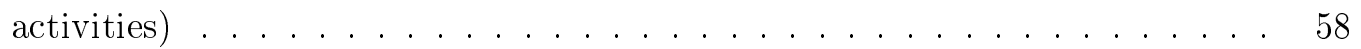

4.10 Negotiation Process class, its slots and relations in the ontology . . . . . . 59

4.11 Negotiation Phase class, its slots and relations in the ontology . . . . . . . . 60

4.12 Negotiation Party class, its slots and relations in the ontology . . . . . . . 61

4.13 Negotiation Issue class, its slots and relations . . . . . . . . . . . . . 62

4.14 Negotiation Protocol class, its slots and relations in the ontology . . . . . 62

4.15 Negotiation Rule class, its subclasses, slots and relations . . . . . . . . . 63

4.16 A debugging example in eclipse . . . . . . . . . . . . . . . . 65

4.17 Inventory level for the extreme case . . . . . . . . . . . . . . . . 67

5.1 Important viewpoints on making OA decisions . . . . . . . . . . . . . . . 74

5.2 Annual profit in the first set of experiments . . . . . . . . . . 76 
5.3 Order acceptance history in the first set of experiments . . . . . . . . . 76

5.4 Delivery history in the first set of experiments . . . . . . . . . . . . 77

5.5 Annual profit in the lower-loaded demand situation . . . . . . . . . . . 78

5.6 Order acceptance history in the lower-loaded demand situation . . . . . . 79

5.7 Delivery history in the lower-loaded demand situation $\ldots \ldots$. . . . . . 79

A.1 Main actors and their interactions in the MPE supply chain from (Behdani et al., 2009) . . . . . . . . . . . . . . . . . . . 101 


\section{List of Tables}

2.1 Summary of analytical models on buyer-seller negotiations . . . . . . . . . 20

2.2 Summary of simulation models on negotiation . . . . . . . . . . . . . 22

3.1 Relations of the components in the social and physical sub-system . . . . . 31

4.1 Common attributes of two agents . . . . . . . . . . . . . . 48

4.2 The buyer agent attributes . . . . . . . . . . . . . . . 51

4.3 Some examples of extreme value test . . . . . . . . . . . . . . 65

4.4 An example of extreme value test . . . . . . . . . . . . . . 66

4.6 Some examples of extreme value test (with model run) . . . . . . . . . . 67

4.7 Results of sensitivity analysis . . . . . . . . . . . . . . . 68

5.1 Evaluation functions of the agents . . . . . . . . . . . . . 72

5.2 Comparison of the number of orders in the first set . . . . . . . . . 77

5.3 Comparison of successful negotiations in different concession-making approaches . . . . . . . . . . . . . . . 80

B.1 Product A, its grades and raw materials . . . . . . . . . . . . . . 102

B.2 Product B, its grades and raw materials . . . . . . . . . . . . . 103

B.3 Product $\mathrm{C}$, its grades and raw materials . . . . . . . . . . . . 103

B.4 Raw material costs . . . . . . . . . . . . . . . . . . . . 103

B.5 Products revenue $(\$ /$ unit $) \ldots \ldots \ldots \ldots \ldots$ 


\section{List of Abbreviations}

$\begin{aligned} \text { AB } & \text { Agent-Based } \\ \text { ABM } & \text { Agent-Based Modeling } \\ \text { BATNA } & \text { Best Alternative to the Negotiated Agreement } \\ \text { DE } & \text { Discrete Event } \\ \text { E\&I } & \text { Energy and Industry } \\ \text { GSD } & \text { Global Sales Department } \\ \text { MAS } & \text { Multi-Agent Systems } \\ \text { MPE } & \text { Multi-Plant Enterprise } \\ \text { MTO } & \text { Make-To-Order } \\ \text { MTS } & \text { Make-To-Stock } \\ \text { OA } & \text { Order Acceptance } \\ \text { PEDD } & \text { Processing Earliest Due Date } \\ \text { SC } & \text { Supply Chain } \\ \text { SD } & \text { Systems Dynamics }\end{aligned}$




\section{Part I}

\section{Problem Exploration and Research Framework}




\section{Chapter 1}

\section{Introduction}

This introductory chapter begins with the description of the research problem in 1.1; then research objective, research scope and research questions are presented in 1.2,1.3 and 1.4 respectively. The contribution of the research is discussed in 1.5. The chapter concludes with the outline of the current document in 1.6.

\subsection{Problem description}

A critical decision for order-driven production firms is order acceptance (Arredondo and Martinez, 2010; Moodie, 1999). Order acceptance policies have tremendous impact on the performance of a firm both in the short-term (e.g. immediate profit) and in the long-term (e.g. customer satisfaction and repeat purchase). Firms should carefully choose which orders are worth accepting and which orders should be rejected from the viewpoint of making progress towards the long-term as well as short-term organizational goals. Accepting every incoming order as long as capacity allows pursues the goal of making profit but at the same time leads to the commitment of production capacity in a way that accepting more profitable orders in the near future is no longer feasible. On top of that, accepting a large number of arriving orders increases the utilization rate of production resources. In such an over-loaded production environment, simple tardiness in the arrival of raw materials may cause a large number of delayed deliveries and decrease customer satisfaction accordingly. Conversely, rejecting some valuable orders can give rise to an unnecessarily low utilization rate of resources and have repercussions for future customer relations as well.

Order acceptance is a complex process that can be investigated from different perspectives. In the relevant literature, different researchers focus on the various parts of order acceptance decisions.

Some focus on the integration of sales/marketing and production, claiming that, in practice, the sales department often makes independent decisions on bids without consulting the production department (Cakravastia and Nakamura, 2002). In one of the first works on the topic, ten Kate (1994) shows that in tight situations with short lead-times and high utilization rate, order acceptance integrated with production scheduling functions performs better than operations where these functions are not closely integrated. van Foreest et al. (2010) compare several order acceptance approaches and conclude that under 
heavy workload the one based on the detailed scheduling of accepted orders outperforms other aggregate approaches.

Another stream of research on the order acceptance is order selectivity based on orders' profit contributions. In this approach, the aim is to satisfy the customers' demand by allocating resources in a way that revenue and profitability are optimized. This approach is referred to revenue-based capacity management in the literature (Defregger and Kuhn, 2007). Missbauer (2003) uses a stochastic model to derive optimal lower bounds for the profit margin of stochastically arriving orders. Only orders whose contribution margins exceed the optimal lower bounds are accepted. Arredondo and Martinez (2010) applies reinforcement learning for online adaptation of profit threshold based on acceptance or rejection of similar orders. Similarity of orders is defined regarding attributes such as product mix, price, size and due date.

The problem of order acceptance is also closely related to a firm's customer relationship management, with many studies focusing on managing incoming orders from different customer segments and assigning capacity to more profitable customers. For this purpose, some works consider various classes of customers in the order acceptance procedure and different priority rules are presented to meet the expectations of different customer segments. Harris and Pinder (1995) consider an assemble-to-order manufacturing company and determine optimal pricing and capacity reallocation policies for a revenue management problem with an arbitrary number of customer classes. Keskinocak et al. (2001) study several online and offline algorithms for quoting various lead times to different customer classes where revenues obtained from customers are sensitive to the lead time. Ervolina et al. (2009) develop a methodology that effectively balances the supply of the seller and the customer's demand by taking advantage of demand flexibility when determining the allocation of products to different customer segments.

Another part of the literature emphasizes that proper negotiations with customers on the order terms is a promising avenue to mange order acceptance problems (Calosso et al., 2004; Cakravastia and Nakamura, 2002). By negotiating on order issues, it would be possible to reach an agreement that is beneficial for the negotiating parties. On the one side, the customer would receive its required products with satisfactory characteristics; on the other side, the firm makes profit by fulfilling orders and selling products. At the same time, the seller also keeps its customer satisfied which in turn leads to development of good-will and increases probability of repeat purchase.

Considering all the different perspectives on the order acceptance procedure, the focus of this research is on the conceptualization and modeling of buyer-seller negotiations as an approach to improve the performance of order management system. To this end, several concepts mentioned in the literature such as integration of sales/production activities, revenue-based capacity management and customer segmentation are also taken into account. The model is then implemented for a specific case of multi-plant specialty chemical manufacturing enterprise. This problem setting is motivated by a real case (Behdani et al., 2010) related to the Ph.D. research of Behzad Behdani on abnormal situation management in industrial networks and supply chain. The research is conducted in the Energy and Industry section of the faculty of Technology, Policy and Management, TU Delft.

The multi-plant enterprise (MPE) in this case, consists of a global sales department (GSD) that coordinates the production of three production plants in different geographical 


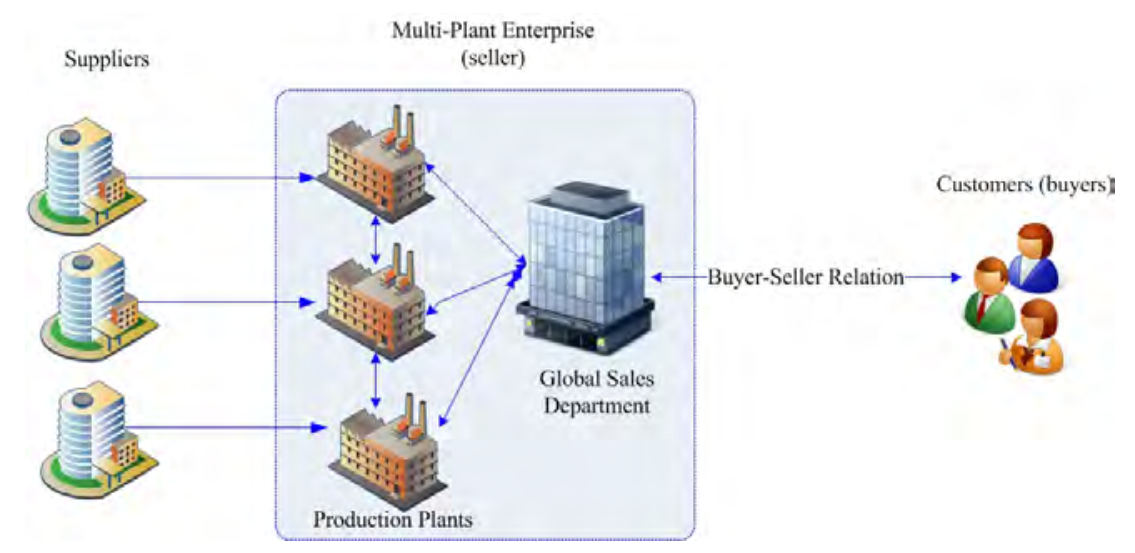

Figure 1.1: The multi-plant enterprise supply chain

locations according to the orders of some external customers (Figure 1.1). Each production plant itself has several functional departments including scheduling, operation, storage, packaging, procurement, and logistics. Each department performs certain tasks with some degree of autonomy.

The actors involved in this system interact by information and material flow and therefore give rise to the overall dynamics of the system. Such an industrial enterprise can be viewed as a socio-technical system with many aspects of intra- and inter-organizational complexities. A part of this complexity stems from the complex relations between different actors in the system; the relationship between the enterprise and its partners can be considered as inter-organizational relations and the relations between GSD and production plants and also among the plants themselves are basically examples of intra-organizational relations.

This research pays attention to inter-organizational relations, i.e. the firm's GSD and customers which, in some literature, are described as buyer-seller relations (Cannon and Perreault, 1999; Cohen and Stathis, 2001). Conflicts often arise in the buyer-seller relations as supply chain partners are self-interested entities aiming to maximize their individual benefits. Each actor has different perspectives, different preferences and various agendas. This conflict is very common in the order fulfillment process for a multi-plant make-to-order enterprise. The customer desires that the seller always accepts his offer with a low price and a short lead time, and delivers the product within a preferred time. On the contrary, the seller intends to accept profitable orders with high price and/or long delivery time (Nie et al., 2006).

In most of the cases, differences in preferences between the buyer and the supplier can be resolved by proper negotiations in which involved parties make a joint decision on the value of issues (Carnevale and Isen, 1986; Raiffa et al., 2002).

\section{$1.2 \quad$ Research objective}

The objective of this research is to improve the order acceptance (OA) performance by incorporating buyer-seller negotiations in the OA procedure of the multi plant enterprise. 
By developing a quantitative model for the buyer-seller encounter and implementing it for the MPE, we aim at understanding the negotiation process between the enterprise as the problem owner and its customers. By doing so, we can provide support for the MPE in developing effective strategies for its order acceptance procedure and enable the enterprise to reach its organizational goals both in the short-term (making immediate profit) and in the long-term (customer satisfaction).

\subsection{Research scope}

Although this research considers different aspects of buyer-seller negotiations (e.g. parties, issues, etc.), the main focus of the modeling effort is on the actors' negotiation in the order acceptance context. Accordingly, the areas such as supplier selection and contract formation are not part of this research. It is also assumed that the seller and the buyers are all from the same country in order to eliminate the effect of cultural differences in the negotiation process.

With regard to the problem setting used, the research focuses on the interface between the global sales department and the customers. The operational procedures and functions inside the enterprise are assumed to be the same as the previously developed model (Behdani et al., 2010).

\subsection{Research questions}

Based on the descriptions in the previous sections, the main research question in this project can be formulated as:

How can the buyer-seller negotiation process contribute to the improvement of order acceptance performance in the multi-plant enterprise?

There are also some relevant sub-questions:

- What are important concepts in the negotiation and how the relations between them can be described?

- What is an appropriate approach to model buyer-seller negotiations?

- What is the process in the negotiations?

- Which conditions can be considered before initiating negotiation?

- How the outcome of negotiation will be determined?

- How the negotiation outcome may influence future behavior of actors?

- How actors' behavior and the negotiation process can be reflected in a model?

- How the developed model can be used to improve understanding of decision makers about the negotiation process in the order acceptance procedure of the MPE? 


\subsection{Research contribution}

The main contribution of this work is to conceptualize and develop a model for the buyerseller negotiation process in order to improve order acceptance performance of a multi-plant enterprise.

To develop the quantitative model, a conceptual framework of important aspects and their relations in a negotiation problem is developed that can be used in various sociotechnical settings. Also, the whole encounter of the seller and the buyer is conceptualized in three phases to show the initiation conditions for negotiation (pre-negotiation phase), the main interaction (negotiation phase) and the consequences of negotiation on the future decisions of the involved actors (post-negotiation phase).

In this conceptualization, several concepts (e.g. customer segmentation and revenuebased management) introduced in the relevant literature are also incorporated to effectively consider different perspectives on order acceptance decisions.

This novel conceptualization is used to develop a model for the buyer-seller interaction in the OA context. The model is then applied for the specific case of a multi-plant enterprise to show its merits.

This model not only provides valuable insights into the nature of negotiation in a supply chain setting, but also, it can contribute to the understanding of strategy development for order acceptance. The model can be used to make comparisons between different strategies and evaluate effectiveness of negotiations in terms of reaching short- and long-term goals of the multi-plant enterprise.

\subsection{Thesis outline}

This thesis is divided into 3 parts, and 6 chapters. The structure of the thesis is visualized in Figure 1.2.

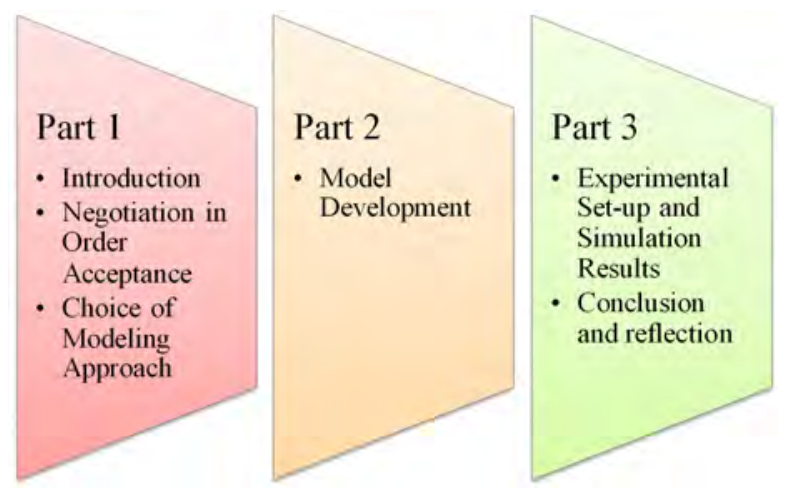

Figure 1.2: Thesis structure

The current part, Part I, deals with the problem exploration and research framework. In Chapter 1, the research issue, research objective and research questions are introduced. Chapter 2 aims to provide some information on the order acceptance in general and negotiation in particular. From the literature review on OA and negotiation, a gap is identified. 
Consequently, a conceptual framework for negotiation-based order acceptance is recommended. This chapter ends with a general framework for negotiation in which the basic concepts of a negotiation problem are specified. Chapter 3 describes the system under study in more detail, identifies its major characteristics and subsequently chooses a modeling approach aligned with the research objective and system characteristics.

In Part 2, the conceptualization and the negotiation framework are utilized to develop an agent-based model for the buyer-seller negotiation process in the order acceptance context.

In the third and the last part, some experiments with the simulation model are designed and implemented in order to provide insight about the negotiation and different order acceptance settings. Chapter 6 concludes the thesis by answering research questions and presenting the research contribution, areas for further research and reflection on the utilized methodology. 


\section{Chapter 2}

\section{Negotiation in Order Acceptance}

This chapter starts with an introduction of order acceptance and its relevant concepts in 2.1. Order acceptance background along with the main perspectives in the literature are presented in 2.1.1. This subsection concludes with some implications of the reviewed literature and emphasize is placed on developing a negotiation based approach for order acceptance. Consequently, Section 2.2 provides some basic information on negotiation. This is followed by the buyer-seller negotiation modeling background in 2.2.2. In this section, a distinction is made based on the modeling approaches used. A framework which provides a systematic view on a negotiation problems is developed in 2.3.

\subsection{Order acceptance basics}

Order Acceptance (OA), the acceptance or rejection of customers' orders, is one of the main functions in the business environment. These decisions are of crucial importance as Hill (2000) stated that:

"The most important orders are the ones that you turn down."

However, order acceptance is a complex issue; primarily because it involves an external actor (the buyer) who often has preferences and objectives that conflict with the seller. Order acceptance is also closely associated with other internal business functions in the firm, in which customer orders are translated into products, resulting in delivery of goods according to the customer requirements.

Upon the arrival of an order, the order is accepted if its terms are satisfactory for the seller (e.g. there are enough products in the stock or the order can be inserted in the production plan). Otherwise, the $\mathrm{OA}$ agent in the seller firm interacts with the customer to fix the order terms. In case agreement is reached, the order will be released for the relevant department for further processing. Next, the finished order will be dispatched for the customer (Lin and Lin, 2006). Subsequently, order acceptance has a large influence on the performance of several departments and the company as a whole. Hence, different aspects should be thoroughly investigated making OA decisions.

The order acceptance process differs to a large extent for various manufacturing environments. Generally, manufacturing environments can be divided into Make-To-Stock (MTS) and Make-To-Order (MTO) categories. 
In MTS manufacturing environment, the production process is mainly driven by demand forecast rather than actual customer orders. A customer order is generally accepted with a short delivery time as the final product is manufactured before the arrival of the order. In case there is no sufficient inventory of the requested product, a later delivery date should be agreed with the customer on the basis of expected stock fill rate (Kolisch, 2001).

The MTS environment is, therefore, common for producing standard products with little customer-specific requirements.

MTS systems have several drawbacks; they rely heavily on the demand forecast, which in many cases is not accurate. Besides, in the highly competitive business environment, firms need to be responsive and flexible in customizing their products to satisfy specific requirements of the individual customers. There is, therefore, an increasing shift towards MTO production system among companies of all sizes and industrial sectors (Calosso et al., 2004; Jalora, 2006).

In contrast to MTS systems, in the Make-To-Order (MTO) environment, production, final assembly and distribution are driven by customers' orders; i.e. the firm "produces after an order arrives, and produces only the quantity ordered" (Parry and Graves, 2008).

By adopting the MTO production strategy, the organization offers greater product variety and makes benefit by eliminating finished goods inventory. The realization of this benefit, however, is highly dependent on the performance of the firm's OA decisions.

Although order acceptance is an important decision in MTS environment, how it is managed is much more important in the MTO manufacturing environments (Nandi and Rogers, 2006; Zorzini et al., 2008).

Order acceptance strongly influences the performance of a MTO firm both in the shortand long-term horizon. On the one hand, rejecting too many orders unduly will lead to low utilization rate and has strategic repercussion for customer relations. It may drastically affect the future order arrival rate and patterns (Arredondo and Martinez, 2010). On the other hand, accepting every incoming order gives rise to an over-loaded production environment in which lead times increase and orders are delivered late. Consequently, the number of satisfied customers decreases and the firm's reputation damages. The greedy OA strategy that accepts every arriving order as long as there is capacity also disables the firm to accept more high-valued orders in the near future as capacity is already fully committed.

In a competitive make-to-order environment, a manufacturer should use capacity efficiently, satisfy the expectations of customers and gain maximum revenue from the incoming orders. All of these can be realized by appropriately managing incoming orders incorporating long- and short-term organizational goals. But the challenging decision here is which orders should be accepted and which ones should be rejected? And how the conflicts with customers in order acceptance process must be solved to improve the short- and long-term performance of a firm?

Next section provides an overview of dominant aspects affecting selection of an OA strategy in the supply chain context.

\subsubsection{Order acceptance background}

There are many researches which have contributed to the study of order acceptance decisions in supply chain; investigating them from different points of view. A part of the 
literature focuses on the integration of sales/marketing and production activities, claiming that integration directly improves company's profits and its service level. The second part looks at OA from the viewpoint of revenue-based capacity management. The aim in this perspective is to allocate firm's capacity to the most profitable orders. Incoming orders are prioritized and only ones that satisfy the profitability requirements will be accepted. Placing emphasis on the value of customers and relation with them is the third dominant stream in the OA literature. Customers are ranked based upon their importance for the company and resources are allocated with regard to the customers' rank. The fourth strand in the literature pays attention to negotiation between buyer and seller during the order acceptance decision-making process.

The following sections provide a brief overview of the studies performed in each category.

\subsubsection{Integration of sales and production activities}

In practice, decisions on order acceptance and production planning are often functionally separated as there are different units responsible for each function. The sales/marketing department is in charge of order acceptance, while the production department is responsible for production planning. The sales department tends to behave greedily and accept all orders, regardless of available capacity, because their goal is to bring as much revenue as possible; while the production department is concerned with limited capacity. With regard to the conflict in the goals of each department, order acceptance decisions are often made without involving the production department or with incomplete information on available capacity in the production unit.

There are several studies in the OA literature which stress the importance of integrating sales and production scheduling in different manufacturing environments.

In the seminal work, Wester et al. (1992) proposed two different OA approaches in a MTO environment in which due dates were determined by customers. In the first approach, the acceptance decision was made according to the current workload of the firm (for previously accepted orders); if the sum of the operation times of already accepted orders and the order to accept was less than a certain critical level, the order was accepted; otherwise it was rejected. The other approach made use of detailed schedule after arrival of a new order. Comparison had been made to show that the detailed schedule performed better than the other aggregate plan.

To find an appropriate OA strategy, ten Kate (1994) compared two different approaches for OA. The first approach was based on the aggregate characteristics of already accepted orders while in the second approach, OA and production scheduling were integrated. The author concluded that in tight situations; i.e. short lead times and high utilization rate, the integrated approach outperforms the other one.

The problem of accepting orders together with capacity loading decisions was studied in multipurpose batch process industries by Raaymakers et al. (2000). Besides the traditional workload and scheduling policies, they also considered a makespan estimation policy which used some aggregate information about the current job mix and total workload. From empirical results, they concluded that the scheduling policy realized a better or equally good service level and capacity utilization performance than the other detailed policies.

Charnsirisakskul et al. (2004) studied an integrated order selection and scheduling prob- 
lem on a single machine with the objective of maximizing manufacturer's profits defined as revenue minus manufacturing, holding and tardiness costs. The study developed insights on how manufacturers benefit from integrating order selection and production scheduling functions and suggested to consider flexibility in setting the lead times.

In the model presented by Roundy et al. (2005), the acceptance decision was made every time a new order arrives, considering whether the existing production schedule was able to accommodate it. If the order could be inserted in a feasible schedule, a schedule that minimizes the sum of setup and holding costs was selected.

Ebben et al. (2005) examined the importance of a proper workload-based order acceptance in an over-loaded job shop environments. They studied several methods, which were different on the level of required details that integrate OA and resource capacity planning. They performed simulation to evaluate performance of various methods in terms of utilization rate.

Huang et al. (2010) considered a coordinated order selection and production scheduling in a MTO environment where the manufacturer had to select a set of orders for processing. They compared the situation where order selection and scheduling are separated with the integrated situation and concluded that using their developed algorithm for integration of OA and production planning would yield higher profit.

Oguz et al. (2010) examined simultaneous order acceptance and scheduling decisions in a single machine environment and developed a linear programming model to show the positive effects of integration on the firm's revenue.

\subsubsection{Order selectivity based on profit}

Another stream of research on order acceptance is order selectivity on the basis of orders' profit contributions. This approach is referred to revenue based capacity management in the literature (Defregger and Kuhn, 2007; Akkan, 1997). The orders are classified according to their profit margin and the decision of accepting or rejecting an incoming order depends on the class of that order. This approach aims at allocating capacity to the most profitable orders. Following this approach enables firms to only serve valuable orders and reserve capacity for future orders with higher profit margins.

Carr and Duenyas (2000) modeled a combined make-to-stock/make-to-order manufacturing system in order to decide which orders should be accepted and how many make-tostock products to make. The firm was contractually obliged to meet demand for the class of MTS products while for MTO, there was an option to accept or reject an order. The MTO orders were prioritized based on their profit margin. Those belonged to the top-tier profit-making class of orders were accepted and released for production.

Missbauer (2003) used a stochastic model to derive optimal lower bounds for the profit margin of stochastically arriving orders. Only orders whose profit contribution margins exceeded the optimal lower bounds were accepted. The lower bound on the contribution margin was determined using full costs of orders, provided that available capacity (constant over time) and arrival pattern of orders were balanced. With a similar idea, Defregger and Kuhn (2007) modeled application of revenue management in a MTO company which had limited capacity. In this model, all incoming orders were attributed to several classes with different profit margins. The comparison of model results showed potential benefits of 
using revenue management rather than adopting first-come-first-serve strategy in making OA decisions.

In an attempt to maximize revenue, Barut and Sridharan (2005) developed a model to selectively accept or reject customer orders for multiple product classes when demand exceeds capacity over short term. The available capacity was allocated by discriminating orders for different product classes with differing profit contributions. Simulation results showed that discriminating orders would yield a substantial increase in the total profit under different order arrival patterns.

Hing et al. (2007) proposed a decision support system for order acceptance problems under demand uncertainty that takes into account opportunity losses caused by rejecting high-valued orders. A model on the basis of reinforcement learning ${ }^{1}$ was developed to find decision policies for order acceptance that reduces opportunity losses.

To maximize revenue of a firm, Fan and Chen (2008) utilized stochastic programming to model the MTO revenue problem and proposed an optimal OA policy. A new coming order would be accepted as long as its revenue was greater than or equal to the minimum of the shadow revenue. Shadow revenue was calculated regarding available capacity and expected profit of an order.

To show the importance of coordinated demand fulfillment and revenue management decisions, Quante et al. (2009) structured and reviewed a variety of applications, models, and software for order fulfillment and revenue management and highlighted commonalities and discrepancies. All the methods shared the idea of distinguishing multiple order classes in which profitability varies but they differed in the way that profitability was defined.

Recently, Arredondo and Martinez (2010) applied reinforcement learning for online adaptation of the profit threshold which is the criterion for making OA decisions. The threshold was changed based on acceptance or rejection of similar orders in previous decision periods. Similarity of the orders was defined regarding attributes such as product mix, price, size and due date.

\subsubsection{Customer segmentation}

Order acceptance is closely intertwined with customer relationship management, with many studies focusing on this aspect by classifying customers into various segments. The underlying idea in these studies is that customers differ in their importance which may go beyond immediate costs and revenues they bring for the firm. Loyal customers are often extremely important and should be served better than occasional customers.

Various priority rules can be used to provide more benefits to the customers who make more profit to the company in the long-term. The aim in customer segmentation is to keep satisfied valuable customers and, therefore, increase the probability of repeat purchase and long-term profitability.

Customer segmentation has received increasing attention in the OA literature. Some of the most important studies are mentioned in the following paragraphs.

\footnotetext{
${ }^{1}$ Reinforcement learning is an area of machine learning in computer science, concerned with how an agent ought to take actions in an environment in order to maximize some notion of cumulative reward (Sutton and Barto, 1998).
} 
Harris and Pinder (1995) considered a make-to-order manufacturing company and determined optimal pricing and capacity reallocation policies for a revenue maximizing problem with an arbitrary number of customer classes. Keskinocak et al. (2001) studied several online and offline algorithms for quoting various lead times to different customer classes where revenues obtained from the customers are sensitive to the lead time.

Korpela et al. (2002) emphasized that customers are not equally important for a company and, therefore, a supplier should select valuable customers in order to allocate its resources optimally. They proposed a model for developing a sales plan where the limited production capacity was allocated to the customers regarding their strategic importance. The strategic importance of the customers was determined using three criteria: (1) the longterm profitability potential for the company resulting from serving a certain customer, (2) the possibilities of establishing a partnership-type relationship with a customer, and (3) the anticipated development of the volumes purchased by a certain customer.

Ervolina et al. (2009) developed a methodology that effectively balanced the supply of the seller and customer's demand by taking advantage of demand flexibility when determining the allocation of products to different customer segments.

Homburg et al. (2008) focused on whether and how customer prioritization pays off. The authors conducted a cross-industry study of 310 firms from business-to-consumer and business-to-business contexts and concluded that customer prioritization ultimately would lead to higher average customer profitability and a higher return on sales because it affected relationships with top-tier customers positively and reduced marketing and sales costs.

Meyr (2009) showed that customer segmentation on the basis of value of customers, in terms of previous revenue brought to the firm, could improve profit substantially. In this study, the emphasis was placed on the choice of an appropriate number of priority classes to avoid promising scarce capacity to wrong customers.

Chamodrakas et al. (2009)considered customer evaluation and prioritization in the context of the order acceptance process of suppliers and proposed the use of fuzzy methods to this end. They used four qualitative criteria which were ranked in an ordinal manner to assess customers' value and assign capacity accordingly.

\subsubsection{Negotiation}

In all the previously mentioned literature, it was assumed that order terms are fixed; either they are already agreed upon by the seller and the buyer or exogenously determined by the customer. Nonetheless, in reality order terms are usually specified by negotiations between the buyer and the seller who often have conflicting preferences over terms in an order. The way that negotiation happens has significant impact on all the previously mentioned aspects, such as seller's profits and its relationship with customers.

Since the order fulfillment process is highly affected by order terms (e.g. agreed lead time and quantity determine the load of production plan and delivery schedule), it is of central importance to consider negotiation in the order acceptance procedure. Effective negotiations would result in an agreement that is satisfactory and profitable for involved parties and also improves long-term relationship of parties.

Although buyer-seller negotiations are addressed in different aspects of the supply chain management literature, there are scant studies which explicitly consider negotiations in the 
order acceptance procedure. Calosso et al. (2003) and Calosso et al. (2004) proposed mixedinteger linear programming models that can be used in a multi-tier supply chain to evaluate an order from a customer, assess a bid submitted by the supplier and select the best offer. They used price and due dates as issues for negotiation. In their models, it was feasible to enumerate possible agreements (i.e. there is limited number of agreements). In the second paper, a negotiation system with the involvement of an intervener was also proposed to help parties reach an efficient agreement.

Ebadian et al. (2008) considered delivery time as the negotiable issue and used capacity planning to generate feasible schedule and make trade-off between price and negotiable due date.

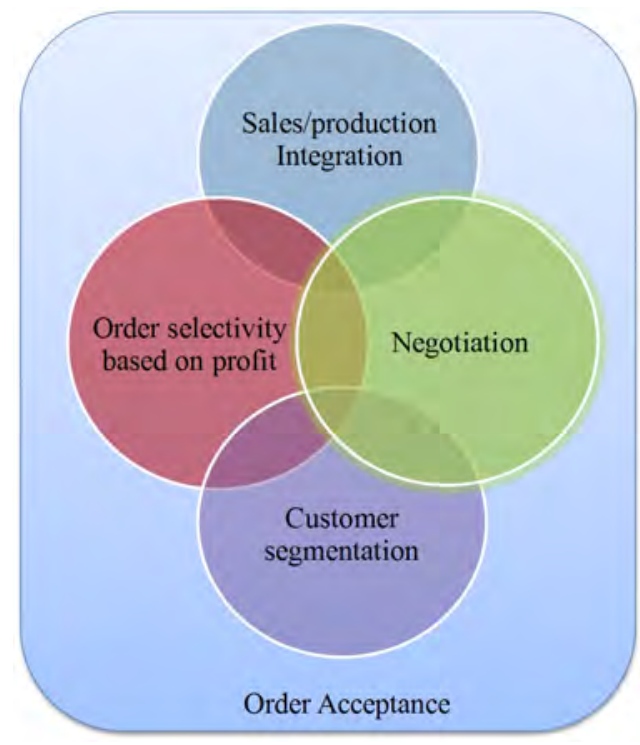

Figure 2.1: Negotiation based order acceptance approach

These studies and some other similar works that are going to be discussed in the next section are mainly focus on a single-session negotiation. They merely place emphasize on negotiation per se and do not consider prerequisites for the initiation of negotiation sessions. The repercussions of each negotiation outcome on the future behavior of actors involved in the negotiations are also ignored. Considering preconditions for entering into negotiation and taking into account the strategic consequences of negotiation results can improve OA performance and help the seller firm to move towards its organizational goals; making profit and maintaining good relations with its valuable customers.

Thus, negotiation can be considered as an important part of the order acceptance process through which conflicts on order terms can be resolved in a way to satisfy involved parties. To do so, we develop a negotiation based strategy for order acceptance in which other important concepts in OA (i.e. sales/production integration, order selectivity based on profit and customer segmentation) are incorporated in the negotiation process as well (Figure 2.1). By doing so, we simultaneously analyze customer-related and financial metrics and hence pay attention to the short- as well as long-term profitability of the enterprise.

In the next section, some basics about negotiation are presented. 


\subsection{Negotiation basics}

Negotiation is a type of interaction between two or more self interested actors (each with its own objectives, needs and viewpoints) seeking to find a common ground and reach an agreement to settle a matter of mutual concern or resolve a conflict (Raiffa et al., 2002). In other words, negotiation is a process where two or more parties jointly search a space of possible solutions with the goal of reaching a consensus (Rosenschein and Zlotkin, 1994; Raiffa et al., 2002).

Negotiation challenges researchers and practitioners from many disciplines including anthropology (Docherty, 2003), psychology and sociology (Bazerman et al., 2007; Francis, 2008), political sciences (Zartman and Rubin, 2002; Slantchev, 2004), economics (Tollison and Willett, 2009; Kremenyuk and Sjostedt, 2000), and law (McMains and Mullins, 2006). Another discipline which addressed negotiation is decision-making (Raiffa et al., 2002; Sebenius, 1992; Young, 1991) that is the main focus in this research and elaborated further in the following sub-section.

\subsubsection{Negotiation in decision making}

According to Raiffa et al. (2002), there are two approaches in decision making: individual decision making and group decision making. In individual decision making, the world is viewed from the viewpoint of a unitary decision entity. Conversely, in the group decisionmaking perspective the emphasis is on the interactions and dynamics between multiple unitary decision entities. Generally, two approaches have been developed in examining group decision making: the theory of games and the theory of negotiation (Figure 2.2).

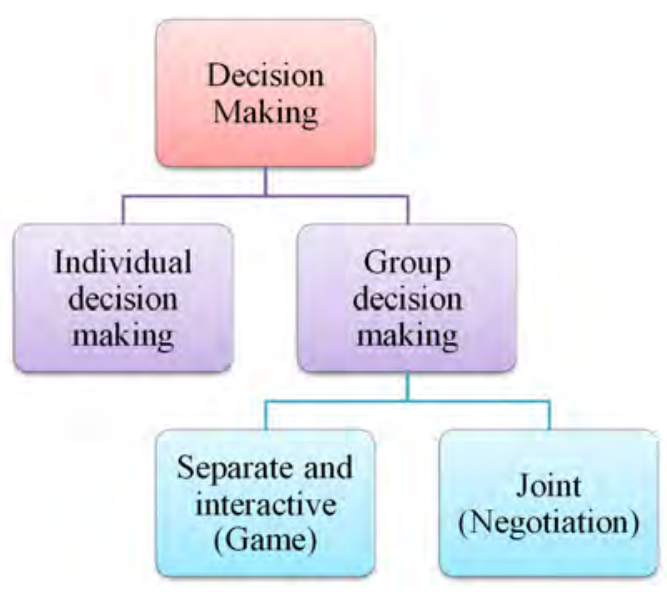

Figure 2.2: Approaches in decision-making (Raiffa et al., 2002)

Interactive decision making (game theory) The situation in which two firms competing to outdo one another by competitive pricing and advertising is examined in the domain of interactive decision making, or the theory of non-cooperative games. The essence of the theory entails a set of individual decision makers (players, in the vocabulary of game theory), each restricted to adopt a choice (strategy) from a specified 
set of choices, and payoff to each player depends on the totality of choices made by all players. Each player must choose, sometimes not knowing the choice of the others. Each must think about what the other might do and realize that the other are, in turn, thinking about what the rest are thinking. The basis of this perspective is that although the individual decision entities make their choice separately of each other, the payoffs they receive are a function of all players' choices (Raiffa et al. 2002).

Joint decision making (negotiation theory). Now consider the situation of community dispute in which parties voluntarily come together to see if they can jointly agree to do something as a group. Imagine them meeting around a table discussing possible compromises. We are now in the realm of joint decision making or negotiations.

Roughly, both negotiation and game situations involve group decision making. However, games involve multiple individuals making separate decisions that interact. The payoffs for each individual are dependent not only on their own decision but also on the decisions of other individuals, and vice versa. Negotiation, in contrast, involves multiple individuals trying to arrive at a join decision. The joint decision entails joint consequences, or payoffs, for each individual.

Moreover, the models in game theory are fundamentally static models in which the focus is on the outcomes rather than on the processes. The advice given to the parties must lead to an equilibrium situation, if the theory says that party A should choose strategy 1 and party B strategy 2, then 1 must be a good retort against 2 and 2 must be a good retort against 1; otherwise the advice would be counterproductive (Raffia et al. 2002). However, these implications do not mean that game theory is not applicable in negotiation. Negotiation theory uses some basic ideas from the theory of games; among them is the bargaining theory which will be explained in Section 2.3.

It is noteworthy that there is a lot of difference between two-party and many-party decision making. If there are more than two parties involved, reaching a decision becomes harder. This type of decision making could be addressed by e.g. cooperative game theory. Cooperative game theory looks at the set of possible outcomes, studies what the players can achieve, what coalitions will form, how the coalitions that form divide the outcome, and whether the outcomes are stable and robust. The case in this study is concerned with the interaction of a buyer and a seller. For this reason, cooperative game theory is out of the scope of this research. Interested readers are referred to e.g. Raiffa et al. (2002, part 5), and Slikker and Van den Nouweland (2001).

\subsubsection{Buyer-seller negotiation modeling background}

As mentioned earlier, negotiation is studied in many different disciplines. However as this research mainly deals with the negotiation between the multi-plant enterprise (as the seller) and its customers, the following subsections will focus on the contributions concerning negotiation between the buyer-seller dyad in supply chain management.

To classify the literature, a key distinction can be made on the basis of the negotiation process; i.e., the activities and their sequence that form the interaction between parties. Considering this aspect, the negotiation process can be categorized as auction or bargaining. 
In auctions, the auctioneer, which is generally the seller ${ }^{2}$, initiates an auction with an initial offer and monitors the auction process while bidders send their own bids in response to the initial offer or bids from other offers. The auctioneer follows a certain auction protocol to pick up the final partner (Fang et al., 2008).

As another possible negotiation mechanism, bargaining allows the bargainers to solve the conflicts by alternating offer and counteroffer round by round until an agreement is reached. This process is referred to Rubinstein's bargaining model (Rubinstein, 1982) in the literature.

There are also several variations of bargaining (Figure 2.3). Based upon the number of actors involved in the negotiation, it can be bilateral bargaining (one-to-one) or multilateral bargaining (one-to-many, many-to-one and many-to-many). In addition, in a multilateral setting, the negotiation with other actors may happen sequentially or concurrently.

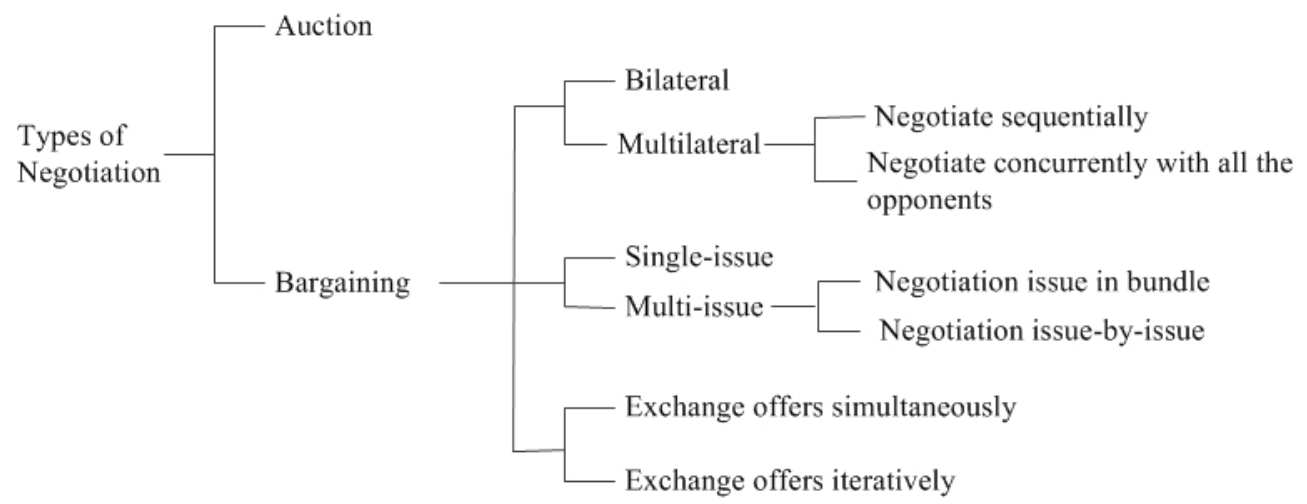

Figure 2.3: Negotiation Types (adapted from Wong and Fang (2010))

The literature on negotiation modeling can be further divided based on the used modeling approaches. Generally, there are two salient approaches in the literature: analyt$\mathrm{ical} /$ mathematical modeling approaches and simulation modeling. In the analytical approaches, the aim is mostly to find an optimal solution for a problem which entails few decision variables and limiting assumptions to make it solvable. Conversely, simulation models do not aim to find an optimal solution, but to analyze a complex problem under different settings with relatively larger number of variables and parameters.

Following this introduction, the next sections are going to provide an overview of the buyer-seller negotiation literature. The first aspect for classification is the modeling approach, and then in each modeling method, further distinction is made on the basis of the negotiation aspects mentioned in Figure 2.3 (e.g. number of parties and issues under negotiation).

\subsubsection{Analytical models}

Literature of analytical models for buyer-seller negotiations in SC does not pay much attention to auction and is mainly concentrated on iterative exchange of offers between the

\footnotetext{
${ }^{2}$ In a reverse auction the auctioneer is the buyer.
} 
buyer and the seller. Some bargaining models directly address exchange of offers; others focus on finding an optimal offer that can be proposed in negotiation rounds.

Some of the initial modeling efforts in the domain of buyer-seller negotiations in a supply chain setting were performed by Banerjee (1986) and Goyal (1988). They focused on the purchase of a manufactured component and the differences associated with the economic order quantity of the buyer and the economic production lot size of the supplier. By considering relevant cost expressions, Banerjee (1986) derived a joint order quantity that proved superior to individual quantities of both buyer and supplier. Later, Rubin and Carter (1990) demonstrated that Banerjee's work can be generalized to a variety of goods and services and showed that compromises by the buyer and the supplier result in improved profitability for both.

Cramton (1991) proposed a bargaining model with transaction costs between a buyer and a supplier. He suggests that in the state of equilibrium an immediate trade, delayed trade, or immediate termination occurs depending on the size of the gains from trade and relative bargaining costs. Rapoport et al. (1995) examined a multi-period bargaining mechanism in which a supplier negotiates with a buyer over the price of a product. All these models use the single criterion of cost as the issue for negotiations between a buyer and a seller.

Weber and Desai (1996) and Weber et al. (1998) initiated the work in the area of multicriteria decision models for buyer-supplier negotiations. In the first paper, a combination of data envelopment analysis (DEA) and methods for analyzing multivariate data were jointly used to evaluate the performance of suppliers and develop negotiation strategies with the suppliers. DEA is a linear programming method to measure the efficiency of several independent decision-making units when the production process has multiple inputs and outputs (Cooper et al., 2007). DEA was used to evaluate the offers received from six different suppliers in terms of price, quality and delivery date. The proposed method provided a starting point for negotiation between the buyer and the supplier. In the second paper, the combined use of DEA and multi-objective programming is proposed for supplier selection and negotiation. The issues under study were price and delivery time. The study identified performance levels which six various suppliers that need to be considered in the evaluation process by the buyer. The performance level established benchmarks to be used by the buying firm when negotiating with suppliers.

Talluri (2002) utilized a combination of DEA and goal programming for identifying efficient marginal costs of supplier outputs (quality and delivery) and demonstrated their use in buyer-supplier negotiations. This model proposed a negotiation strategy with all suppliers that, while effective, may not be ideal in all circumstances. It is likely that the buyer might want to plan effective scenarios during the negotiation process that can enable him to engage in negotiation strategies contingent on relative supplier performance and supplier capabilities. With the similar idea, Zhu (2004) showed that the Talluri's proposed model can be simplified. The paper presented a new buyer-seller model where the efficiency ${ }^{3}$ was maximized on the basis of multiple targets for issues specified by the buyer. It allowed the buyer to assess and select the suppliers who has the largest efficiency.

\footnotetext{
${ }^{3}$ The efficiency is defined as the ratio of weighted outputs to weighted inputs. The weights reflect the tradeoffs among multiple outputs and multiple inputs.
} 
Cakravastia and Nakamura (2002) proposed an integrated supplier selection and negotiation process for multiple parts/materials procurement. Their study aimed at integrating decisions in the internal supply chain of a make-to-order (MTO) manufacturer. The model was designed to support the negotiation process by generating a set of effective alternatives to support the decision-maker in each negotiation round. The issues for negotiation were price and delivery lead time and negotiation was between a MTO manufacturer and its multiple suppliers who bid simultaneously.

To deal with the problem of supporting negotiations among manufacturing firms that operate on MTO basis, Calosso et al. (2004) firstly, presented a mixed-integer linear programming model of negotiation between a generic customer-supplier pair over price and due date. Then, they proposed a model based upon an intervener which allowed the parties to reach efficient utility-sharing solutions.

Babaioff and Walsh (2005) proposed a negotiation mechanism to coordinate the buying and selling of goods across a supply chain. The mechanism was based on auction to encourage supply chain members to report their private information truthfully. They utilized integer programming for this purpose.

Guillen et al. (2005) proposed decision support in making optimal offer proposals during the negotiation process between a general customer-supplier pair that takes place in chemical industry supply chains. The issues for negotiation were price and due date. The work helped the supplier to simultaneously process production and transport data as well as customer preferences and thus enabled him to make rational offers.

Nie et al. (2006) presented a two-phase model for price/due date negotiation between a manufacturer and a supplier in a make-to-order supply chain. In the first phase, a mediator was involved to help the actors search an acceptable due date. The actors negotiated on price in the second phase after the limit level of price had been adjusted on the basis of results in the first phase. The study found that the supplier and the buyer were cooperative on due date issues, i.e. improving performance of the whole supply chain, while competitive on the price issues, i.e. transfer payment from the manufacturer to the supplier.

Chen and Huang (2007) integrated analytic hierarchy process with bi-negotiation agents based on multi-criteria decision-making approach for the supplier selection problem. The linear programming model enabled buyers and suppliers to negotiate on multi-attributes for a deal, including price, quantity, quality and delivery performance.

Talluri et al. (2008) utilized a combination of data envelopment analysis and multicriteria decision models to determine negotiation strategies with selected suppliers. The approach enabled effective tailoring of supplier specific negotiations by benchmarking the performance of each potential supplier against the performance of existing suppliers.

Jung et al. (2008) proposed a linear programming negotiation model to reach an acceptable contract between a distributer and a supplier in the supply chain. The issues for negotiation in this model were supply quantities from the manufacturer for several products of different production facilities. They showed that their proposed process while require the minimum information sharing between the partners, achieve small gap from the solutions of ideal centralized planning models.

Kelle et al. (2009) examined the effect of yield uncertainty (imperfect quality) on cooperation and negotiation of a buyer-supplier pair. The issues for negotiation are shipment size and the wholesale price. They provided analytical tools and approximation methods 
to optimize decisions of the buyer and the seller under two scenarios: when the buyer or when the supplier makes $100 \%$ inspection.

Table 2.1 summarizes analytical models of the buyer-seller negotiation.

Table 2.1: Summary of analytical models on buyer-seller negotiations

\begin{tabular}{lll} 
Negotiation Process & \\
\hline Auction & & Babaioff and Walsh (2005) \\
\hline $\begin{array}{l}\text { Bargaining } \\
\text { (Bilateral) }\end{array}$ & Multi-issue & $\begin{array}{l}\text { Weber and Desai (1996), Weber et al. (1998), Talluri (2002), Zhu } \\
(2004), \text { Cakravastia and Nakamura (2004), Calosso et al. (2004), } \\
\text { Guillen et al. (2005), Nie et al. (2006), Chen and Huang (2007), Talluri } \\
\text { et al. (2008), Kelle et al. (2009) }\end{array}$ \\
& & $\begin{array}{l}\text { Banerjee (1986), Goyal (1988), Rubin and Carter (1990), Cramton } \\
\text { (1991), Rapoport et al. (1995), Jung et al. (2008) }\end{array}$ \\
& Single-issue &
\end{tabular}

It can be concluded from the above examples that analytical and mathematical modeling approaches are definitely useful in understanding fully-defined problems which entail few decision variables and limiting assumptions to make them solvable. When more complex systems are involved like the interaction of buyer-seller in the supply chain with heterogeneous actors, random demand pattern, random order attributes, adaptive behavior of parties, these approaches may not be satisfactory in providing desired results.

\subsubsection{Simulation models}

The other alternative approach to study the buyer-seller negotiations is simulation models which are widely used in the literature. The simulation models are flexible tools that can be used to analyze complex problems and enable us to study such systems in detail (van der Vorst et al., 2000; Jansen et al., 2001). Value of parameters in a simulation model could be varied easily in a way that analysis of different combinations of the parameters are possible; therefore, the cost to make a decision could be reduced, and response to such modifications could be obtained very fast (Manzini et al., 2005). In the interim, unlike traditional mathematical optimization approaches, results in intermediate stages could be captured during the simulation process so that the dynamic behavior of the system could be analyzed at different points.

Simulation modeling of buyer-seller negotiations is mainly addressed in the research area of multi-agent systems (MAS) (Shoham and Leyton-Brown, 2009). MAS is used to represent characteristics of a system composed of multiple autonomous components where: (1) each agent has incomplete capabilities to solve a problem, (2) there is no global control in the system, and (3) data is decentralized (Jennings et al., 1998).

In these studies, agents act on behalf of supply chain members; making use of autonomous characteristics and decision-making capabilities. The agents work together to find answers to problems that are beyond their individual capabilities or knowledge.

Chen et al. (1999) developed a MAS for supply chain management in which SC functionality was implemented through agent-based negotiation. The proposed system was used to 
construct pair-wise and third party auction negotiation protocols for agents' cooperation.

Ito and Rizal Salleh (2000) used blackboard-based negotiation to develop a collaborative supply chain system. In a blackboard-based architecture, each agent interacts and shares information using a so-called blackboard. Blackboard is a common centralized database on which all agents write messages, post results, and obtain information. For replenishment of parts/materials, an organization proposes an offer and publishes it to a public blackboard for information exchange to find an appropriate supplier in a bargaining process.

Garcia-Flores and Wang (2002) proposed a MAS to simulate dynamic behavior of distributed and cooperative actors in a chemical industry supply chain over internet. The actors coordinate their relevant functions using bargaining-based negotiation on price and quantity.

Kaihara (2003) utilized auction-based negotiation model to optimize product allocation in a supply chain. The study developed a multi agent virtual market-based supply chain to solve the product allocation problem by distributing scheduled resources based on agent interactions in the market.

Valluri and Croson (2005) developed an agent-based model for the supplier selection problem. The model was concentrated on an auction-based interactions of a single buyer with a heterogeneous group of sellers, which results in both separation of sellers capable of producing high-quality goods from those incapable of doing so, and continuing incentives for high-quality-capable sellers to produce at the maximum quality possible. Through simulation, it was shown that the buyer would be better off if he outsources to only a relatively small number of suppliers, as any more or fewer would result in a decrease in the buyer's total profit.

Umeda and Zhang (2006) developed an agent-based simulation model to study three different operation models (reorder-point, centralized, and pull). A bargaining negotiation protocol was developed in finding next order volumes between operational managers and parts suppliers of the distributed supply chain.

Praca et al. (2006) presented a multi agent market simulator to analyze agent market strategies on the basis of buyer and seller behaviors, their preferences and pricing approaches. The analysis supported agents in proposing a bid from the pool of bids in an auction based mechanism. Also it enabled agents to improve their negotiation mechanism to establish bilateral contracts.

Lin and Lin (2006) believed that the coordination of order fulfillment process among supply chain partners can be viewed as a distributed constraint satisfaction problem (DCSP $)^{4}$. Therefore, they combined multi-agent negotiation with existing approaches to solve distributed constraint satisfaction problem, and then evaluated the performance of the system by conducting experiments on the order fulfillment process in the context of metal industry. They considered 10 companies which share information to build global task tree, and schedule the production schedule by pooling complete capacity information from each company. The only issue for negotiation was delivery time.

Russ and Walz (2009) developed a bargaining negotiation protocol for bilateral price negotiations in a multi-agent supply chain. They designed an adaptive negotiation module

\footnotetext{
${ }^{4}$ A DCSP is a constraint satisfaction problem in which variables and constraints are distributed among multiple agents. A DCSP is a problem to find a consistent assignment of values to variables (Yokoo et al., 1998).
} 
in Java that allows the agents to adapt their negotiation behaviors based on previous trades on price values. Simulation was used to show the effects of different values of parameters in the learning mechanism on the overall profit and sales of the supply chain.

Renna and Argoneto (2010) used a multi-agent architecture and discrete-event simulation environment to create a link between production planning and negotiation in emarketplace for small, medium enterprises (SMEs). The simulation model was based on auction and supported SMEs in making decisions whether to enter in the e-marketplace or not, considering market conditions.

Ji and Yang (2010) proposed a multi-agent model for price negotiation between a buyer and a supplier. Using this bargaining model, buyer and seller would be able to form strategic partnership and share profit. A facilitator helped the actors to reach an acceptable price.

Table 2.2 summarizes the literature of simulation models on the basis of the type of negotiation process.

Table 2.2: Summary of simulation models on negotiation

\begin{tabular}{lll}
\hline Negotiation Process & \\
\hline Auction & $\begin{array}{l}\text { Chen et al. (1999), Kaihara (2003), Valluri and Croson (2005), Praca et } \\
\text { al. (2006), Renna and Argoneto (2010) }\end{array}$ \\
\hline $\begin{array}{l}\text { Bargaining } \\
\text { (Bilateral) }\end{array}$ & Multi-issue & Ito and Salleh (2000), Garcia-Flores and Wang (2002) \\
& Single-issue & Lin and Lin (2006), Russ and Walz (2009), Ji and Yang (2010) \\
\hline
\end{tabular}

Although the mentioned studies incorporate many different aspects of the buyer-seller negotiation problem, the focus is mainly on a single session negotiation; i.e. the activities precede each negotiation session, and the consequences of negotiations on the future decision making behavior of actors are rarely considered. In addition, to evaluate the outcomes of the developed models, mostly financial criteria and immediate yield are used and little attention has been paid to the aspects like customer satisfaction which definitely determine the future position of an enterprise in a market.

\subsection{General framework for negotiation}

As it can be observed from the mentioned literature, there are some concepts common in each negotiation problem: various parties with different objectives and behavior are involved in the negotiation process, negotiating on a negotiation subject that can be described by several issues such as price, lead time, quality. Negotiation happens in a specific context and has particular outcome. These concepts are conceptualized in a general framework for negotiation (Figure 2.4). This framework provides us with a systematic view of each negotiation problem; it is also the basis for negotiation formalization presented in Chapter 4. The framework consists of five components that are described in the following sections.

Negotiating parties Negotiation parties are the participants in the negotiation. On the 


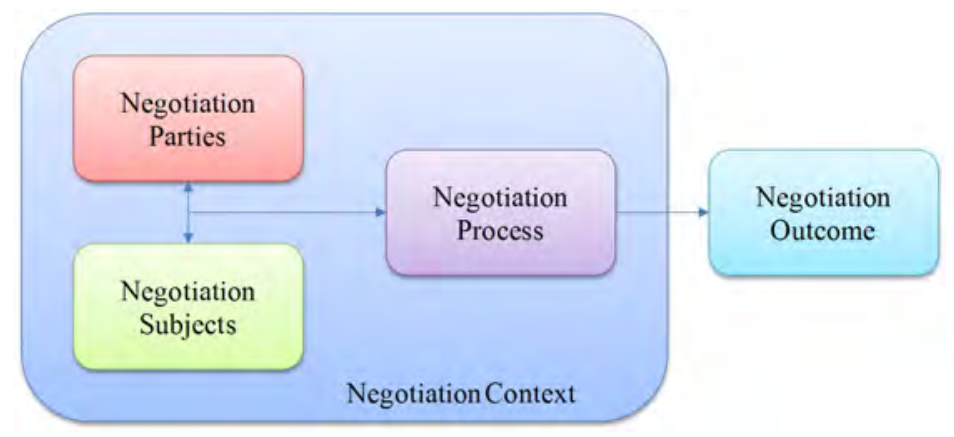

Figure 2.4: Negotiation framework

basis of the number of participants, negotiations can be classified into 3 classes: 1 to-1, 1-to-many, and many-to-many. In 1-to-1 negotiation, one party negotiates with exactly one opponent (bilateral negotiation). In 1-to-many, one party negotiates with the group(s) of opponents and in many-to-many; two or more parties negotiate with groups of opponents. Sometimes negotiating parties ask a third party to intervene the negotiation. His role is to suggest agreements or to offer facilities. One type of intervener is a mediator that is a neutral party gathering some confidential information from the involved parties, making suggestions for them and assisting them to find a jointly accepted agreement. Another type of intervener is an arbitrator that analyzes the problem and, unlike the mediator, dictates the solution for the parties (Raiffa et al, 2002).

Each party in the negotiation has a profile in which preferences, objectives, options, limitations, etc are specified.

- To approximate party's preferences, the idea of "utility function" is used in the literature (Russell and Norvig, 2002). A utility function assigns a single number to express the desirability of each offer in the negotiations. The objective of a party in the negotiations would be to maximize its utility function.

- Utility functions have different forms. One of the determinants of the form of a utility function is the level of risk that parties are willing to take. A linear utility function shows risk neutrality of the party. In contrast, concave and convex utility functions represent risk-averse and risk-seeking behaviors respectively (Muthoo, 1999).

- Each party has also an option outside the negotiation. In case negotiation fails, the outside option would be the alternative for the party. This is called Best Alternative to the Negotiated Agreement (Raiffa et al, 2002; Fisher et al., 1991). As an example, $B A T N A$ for a buyer could be purchasing the desired product from another seller.

- Rather than the outside option, parties can also have inside options. Consider that a buyer and a seller bargain over a house. As long as they are bargaining and temporarily disagree, the seller can obtain specific payoff as the house is still is his possession (Muthoo, 1999). The utility (payoff) of selling the house should be larger than the utility of keeping the house; otherwise, there is no gain from the trade. 
- There could be also some limitations for each party during the negotiations. For example time limitations; no negotiation can continue forever. This limitation is important as Muthoo (1999) claimed that parties will reach an agreement if and only if time is valuable to at least one of the two parties in a bilateral situation. In the interim, involved actors may have different constraints regarding different issues discussed in the negotiation subject. For example, a seller or a buyer may have different acceptable ranges for price or due date of an order and they are not willing to accept or negotiate on the values beyond those ranges.

- Each party also has evaluation functions for negotiation issues. This is addressed under negotiation subject.

Negotiation subject Negotiation subject is the topic of discussion that is of a particular interest for involved parties in the negotiations, e.g. price, delivery date, quantity. Each subject has a range, one of which should ultimately be agreed upon by negotiation parties in order to reach an agreement. The number of subjects (issues), the range of values per subject, and possible interdependencies between issues would influence the complexity of a negotiation problem. Regarding the number of issues, negotiations can be classified into two main categories: single-issue and multi-issue negotiations. Single issue negotiation is also known as the "splitting a pie" situation (Osborne and Rubinstein, 1994) and is concerned with the division of a single issue, e.g. money. Such negotiations are called "win-lose" negotiations (Raiffa et al, 2002) because increasing a share of a pie for one party means decrease of the share for the other. Negotiations with multiple issues can be "win-win" meaning that by trading less important issues for more important ones, both parties benefit from the possible agreement. In general, a large number of issues increases the opportunities for "win-win" solutions.

Besides the number of issues discussed in a negotiation problem, possible interdependencies between issues also determine the form of the "utility function". A widely used type of utility functions is the type of linear additive utility function (Keeney and Raiffa, 1993) in which the contribution of every issue to the utility is linear and does not depend on the values of other issues (no issue dependencies).

The value of each issue in a specific offer can be assessed using "evaluation functions". These evaluation functions map the value of issue to a single number indicating its desirability. A utility function is used to evaluate the desirability of an offer as a whole, while an evaluation function is utilized to assess a single issue. As an illustration, consider price as an issue for negotiation between a buyer and a seller. The buyer prefers to purchase with the lowest possible price.

So, the evaluation function of price for the risk-neutral buyer could have the downhill form similar to what is depicted in Figure 2.5.

The utility function for the buyer is then the sum of evaluation functions for each issue which is multiplied by a weight representing the importance (sensitivity) of that particular issue from the buyer viewpoint. Assume that the buyer is price sensitive and desires to buy at a low price. If the negotiation issues are price and delivery time; the utility function 


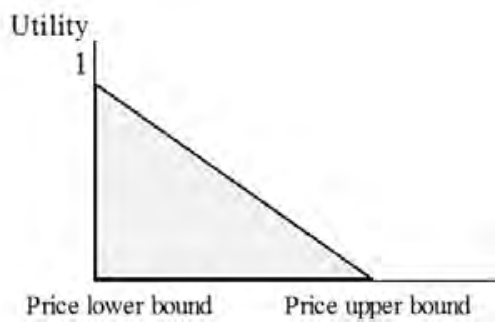

Figure 2.5: Downhill evaluation function for price

would be:

$$
U_{\text {buyer }}=w_{1} f(\text { price })+w_{2} f(\text { delivery time })
$$

In which $\mathrm{w}_{1}$ and $\mathrm{w}_{2}$ are the weights for price and delivery time respectively. Evaluation functions are denoted by $\mathrm{f}$ (price) and $\mathrm{f}$ (delivery time). For a price sensitive buyer, $\mathrm{w}_{1}$ has a higher value compared to $\mathrm{w}_{2}$ (e.g. 0.7 for $\mathrm{w}_{1}$ and 0.3 for $\mathrm{w}_{2}$ ).

The following four types of evaluation functions are widely used in the literature (Tykhonov, 2010; Chen and Huang, 2007):

- Downhill function: minimal issue values are preferred over other values of issue.

- Uphill function: maximal issue values are preferred over other issue values.

- Triangular function: a specific issue value somewhere in the issue range is valued most and issues to the right and left are valued less.

- Trapezoid function: a specific range of values somewhere in the issue range is valued most and issues to the right and left are valued less.

Negotiation process Negotiation process is a series of activities and their sequence that form the interaction between parties. Depending on the activities, negotiations can be categorized as auction and bargaining which already mentioned in Section 2.2.2.

In auctions, the auctioneer initiates an auction with an initial offer and monitors the auction process while bidders send their own bids in response to the initial offer or bids from other offers. Different types of auction protocols, such as English auction (first-price ascending), Japanese auction (second-price ascending), first-price sealedbid auction, Vickrey auction (second-price sealed-bid), and Dutch auction (first-price descending), etc., are different in the way prices are quoted and in the manner in which bids are tendered (Fang et al., 2008).

Despite the advantages of acutions in terms of accumulated profit for the seller, researchers (Guttman and Maes, 1998; Rahwan et al., 2002; Nguyen and Jennings, 2005) realized that auction is not well suited for cooperative or semi-competitive negotiation. They show several limitations. Firstly, auctions only allow negotiation for price and thus many other relevant attributes (e.g. delivery and after-sales service) are 
ignored. Secondly, auctions are usually scheduled in advance and with time restrictions. Some buyers/sellers may not want to wait until an auction opens or finalizes. Thirdly, auctions fail to support two-way communication of offers and counter-offers. One side is allowed to propose counter-offers but the other side can only accept/reject the opponent's counter-offers. Lastly, in auctions, it is impossible to exercise different negotiation strategies with different partners (Wong and Fang, 2010).

As mentioned earlier, an alternative to auction is bargaining which allows the bargainers to solve the conflicts by alternating offer and counteroffer round by round until an agreement is reached. Making offers and counteroffers lies at the heart of many real-life negotiations (Muthoo, 1999). A bargaining model involves multi-round negotiations, its process is more complex than that of bidding, and the strategy used is more complex than that of auctions.

Negotiation context Negotiation context represents the environment in which negotiation happens. This could be an industrial context or a real-state context. The elements of the negotiation framework e.g. negotiation issues may be different in various contexts.

Negotiation outcome A negotiation eventually can be unsuccessful or successful based on the choices that negotiation parties make during the interaction. It can be unsuccessful either because there is no agreement between parties or because parties may quit negotiations due to reasons like time limitations.

The agreement at the end of a successful negotiation can be analyzed further. A number of criteria have been proposed in literature (see e.g. Raffia et al. 2002) for analyzing the final agreement.

One of the most important criteria is Pareto efficiency. A bid is Pareto efficient if given a set of alternatives, no movement from the offer to an alternative exists that can make at least one individual better off without making any other individual worse off. Typically there are multiple Pareto optimal solutions that form a Pareto optimal frontier ranging from an outcome in which one negotiator gets everything and the other gets nothing to an outcome in which the other gets everything and the first nothing. To select a single outcome on the Pareto optimal frontier several criteria have been proposed including the Nash product and Kalai-Smorodinsky; see Raiffa et al. (2002) for more details.

\subsection{Chapter conclusion}

This chapter tried to review some of the main concepts of order acceptance in general and negotiation in particular. On top of that, it presents an overview of previous studies performed in these fields.

The importance of OA decisions in Make-To-Order manufacturing environments was highlighted and some major viewpoints on making OA decisions have been discussed in the relevant literature. It was concluded that three dominant streams in the OA literature, i.e. integration of sales/production functions, order selectivity based on the profitability level of 
orders, and customer segmentation assume that order terms (e.g. price and delivery date) are predetermined, which is not always tenable. In real situations, order terms are specified by negotiation between the buyer and the seller. There is, however, scant literature which directly address negotiation in the OA context and those which incorporate negotiation consider negotiation per se in a single session. Little attention has been paid to initiation conditions for negotiation and also repercussions of each negotiation outcome.

The chapter then turned to provide some basic information about negotiation: its definition, introduction of some theories on negotiation, and overview of buyer-seller negotiation modeling in supply chain management. A distinction was made between analytical and simulation models.

It was inferred that current negotiation models do not consider activities precede each negotiation session, and the consequences of the negotiations' outcome on the future decisionmaking behavior of the involved actors.

Review of order acceptance and negotiation modeling in supply chain leads us to consider a negotiation-based order acceptance strategy in which negotiation is considered simultaneously with other mentioned concepts in the OA literature. In other words, to have a comprehensive model which can capture the performance of an enterprise, we suggest considering all steps of each negotiation process; namely:

1. in which conditions a firm initiates negotiation with its counterparts;

2. how the negotiation takes place, and

3. how the negotiation outcome, directly or indirectly, influences the counterpart behavior for future interactions.

This process would happen several times during a specific time horizon (e.g. one year) between the enterprise and its different customers; and it can provide the decision-maker with valuable insights of the performance of its OA procedure.

Finally, to provide a systematic view of each negotiation problem and a conceptual basis for modeling in the next chapters, a general framework for negotiation has been developed in Section 2.3. 


\section{Chapter 3}

\section{Choice of Modeling Approach}

In this chapter we start with the description of the system under study in 3.1. From the system description, major characteristics of the system are derived in 3.2. Section 3.3 deals with the importance of simulation modeling for the system under study. Consequently, in 3.4 major simulation paradigms are discussed. Eventually in Section 3.5, the use of agent-based modeling is justified for this research.

\subsection{System description}

The system under study is the supply chain of a multi-plant specialty chemical manufacturing enterprise in which raw materials along with other required sources are transformed to finished products and delivered to the customers.

The Multi-Plant Enterprise (MPE) has a global sales department (GSD) that directly interacts with the customers and three production plants in different geographical locations. Each plant has several functional departments with particular roles and tasks. Departments' performance and their interactions form the behavior of each plant.

Each plant works on a Make-To-Order basis; i.e. the production is triggered by incoming order of customers and there is no inventory storage for the products. Three different products from eight raw materials are produced in each plant.

The GSD receives orders from 50 customers located in different places around the world and decides whether to accept the order or not. An order is accepted if (a) the offered price lies within the acceptable range that the enterprise previously has set for itself and (b) the production schedule of one of the plants can accommodate the order and produce the required quantity before the proposed delivery time in the order.

To check whether the due date is feasible for production, the GSD passes the order information to the scheduling department of each plant. Each scheduling department attempts to insert the new order into its production schedule following the "Processing Earliest Due Date" (PEDD $)^{1}$ scheduling policy to get the earliest date for fulfilling that order. Then plants inform the GSD on their earliest date. If one of the reported dates by the plants

\footnotetext{
${ }^{1}$ The PEDD scheduling policy implies that the order with earlier processing due date should be processed earlier.
} 


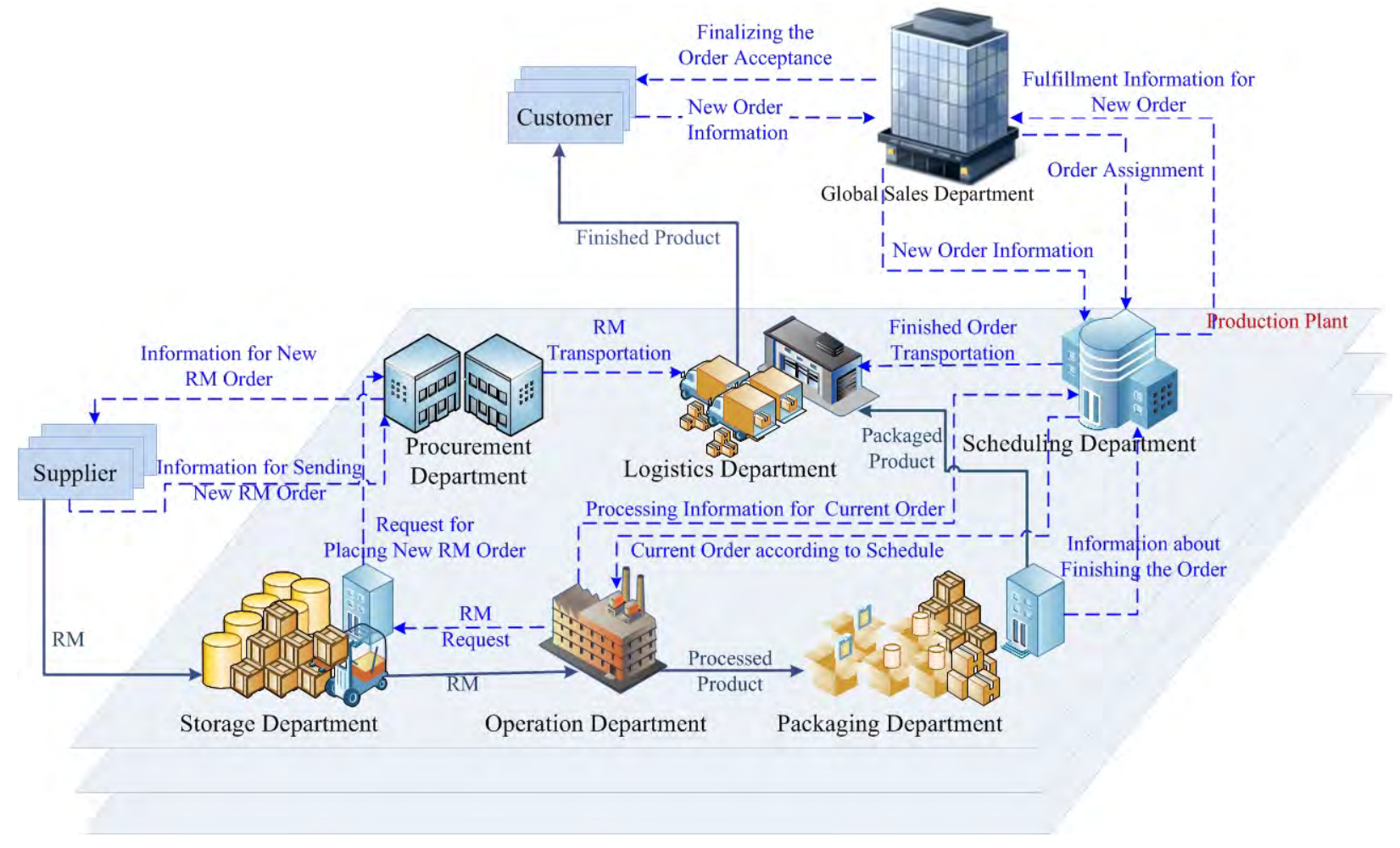

Figure 3.1: The multi-plant enterprise operations, adapted from Behdani et al. (2010)

is earlier than the requested due date by the customer, then order can be accepted (if the offered price is acceptable as well).

If the order does not meet these conditions, the enterprise and the customer initiate Negotiations $^{2}$ to find satisfactory terms for both sides.

In case agreement is reached, then GSD assigns the customer order to the plant with earliest completion date. The scheduling department of the selected plant then proceeds to insert the order into its job schedule.

Within each plant, the scheduling department activates the next order in the schedule to be processed by the operations department. For this purpose, it communicates with the storage department to ensure the availability of raw materials before releasing the order. The operations department processes the order and oversees the conversion of raw materials to product. It sends a request for release of the required raw materials to the storage department. Each batch of reactants are fed to the reactors and blenders (which are called production facilities) and processed following pre-specified recipes to produce the required products of the order. Following this production step, the products are sent for packaging. Subsequently, transportation of the finished order is arranged by the logistics department.

Another important process in each plant is raw material management which involves several departments. Firstly, the storage department (which is responsible for controlling

\footnotetext{
${ }^{2}$ The details of the negotiation process between GSD and customers are presented in Chapter 4.
} 
and monitoring the storage facilities) sends the request for raw material purchase to the procurement department. The procurement department places an order for raw materials with the suppliers and finally the transportation of the purchased raw materials to each plant is managed by the logistics department (Behdani et al., 2010). Figure 3.1 depicts operations in the MPE; solid lines show material flow and dashed lines illustrate information flows (see also Appendix A).

\subsection{System characteristics}

Having described the system, it is now possible to identify major characteristics of the system. MPE supply chain is a:

Socio-technical system The system described in the previous section can be considered a socio-technical system. It comprises a sub-system that involves social actors and their interactions- the social sub-system- and a technological part with the technological intricacies- the technological/physical sub-system. The two sub-systems interact with one another; and this gives rise to the overall behavior of the system.

Actors in the social sub-system are organized e.g. in organizations, departments and manage the operation of elements in the technical sub-system e.g. production facilities. The actors in the social sub-system are the owner of physical sub-system components; making decisions on the future development of those technical components. On the other hand, the components in the physical sub-system constrain the decisions made in the social sub-system.

In the MPE supply chain, customers, suppliers and MPE with GSD, the production plants and departments form the social sub-system. The network of various facilities that components in the social sub-system use to perform their tasks is the physical sub-system. These two sub-systems have interaction with one another and together form the overall behavior of the supply chain (Figure 3.2).

For instance, the operations department in the social subsystem is the owner of production facilities in the physical sub-system. The production capacity of the facilities is determined by the decision of the operations department, also the decisions of the operations department are restricted by production facilities. The facilities have certain capacity beyond which the operations department cannot accept jobs. In a similar way, the interaction of other departments (and other organizations) with the physical elements that they own/control can be described.

Table 3.1 lists the actors in the social sub-systems and their relation to the components in the physical sub-system.

It is noteworthy that in the MPE supply chain, the physical and social sub-systems are not fixed; they change during time resulting in a dynamic structure of this socio-technical system. For example, it is possible that the production plant turns to another supplier for raw materials and a customer switches to an alternative enterprise (rather than MPE) to satisfy its need.

Multi-level system The MPE supply chain is a multi-level system which can be divided into three levels (Figure 3.3):

- Global level: this level comprises three main actors: MPE, its suppliers, and its 


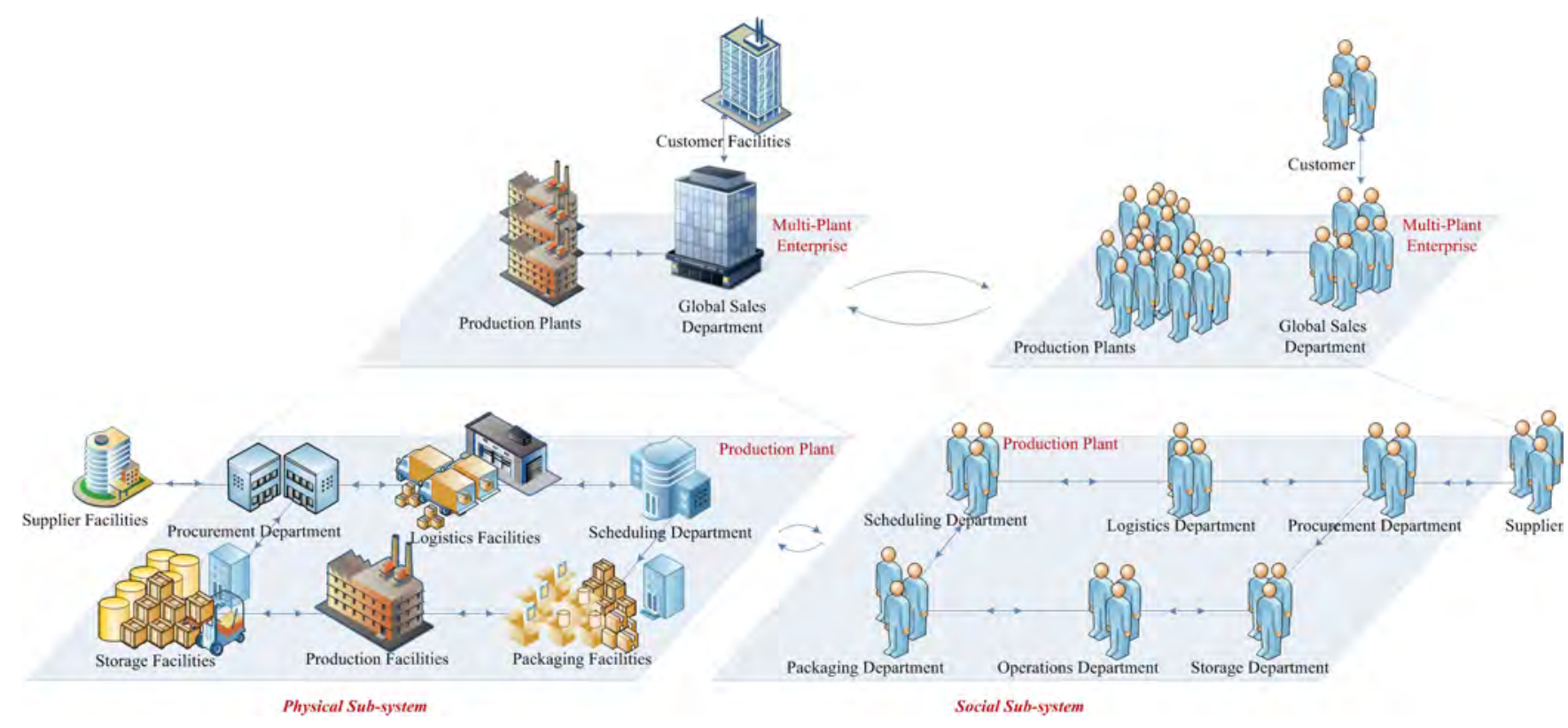

Figure 3.2: Social and physical sub-systems in the MPE supply chain (simplified version)

Table 3.1: Relations of the components in the social and physical sub-system

\begin{tabular}{|c|c|c|}
\hline Social Component & Relationship & Physical Component \\
\hline Customer & owns/controls & Customer facilities \\
\hline Global sales department & - & not applicable \\
\hline Production plant & owns & Production facilities \\
\hline Production plant & owns & Storage facilities \\
\hline Production plant & owns & Packaging facilities \\
\hline Production plant & owns & Transportation facilities \\
\hline Scheduling department & - & not applicable \\
\hline Operations department & controls & Production facilities \\
\hline Storage department & controls & Storage facilities \\
\hline Packaging department & controls & Packaging facilities \\
\hline Procurement department & - & not applicable \\
\hline Logistics department & controls & Transportation facilities \\
\hline Supplier & owns/controls & Supplier facilities \\
\hline
\end{tabular}




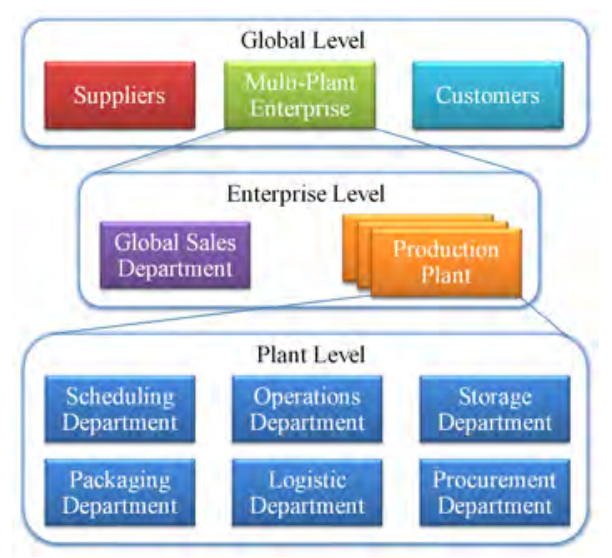

Figure 3.3: The multi-level system of MPE supply chain

customers.

- Enterprise level: the manufacturing enterprise comprises of a global sales department and three production plants.

- Plant level: each plant consists of 6 functional departments: scheduling, operations, storage, packaging, procurement, and logistics department.

The control of the MPE supply chain system is consequently highly dispersed and decentralized. There is no single entity which manages and controls the coherent behavior of the system. Overall behavior of the system arises from the collective behavior, i.e. interactions among individuals at different levels performing their jobs individually, or together, which creates a kind of behavior that actors themselves cannot produce. The decentralized decision making in the system is especially more evident in the global level of the system where the customers themselves decide what to order and in which quantity; the enterprise has no control on customer orders. The suppliers are autonomous decision makers as well.

In the enterprise -and plant- level, some decisions are made by each plant and department independently (e.g. inventory management) but - to facilitate the performance improvement of the enterprise as a whole - some other decisions are made by a central actor. For example, the order acceptance from customers and its assignment to the production plants are performed by a central decision maker (GSD). However, this central decision maker is not allowed to intervene in other decisions made at the plant level; e.g. the GSD cannot control the inventory level of a specific plant. The inventory level is determined by the operations department of the plant.

Complex adaptive system A number of features in the MPE supply chain system can be identified that leads us to consider it a complex adaptive system. The features are (McCarthy, 2003; Nilsson and Darley, 2006):

Decentralization As described in the previous section, there are individual actors, organized as different organizations and/or departments, making decisions autonomously, interact with each other and form the behavior of the whole MPE supply chain. 
Emergence The overall system behavior in the MPE supply chain is determined by interactions of the system's components (both social and physical) with one another. The actors' local behavior and their interaction will result in the emergence of behavior patterns at the system level (Choi et al., 2001; Stacey, 2000).

Heterogeneity There are 3 major actors (supplier, MPE, and customer) in the system with different needs, objectives, and decision making behaviors; each of which strives to meet its objectives that may be in conflict with the objective of other actors. The enterprise seeks to make profit and therefore requests high prices for its products; yet, the customer intends to satisfy its need with the lowest possible cost.

The heterogeneity is also evident in differences between customers, their location, perception about the enterprise, acceptable range for issues under negotiation and their sensitivity to price and lead time.

Each plant also has distinguishing characteristics. This ranges from e.g. the geographical location and operational procedures in each department to the trusted supplier and production efficiency of the plant.

Adaptiveness Adaptiveness refers to the ability of the system's components to change their behavior as a result of their interactions with other components and the environment (Macal and North, 2010). In this case, actors response both to the environment and to the action of other entities. For example, customers and the MPE change their opinion and perception about each other after a decision on an order is made. The enterprise adapts its order acceptance policy regarding the history of customers' previous purchases. With regard to interaction with the environment, customers define their acceptable range for price according to the average price in the market for a specific product. Suppliers are also set the price for raw materials based upon the market price.

Path-dependency Path-dependency means that the current state, performance of actors and the system depend on their previous states (Choi et al., 2001). Path-dependency is also reflected in the decision-making of actors where the set of decisions one faces for any given circumstance is limited by the decisions it has made in the past, even though past circumstances may no longer be relevant. As an illustration, each time, one of the negotiation parties intends to make an offer; he uses the information of previous offers of his own and also that of the counterparty. Hence, order terms in the new offer depend on the terms in previous offers. Additionally, the opinion that each party forms after each trade about his counterpart will determine the possibility of future trade with the same counterparty. For example, accepting a new order from a customer by enterprise highly depends on its previous decisions regarding accepting the orders from the same customer and also the set of previously-accepted orders waiting for processing in the plants. Accepting an order to fulfill today will also limit decision-making on orders coming from customers in the future.

Dynamism The relations and states in the system change through time. Current capacity of the storage department depends on the previous production rate of the operations department. Also, the structure of the system changes over time according to the 
interactions of suppliers, GSD, customers, plants, departments with one another. It is not possible to define the structure of the whole system beforehand. Only the decision-making behavior of the actors which form the collective system behavior can be determined in advance.

Considering described characteristics of the MPE supply chain, we need a modeling approach that can take into account different features of the multi-level, complex adaptive system. More specifically, we need a modeling method that:

- can capture heterogeneity in the system i.e. the distinguishing characteristics of various components (e.g. GSD and customers) in two sub-systems (social and technical sub-systems) and their interactions;

- is able to express the characteristics of each level of the system as well as required emergent characteristic of the overall system (which stems from the decentralized nature of the problem). It is necessary to look at the individual level of actors (e.g. the buyer and the seller) and allows the system behavior to emerge from the interactions at the individual level;

- can represent the adaptive behavior of the system components (e.g. opinion formation of each party about its counterparty in negotiations) and its effect on the future behavior of entities;

- can consider the system changing states and relations as time proceeds and also the path-dependency between the states;

\subsection{Modeling approach for the MPE supply chain}

In Chapter 2, we made a distinction between two different approaches widely used for supporting decision makers in better understanding of the system of their interest: analytical models or computer-based simulation models.

Analytical and mathematical modeling approaches are definitely useful in understanding fully-defined problems which entail few decision variables and limiting assumptions to make them solvable. Nevertheless, when more complex systems are involved like that of this research with heterogeneous actors in different sub-systems and levels, random demand pattern, random order attributes, and adaptive behavior of the parties, analytical approaches may not be satisfactory in providing desired insights about the system they emulate. Analytical models are ineffective in considering all variables and constraints involved in complex instances because they often require a lot of computing time and present poor flexibility in terms of model changes (Manzini et al. 2005).

The alternative is simulation modeling. A simulation generally refers to a computerized version of the model which is run over time to study the implications of the defined interactions (Zeigler et al., 2000).

The simulation models are flexible tools that can be used to analyze complex problems and enable us to study such systems in detail (van der Vorst et al. 2000, Jansen et al. 2001). Value of parameters in a simulation model can be manipulated easily in a way that 
analysis of different combinations of parameters are possible; therefore, with getting insight about the system behavior, the cost to make a decision could be reduced, and response to such modifications could be obtained very fast (Manzini et al. 2005). In addition, unlike traditional mathematical optimization approaches, results in intermediate stages could be captured during the simulation process so that the dynamic behavior of the system could be analyzed in different time steps; for example, with simulation modeling, it would be possible to follow how the buyer and the seller form opinion about each other during different trading sessions in which they interact with one another.

Consequently, the simulation modeling and analysis is very much useful when the purpose of study is (Chung, 2004):

- gaining insight into the operation of a system,

- developing operating policies to improve system performance, and

- testing new strategies and/or systems before implementation

Considering the (a) aim of this research to improve order acceptance performance of the MPE by incorporating negotiation in order acceptance decisions and examining various OA policies that cannot be achieved by analytical models, (b) the characteristics of the system under study (i.e. multi-level, complex adaptive socio-technical system) and (c) the aforementioned advantages of simulation modeling (e.g. its capability to consider several variables and parameters, and easily manipulation of parameters), computer-based simulation approach is chosen for this research.

With this intention, in the next section, an overview of some of the most common simulation paradigms and their possible advantages and disadvantages for modeling the MPE supply chain (with the characteristics mentioned in Section 3.2) will be presented.

\subsection{Overview of some simulation paradigms}

A simulation paradigms is regarded a set of fundamental assumptions (implicit or explicit) regarding the key aspects of the world which wants to be abstracted into a model (Borshchev and Filippov, 2004). There are many different types of paradigms for modeling and simulation. Borshchev and Filippov (2004) listed three major approaches suitable to analyze a complex system: System Dynamics (SD), Discrete-Event (DE) modeling and Agent-Based (AB) modeling. Sections below provide details on these approaches.

\subsubsection{System Dynamics}

In $\mathrm{SD}$, the real world processes are represented in terms of stocks, flows between these stocks, and information that determines the value of these flows. SD abstracts from single events and entities and take an aggregate view. Consequently, to approach the problem in SD style, one has to describe the system behavior as a number of interacting feedback loops, balancing or reinforcing, and delay structure.

Then, this structure is represented as a set of mathematical equations which are solved numerically. With few equations, relationships and parameters, one can create insight into systems that would otherwise have been considered quite complex. 
One of the main characteristics of SD is its aggregation philosophy; the observables of a system are aggregated under some stocks (Rahmandad and Sterman, 2008). Thus, the objects being modeled (people, products, events, and other discrete items) are modeled homogeneously and represented in SD models by their quantities described as system's observables. But, this top-down approach and high aggregation level could be problematic in some situations like that of this research. More specifically, SD is not so much suitable to model what is occurring at individual level especially when there are heterogeneous agents with different characteristics. In Other words, in SD, the modeler has to think in terms of global structural dependencies and as long as the model works only with aggregates, the item in the same stock are indistinguishable, and they do not have individuality. As an example, consider that all the current customers of the MPE are modeled using a stock which has an inflow of new customers who get influence from the reputation of the enterprise. When customers are entered into the stock, it is no longer feasible to track an individual customer with specific degree of influence as all the customers are mixed and there is no individual heterogeneity for customers. The overall behavior of all the customers in the stock can solely be tracked; not the behavior of an individual customer. Therefore, an SD model will lose individual properties, or histories in the micro-level of the system.

In addition, SD models operate on global laws defined by the equations and apply to all members of the compartment (Bobashev et al., 2007). We refer back to the customer's example; it is not possible to define different behavior rules for various customers in the stock. All the customers in the compartment follow a global rule. Hence, it is not possible for customers in the stock to change their behavior towards the MPE if their orders are rejected.

Besides, although SD models can capture adaptive behaviors, they necessarily assume a static internal system structure (Nikolic, 2009) which cannot represent emergence in the system.

Because in this research, the interaction among individual entities of buyer, seller, GSD, and production plants is an essential system property which gives rise to the collective behavior of the system, and we aim to understand how the interactions affect the performance of MPE; therefore, it can be concluded that the top-down modeling approach of SD with static system structure is not quite compatible with our modeling objective for the MPE supply chain.

\subsubsection{Discrete Event}

Discrete event approach is based on the concept of entities, resources and block charts describing entity flow and resource sharing. This approach roots to 1960s when Geoffrey Gordon conceived and evolved the idea for GPSS and brought about its IBM implementations (Gordon, 1961). Entities (transactions in GPSS) are objects that represent people, parts, tasks, etc. They travel through the blocks of the flowchart where they stay in queues, are delayed, processed, seize and release resources, split, combined, etc. See Figure 3.4.

In DE simulation, the operation of a system is represented as a chronological sequence of events. Each event occurs at an instant in time and marks a change of state in the system (Robinson, 2004). Subjects of simulation in this approach are passive objects that are processed by the model blocks. Additionally, the system structure in DE models is pre- 
defined and there is no room for autonomous decision making and interactions of entities in the model.

Although DE simulation can consider the heterogeneous nature of entities in the MPE supply chain, it does not support the emergent characteristic of the system as the structure of the model is predefined and static. Objects are only processed in different blocks and they are not capable of interactions with other objects. Also, modeling the concepts like perception of parties in negotiation about each other and their adaptation process is difficult in $\mathrm{DE}$ and requires complicated modules that are not easy to develop. All these aspects considered, the DE modeling paradigm is not quite suitable for the objective of this research.

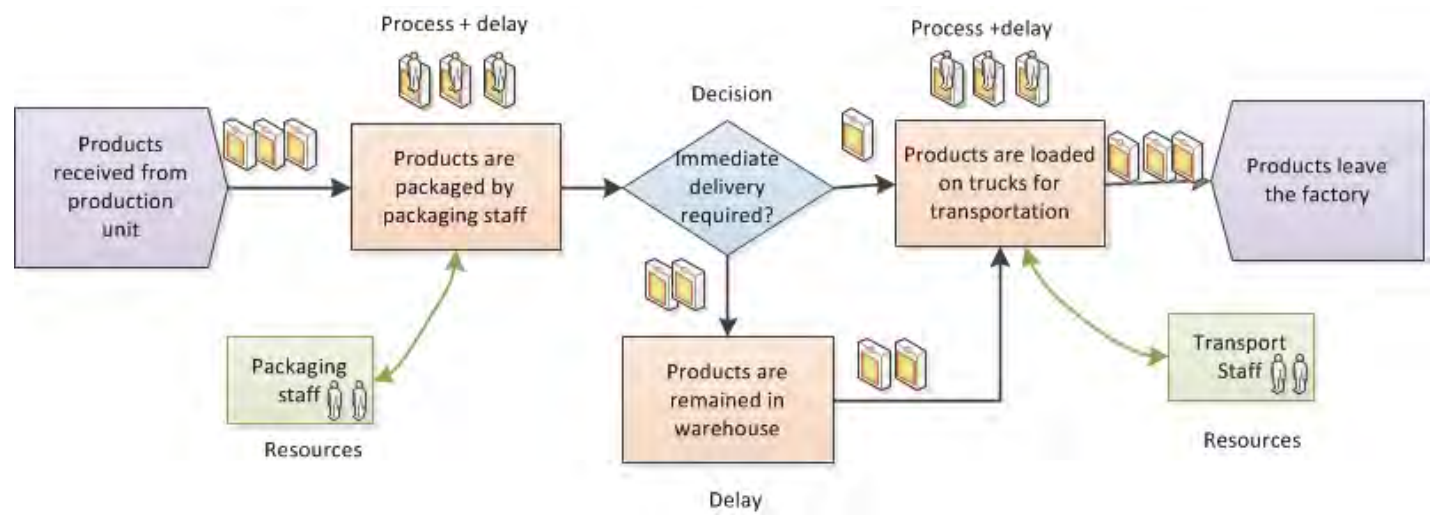

Figure 3.4: A discrete event model: products storage and transport

\subsubsection{Agent Based}

In $\mathrm{AB}$ modeling, a system is modeled as a collection of autonomous decision-making entities called agents and their possible relationship and interactions. Each agent individually assesses its situation and makes decisions on the basis of a set of rules; then, the systemlevel behavior emerges from micro-level (agents) behavior and interactions. Agents are defined by Jennings (2001) as:

"An agent is an encapsulated computer system that is situated in some environment and that is capable of flexible, autonomous action in that environment in order to meet its design objectives."

Even a simple agent-based model with agents and their relationships can exhibit complex behavior patterns and provide valuable information about the dynamics of the real-world system it emulates (Borshchev and Filippov, 2004).

One important feature of agent-based models is that they are essentially decentralized. Compared to SD or DE models, there is no such a place in an $\mathrm{AB}$ model where the global system behavior (dynamics) would be defined. Instead, the modeler defines behavior at individual level and the global behavior of the system emerges as a result of several individuals, each following its own behavior rules, living together in some environment and communicating with each other and with the environment as well.

Hence, one of the important features of $\mathrm{AB}$ is that it captures emergent phenomena which result from interactions of individual entities (emergence). 
AB modeling is also a flexible modeling approach. Flexibility can be addressed in several dimensions. Firstly, it is almost easy to add more agents to an agent-based model. The bottom-up perspective in an agent-based model makes it also possible to define experiments by changing the behavior (set of rules) of agents and evaluate their effects on the system performance (e.g. the MPE supply chain in the case of this research).

Another dimension of flexibility is the ability to change levels of description and aggregation: one can easily play with aggregate agents, subgroups of agents, and single agents, with different levels of description coexisting in a given model. The flexibility of AB models makes them easier to maintain (Borshchev and Filippov, 2004).

Besides all these aspects of flexibility, agents developed for a particular problem might be customized for similar problems in other domain (van Dam, 2009).

However, there are several issues regarding agent based modeling that may influence its application for modeling complex systems. AB is a bottom-up approach which involves describing the individual behavior of potentially many constituent units. Simulating the behavior of all of the units can be extremely computation intensive and therefore time consuming. Although computing power is still increasing at an impressive pace, the high computational requirements of $\mathrm{AB}$ modeling remain a problem when it comes to modeling large systems (Bonabeau, 2002). As also stated by Rahmandad and Sterman (2008):

"Agent-based models can capture heterogeneity across individuals and in the network of interactions among them. Agent-based models relax aggregation assumptions, but entail computational and cognitive costs that may limit sensitivity analysis and model scope."

Accordingly, it is highly difficult to perform sensitivity analysis on all the parameters of e.g. decision rules of various agents especially when there is large number of agents in the system.

\subsection{Choice of agent-based modeling}

Considering the requirement for the modeling approach- individuality, heterogeneity and decentralization, emergence, adaptiveness, path-dependency, and dynamism- agent-based modeling is more suitable approach for this study.

In $\mathrm{AB}$ modeling the focus is on individuals and their interrelationships with other individuals and entities (Cicirello and Smith, 2004; Jennings et al., 1998). It can effectively capture heterogeneity of individuals in the system. It is of crucial importance to consider the individual entities in the MPE supply chain which are organized in different firms, and departments with various objectives, needs and decision-making behavior. The interaction of the customer organization and the GSD on the one hand and the GSD with other relevant departments on the other hand should be clearly captured in the model. AB modeling is a promising avenue in considering the individuality of actors in the system along with their different characteristics in terms of their objectives, resources, behavior, perception about other parties, etc.

This characteristic of $\mathrm{AB}$ approach is especially aligned with the aim of this research to model the individual buyer and seller along with the rules based on which they make decisions (e.g. utility maximization, opinion formation) and consequently give rise to the overall performance of the system. There is no central entity in the supply chain that can 
manage and control the buyer, the seller and their interactions. The buyer and the seller themselves determine their actions based upon their internal decision rules.

As Bonabeau (2002) claimed, the only way to analyze and understand emergent phenomena is to model them from the bottom up. ABM is a bottom-up approach in which the programmer only models the behavior of an individual (Garcia, 2005) and the collective behavior of the system emerges from the interactions of individuals. Therefore, ABM is a suitable modeling and simulation approach for systems distributed in time and space showing emergent properties (such as the MPE supply chain described in this research) (Jennings et al., 1998; Lim and Zhang, 2003).

ABMs also offer a good way to include the social and behavioral aspects of a sociotechnical system (van Dam, 2009). The physical components of technical sub-system in the MPE supply chain, not only the nodes (e.g. storage and production facilities) but also the links (e.g. raw material pipes between storage and production facilities) can be presented by separate objects in an agent-based model. In addition social actors in the system can also be modeled as agents making decisions about operation and development of the technical network.

Furthermore, AB modeling makes it possible to model the adaptive behavior that arises due to interaction between the buyer and the seller in the social sub-system at different negotiation sessions.

As a simulation paradigm, $\mathrm{AB}$ furthermore allows performing experiments with the model and can effectively capture path-dependency and dynamism in the system (as described in 3.3). The states and relations in the buyer-seller interaction change, and $A B$ can effectively consider this aspect. Also, AB can capture dependency between previous decisions of the negotiation parties and its effect on their future decisions.

All in all, AB modeling outperforms the other two regarding model requirements and research objective and is chosen for model development in the next part of the thesis.

\subsection{Chapter conclusion}

This chapter started with the description of the system under study, the multi-plant enterprise supply chain. To gain some perspective on the system, we then presented different characteristics of the MPE supply chain. The MPE can be considered as a socio-technical system which comprises two sub-systems: social actors and their interactions in the social sub-system and a technological sub-system with the technological intricacies. The two sub-systems interact with one another; give rise to the overall behavior of the system.

The MPE supply chain system is also a multi-level system which implies that the control of the system is highly dispersed and decentralized. There is no central controller or manager for the system. Individual actors in each level make decision following their internal decision rules, interact with other actors and the overall behavior of the system arises from interactions among individuals at different levels.

The system, additionally, has characteristics of heterogeneity, emergence, adaptiveness, path-dependency and dynamism which lead us to categorize it as a complex adaptive system.

Next, the chapter presented some requirements for the modeling approach according to 
the characteristics of the system. The application of simulation modeling and its ability to capture complexities of the system was then emphasized for this case.

Amongst the possible simulation paradigms which can provide an understanding of the negotiation process in order acceptance of the MPE, agent-based modeling was selected since the attributes of the system perfectly correspond to the characteristics which agentbased can deal with e.g. agents heterogeneity and interactions. 


\section{Part II}

\section{Development of the Negotiation Model in MPE}




\section{Chapter 4}

\section{Agent-Based Model for Negotiation in MPE}

In the previous part of the thesis, the research issue was described and agent-based modeling was chosen as the suitable modeling approach for this case. In this part, knowledge from the previous three chapters is applied to develop an agent-based model for the negotiation process in the multi-plant enterprise.

To develop the model, the steps of an agent-based methodology developed by Padgham and Winikoff (2003) are followed. The steps are problem formulation, system identification, architectural design, detailed design, and verification and validation. Each section of this chapter addresses one of these steps.

\subsection{Problem formulation}

The problem (issue for research) is described in Chapter 1. The aim of this research is to improve the order acceptance performance of the multi-plant enterprise by incorporating buyer-seller negotiations in its OA procedure.

The problem owner in this case is the decision-maker on order acceptance in the MPE (usually the manager or the sales department) who has interest, means and power to consider and implement negotiation as an approach in the order acceptance procedure of the enterprise.

\subsection{System identification}

The system under study is the multi-plant enterprise supply chain which is described in Section 3.1. Following Chapter 3, the system entails three main actors:

- Multi-plant enterprise MPE is a make-to-order manufacturing enterprise. The enterprise has a global sales department (GSD) that directly interacts with customers and three production plants in different geographical locations. Each plant has several functional departments with specific roles and tasks. Departments' behavior and their interactions form the performance of each plant. Three types of products from 


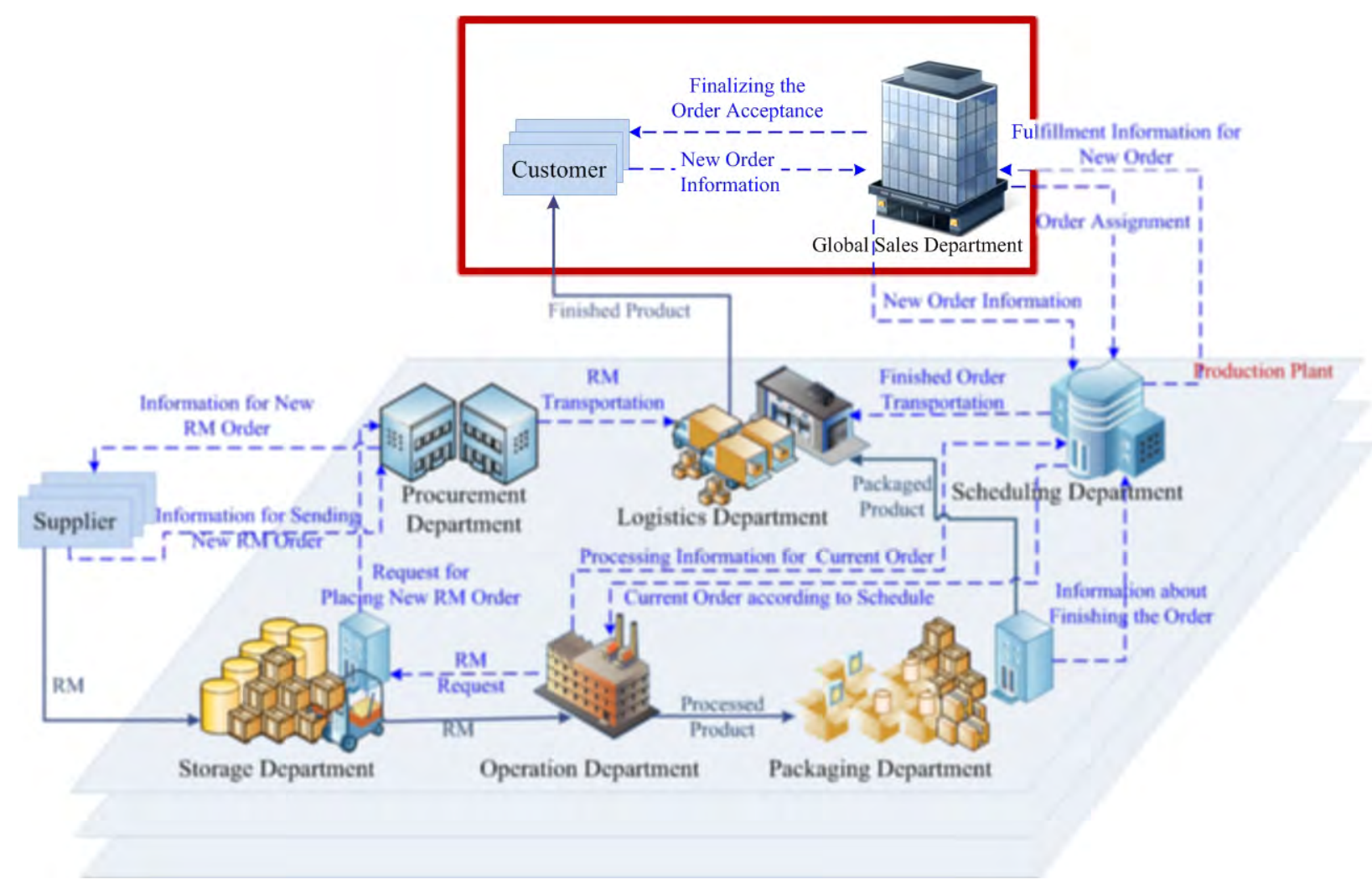

Figure 4.1: The interface of GSD and customers in order acceptance

eight different raw materials are produced in each plant. (See Section 3.1 for further information).

- Customers The MPE has 50 customers in various geographical locations. Customers may have different characteristics, but in general they are classified into two main categories: wholesalers and industrial customers. The main distinction between these two classes of customers is reflected in their sensitivity to price and delivery time.

- Suppliers each plant has its own suppliers which provide required raw materials for production.

The model for internal operations of the lube oil multi-plant enterprise is already developed by Behzad Behdani in the E\&I section. The current study pays attention to the interface between the GSD and customers in the order acceptance context (Figure 4.1). In addition, as one of the goals of this work was extending the previous model to incorporate the buyer (customer)-seller (enterprise) negotiation, the justification on overall structure of the enterprise (e.g., number of plants) and the behavior of different departments of each plant is out of the scope of this research.

Therefore, in the current modeling attempt, customers as buyers and GSD as the seller are the focal agents in the system. The other relevant agents, which are already designed, are: the 6 various departments in each production plant and 3 suppliers for each plant. 


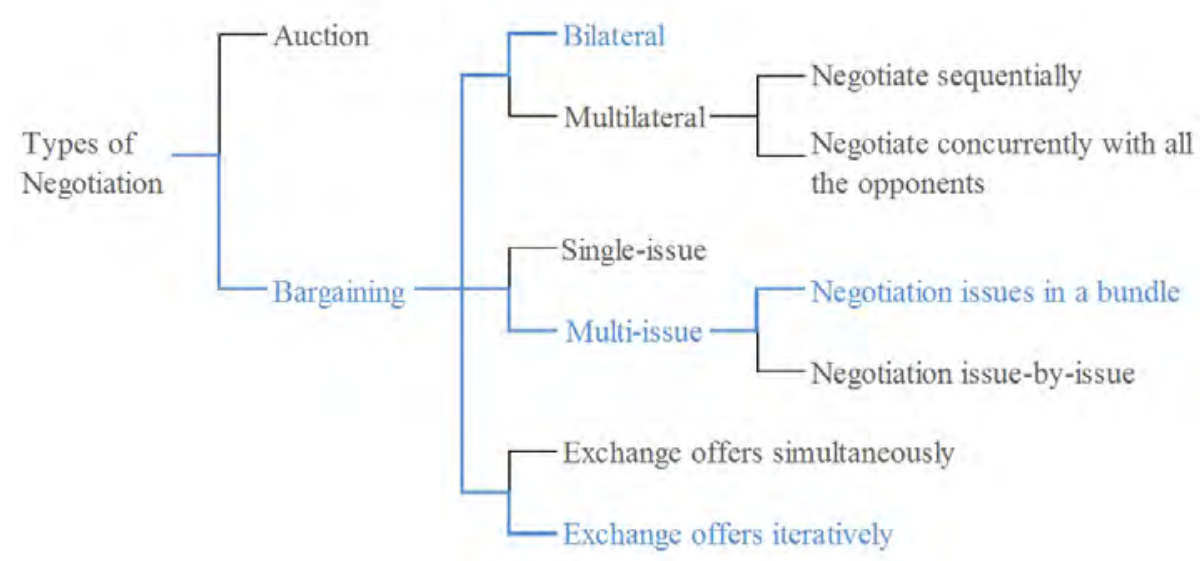

Figure 4.2: Type of negotiation in this research

In this system, whenever a customer comes, if its order is not acceptable for the enterprise (in terms of the offered price and delivery time), negotiation will be initiated between the customer and GSD. In negotiations, GSD and the customer follow the Rubinstein's bargaining model (Osborne and Rubinstein, 1994); i.e. they take turn to make offer to each other until the agreement is secured. They negotiate on the price and delivery time together in a bundle (and not one-by-one). Based on the classification presented for negotiation situations in Chapter 2, Figure 4.2 shows the type of negotiation in this research.

\subsection{Architectural design}

Following system identification, in the architectural design stage, it is determined what the agent specifications are and how they interact. To do so, main concepts and their relations in the system are specified in 4.3.1. This is followed by agent architecture in Section 4.3.2. First individual agents, and then their interactions are described.

\subsubsection{Negotiation Ontology}

The main concepts in each negotiation problem are identified in the framework for negotiation in Chapter 2. This sub-section extends the framework further in the ontology for negotiation by introducing new concepts and specifying the relations between the concepts. Ontology deals with explicit formal specifications of concepts and relations among them (Noy and McGuinness, 2001).

The ontology is the formal description of entities, their properties, and relationships that helps the agents in the model to share the same conceptual model of the problem in order to understand the concepts and get effective communication. It would not be possible to have interaction between the agents if the agents refer to one concept with different names.

Figure 4.3 depicts negotiation concepts and relations among them. In the negotiation ontology, the interaction between the Negotiation Parties is called the Negotiation Process. The Negotiation Process has several Negotiation Phases which in turn, are made up of 
Negotiation Activities. The Negotiation Activities are performed by the Negotiation Parties during the Negotiation Process. The Negotiation Parties deal with Offers to one another. There could be several Negotiation Issues in each Offer exchanged between the Negotiation Parties. The whole Negotiation Process is governed by a Negotiation Protocol which consists of several Negotiation Rules.

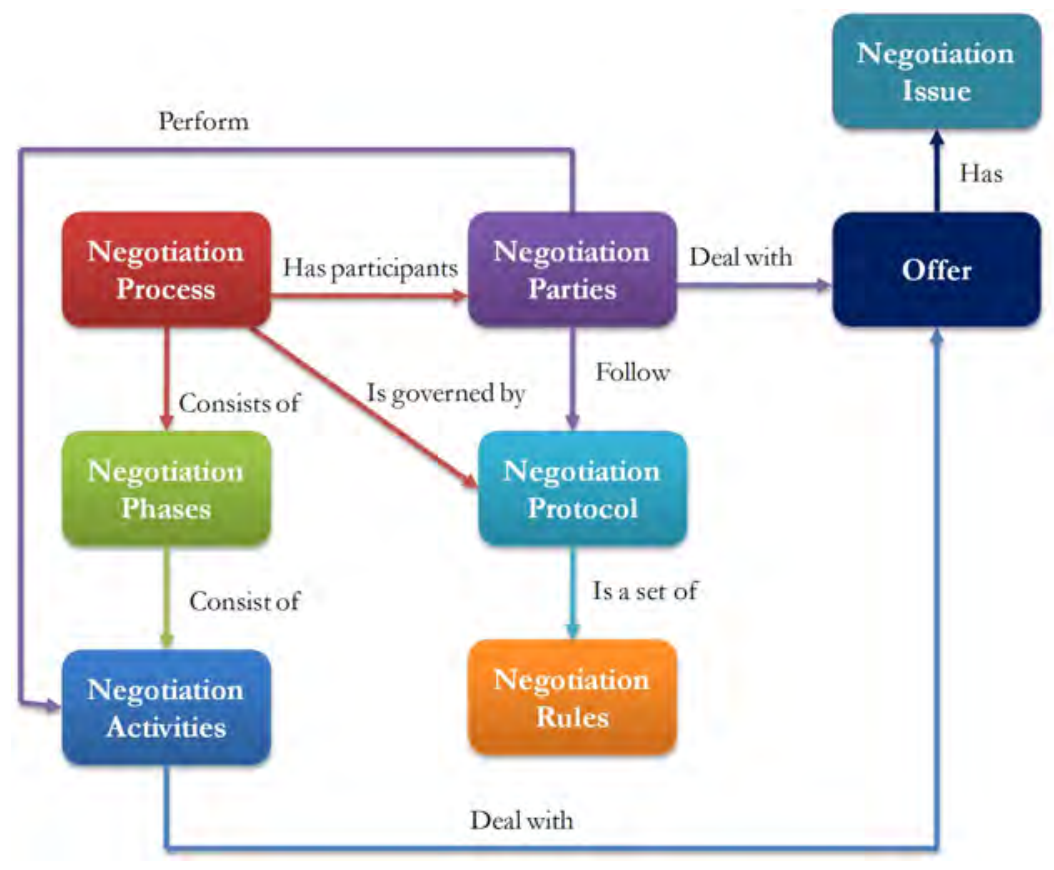

Figure 4.3: Simplified version of the negotiation ontology

The developed ontology is used in the next section to define classes (concepts in the domain of discourse), arrange the classes in a taxonomic (subclass-superclass) hierarchy and to define slots (properties of each concept describing various features and attributes of the concept).

It is noteworthy that some definitions are considered in the negotiation ontology to make it compatible with the ontology for socio-technical systems developed in the Energy and Industry (E\&I) section. The E\&I ontology views the world as a network. Everything in the world is considered as Node, Edge, Data, or Knowledge. These four are the main classes. The ontology makes distinction among technical artifacts and social components: a Node can be either a physical node or a social node. Edges form the relationships between Nodes and they can also be physical or social.

In the negotiation ontology, for agents, a role of Negotiation Party has been defined. Also the interaction between parties, the Negotiation Process, is considered as a social edge in the E\&I ontology. For more information on E\&I ontology see van Dam (2009) and Nikolic (2009). 


\subsubsection{Agent architecture}

The MPE supply chain can be considered a Multi-Agent System (MAS) composed of multiple autonomous agents. Agents act on behalf of the supply chain members - customers, suppliers, the GSD, and 6 different departments in each plant. The two focal agents in this research are customers as the buyers and the GSD as the seller. These agents are explained further in the following paragraphs. First a brief description of the agent's behavior and their attributes are provided for the two focal agents. Later, the details of the agents' behavior during the interaction are described in the agent interaction section (4.3.2.3).

\subsubsection{Seller Agent}

The seller agent is the GSD who directly interacts with customers and production plants. The GSD has the ability to finally accept or reject a customer's order on the basis of information it gets from production plants.

The GSD receives an order from the customer and decides on the order's status (OA decision-making).

In the OA decision-making state (Figure 4.4), on the basis of three factors (the order's profit contribution, production capacity of plants and customer's value) an order will be: (a) accepted, (b) rejected or (c) set for negotiation. The events that follow these OA decisions are:

(a) the accepted order is assigned to the production plant with the earliest completion date and the GSD agent waits for a new order;

(b) In this case the order is rejected, and the GSD agent waits for the arrival of a new order;

(c) The GSD prepares and sends an offer to the customer whose order is set for negotiation. The GSD agent waits for the customer's response to the sent offer. On the basis of the buyer's agent reaction to the offer, there could be three situations:

(a) the offer is accepted, it is then assigned to the production plant and the GSD waits for a new order.

(b) the offer is rejected and the buyer breaks off negotiation.

(c) the offer is rejected but the buyer sends a counter-offer.

In the third case, the seller evaluates the received counter-offer of the buyer and decides whether to accept, reject and quit (because of time limitation) or reject and respond with a counter-offer.

The state transition diagram for the seller agent is shown in Figure 4.4. In this figure, the bubbles represent the agent states and corresponding events are illustrated on the arrows.

The seller agent can be described by a number of attributes. The common attributes between two agents are listed in Table 4.1 and some of the seller agent specific attributes are discussed below. The details of attributes and decisions are specified in the agent interaction section (Section 4.3.2.3).

There are also some seller agent specific attributes:

- Profitability lower bound. The seller agent classifies incoming orders to the profitable and not profitable orders. The criterion for this classification is the profitability level. 


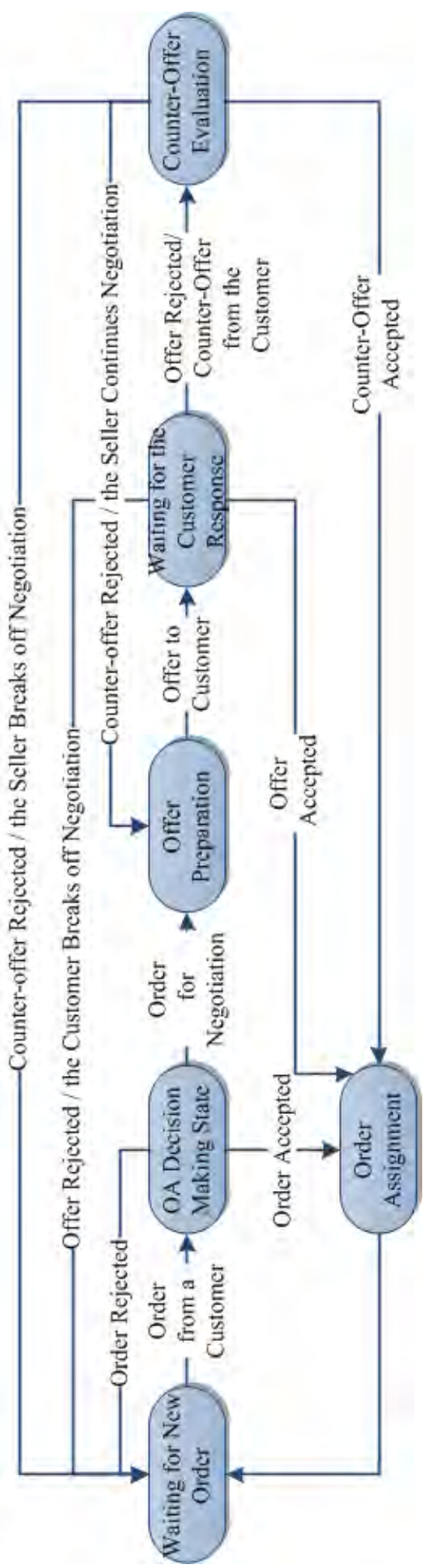

Figure 4.4: The seller state transition diagram 
Table 4.1: Common attributes of two agents

\begin{tabular}{|c|c|}
\hline Attribute & Description \\
\hline $\begin{array}{l}\text { Acceptable range for } \\
\text { issues under negotiation }\end{array}$ & $\begin{array}{l}\text { The offers in which the value of issues violates the acceptable range } \\
\text { will not be accepted. }\end{array}$ \\
\hline $\begin{array}{l}\text { Weight factors for issues } \\
\text { under negotiation }\end{array}$ & Weight factors show the importance of each issue for the agent. \\
\hline $\begin{array}{l}\text { Evaluation function for } \\
\text { issues under negotiation }\end{array}$ & $\begin{array}{l}\text { The value of each issue in an offer is evaluated using an evaluation } \\
\text { function. The evaluation functions assign a number (between } 0 \text { and } 1 \text { ) } \\
\text { to each value of issue. See Chapter } 5 \text { for evaluation functions of the } \\
\text { agents. }\end{array}$ \\
\hline Utility function & $\begin{array}{l}\text { The utility function is used to evaluate the offer of the counter-part } \\
\text { and in preparing the offer for the counter-part. The utility function in } \\
\text { this research has a linear form, that is: the overall utility ( } \mathrm{U} \text { ) is the } \\
\text { sum of the value of evaluation functions (E) for each issue (denoted by } \\
\text { j) multiplied by its corresponding weight (w): } \quad U=\sum_{j} W_{j} E_{j}\end{array}$ \\
\hline Step limit & $\begin{array}{l}\text { To consider the effect of time during the negotiations, step limit is } \\
\text { used. Step limit is the maximum number of negotiation rounds for } \\
\text { each party. }\end{array}$ \\
\hline Utility gap size & $\begin{array}{l}\text { The acceptable difference between the utility of the agent and its } \\
\text { opponent is measured by the utility gap size. }\end{array}$ \\
\hline Concession factor & $\begin{array}{l}\text { Concession factor is the measure of how far concession can be made in } \\
\text { preparing a new offer. }\end{array}$ \\
\hline Negotiation speed & $\begin{array}{l}\text { The measure of how fast concession can be made in preparing a new } \\
\text { offer. }\end{array}$ \\
\hline History & $\begin{array}{l}\text { On the basis of the result in a previous trade experiences, the agent } \\
\text { form some perception about its counter-part which is called history in } \\
\text { this document. The history represents the adaptive behavior of agents. } \\
\text { A previous trade interpreted either as a completely positive experience } \\
\text { or a completely negative experience. According to the interpretation, } \\
\text { an update amount will be added (either positive or negative) to the } \\
\text { threshold of history that the agent has for itself. The history plays role } \\
\text { in making decisions for future trades with the counter-part. }\end{array}$ \\
\hline
\end{tabular}


This level is some portion of the order's incurred cost.

- History threshold of customers. This value defines the initial perception of the GSD on the customers.

\subsubsection{Buyer Agent}

The buyer agent is the customer of the enterprise who places an order with the GSD. An order will be (a) accepted, (b) rejected, (c) asked for negotiation on its terms. The agent's states following each of these events are:

(a) If the order is accepted by the GSD agent, the buyer agent waits for the delivery of its order.

(b) If the order is rejected, the buyer agent places an order with another supplier.

(c) If the order is asked for negotiation on its terms, the buyer agent either rejects the order and goes to another supplier, or accepts the negotiation request and evaluates the new offer of the seller agent.

The evaluation state leads to three events:

(a) The new offer of the seller is accepted and the buyer agent waits for the order delivery.

(b) The new offer of the seller is rejected and the buyer breaks off negotiation. The buyer agent goes to another supplier for its need.

(c) The new offer of the seller is rejected and the buyer responds the offer with a counter-offer and waits for the seller's response.

Figure 4.5 shows the state transition diagram of the buyer agent. 


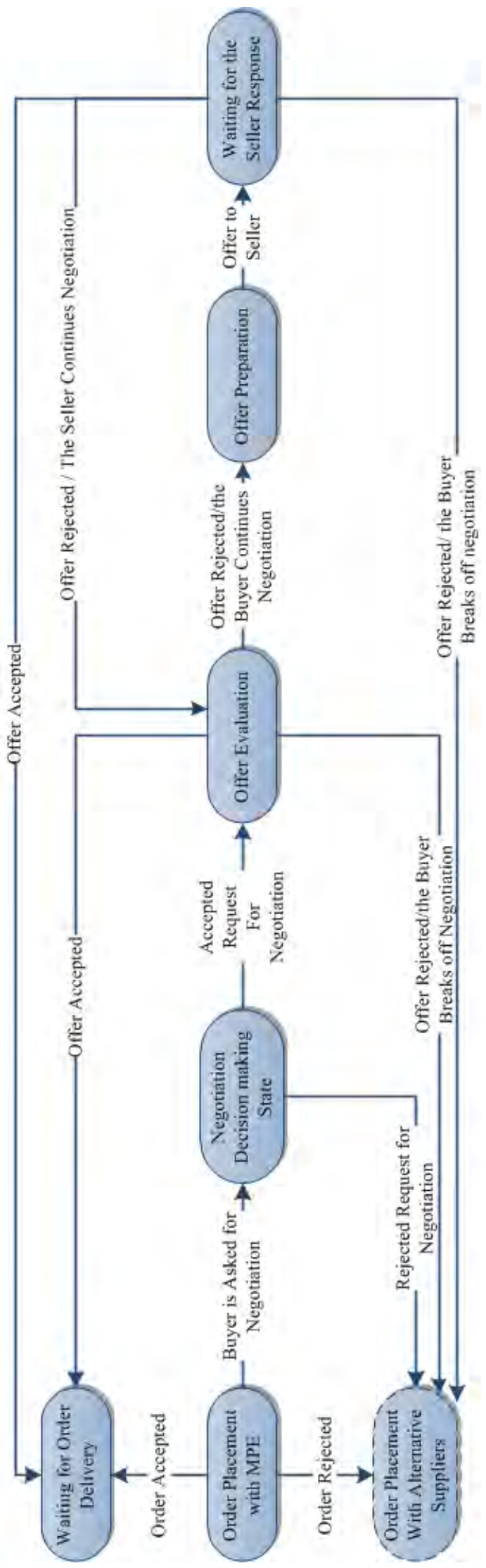

Figure 4.5: The buyer state transition diagram 
Table 4.2: The buyer agent attributes

\begin{tabular}{ll}
\hline Attribute & Description \\
\hline \hline Demand pattern & $\begin{array}{l}\text { The order pattern of the buyer agent follows a } \\
\text { Poisson distribution. }\end{array}$ \\
\hline Best Alternative & $\begin{array}{l}\text { When the buyer agent places an order with GSD, it } \\
\text { to the Negotiated }\end{array}$ \\
also places an order with other suppliers. The value \\
of issues in the simultaneous order is not negotiable. \\
Whenever, the buyer agent reaches a point that it \\
should decide whether to continue negotiation with \\
the enterprise, it will check the alternative suppliers. \\
This can be considered as an outside option \\
(Muthoo,1999) or the best alternative to the \\
negotiated agreement (BATNA) according to the \\
negotiation analysis vocabulary (Raiffa et al., 2002). \\
The probability that at least one supplier accepts the \\
buyer's order increases as the number of negotiation \\
rounds increases.
\end{tabular}

The most important buyer specific attributes are specified in Table 4.2.

\subsubsection{Agent Interaction}

In this section, the details of agents' actions and decisions during the interaction are explained. As mentioned in the ontology, the buyer-seller encounter -Negotiation Processhas three phases. In the pre-negotiation phase, each party evaluates his counterparty and decides whether to enter negotiation with the opponent or not. The negotiation phase constitutes the main interaction in which offers are exchanged between the parties. The result of this phase could be a successful negotiation or a failed one. On

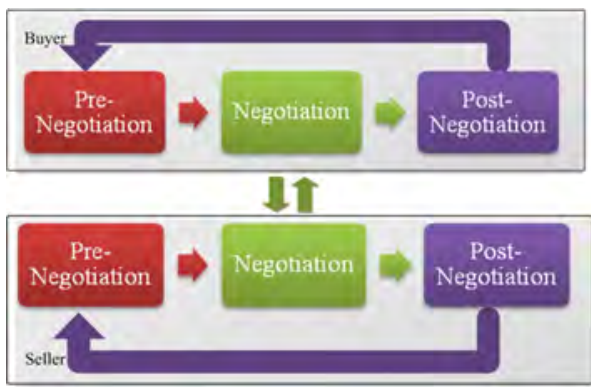

Figure 4.6: Negotiation phases 


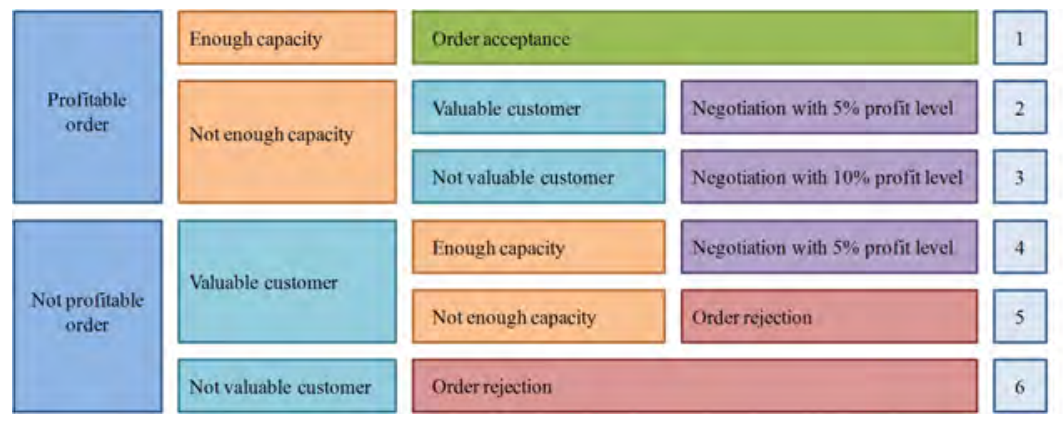

Figure 4.7: Seller pre-negotiation phase

the basis of the result in the negotiation phase, parties update their history about each other. The history plays role in making decisions for future trades with the counter-party. Figure 4.6 presents the interaction schematically.

Reminder of this section describes activities and their sequence in each phase.

Pre-negotiation phase The starting point for a make-to-order firm is order placement by a customer. There are several tasks that need to be performed by the customer prior to placing an order. First, the buyer should identify the need for a product, then determine the characteristics of the need and finally make an order to satisfy the need. The next stage would be evaluation and selection of a supplier who is competent to fulfill that order. The basis of selection for this stage is the history that buyer has for different sellers. The history is formed on the basis of previous trading experience of the buyer with different sellers. In this case, the experience could be completely positive or negative. If the trading event is interpreted as a negative experience, the history value will reduce to some degree, and this will have effect on choosing that specific seller for future trading. See "post-negotiation phase" for more details on history update.

When the seller is chosen, the order will be sent to him. At the same time, the buyer places an order for other sellers with non-negotiable price and delivery time values. This can be considered as the outside option for the buyer (Muthoo, 1999). It is assumed that alternative suppliers accept the order with a probability that will increase as negotiation proceeds in order to consider the effect of time implicitly (see Table 4.2). Whenever, a buyer agent has to make a decision on continuing the negotiation process with this specific seller, it will check alternative sellers. If at least there is one supplier who accepts its offer, then the buyer steps out of negotiation with the current seller.

The other side of the trade is the seller (GSD). The pre-negotiation phase for the seller involves 6 cases (Figure 4.7).

When the order arrives for the seller agent, first, it determines the profitability level of the received order. For this purpose, revenue and costs of the order will be calculated. Revenue is formalized as:

\section{Revenue $=$ Initial price offered by the buyer $\times$ Order quantity}

The total cost of the order is the sum of raw materials, processing, packaging, inventory, and fixed costs. The details of cost estimation is presented in Appendix B. An order is 
considered profitable if its revenue is equal or larger than a specific threshold that is assumed here as $20 \%$ of its incurred costs.

Having the definition of profitability, cases in Figure 4.7 can be described as following:

Case 1 is the situation in which the seller receives a profitable order and also there is enough capacity for producing the order. If there is not enough capacity, the seller agent asks the customer whether it is willing to negotiate on order issues. At this time, GSD classifies the current customer as valuable and not-valuable customer. The criterion for this classification is the order history of the customer. In case the customer's previous order amount multiplied by the agreed price for each order is larger than the average value for all the other customers, the buyer is categorized as a valuable customer. Moreover, if the history of each customer that the enterprise keeps for itself goes beyond a specific value which is 0.5 here, the customer is considered as a valuable one.

For each class of customers, there are different profit levels that the seller agent aims to achieve during trading with the buyer. For valuable customers, the enterprise is willing to make concession in the price issue till $5 \%$ of the initial profit level (case 2). In this case, the seller gives up some part of its profit in order to maintain relationship with the valuable buyer. For not-valuable customers, this amount is increased to $10 \%$ (case 3 ).

There is another case in which the seller asks about the inclination of the buyer for negotiation: when the order is from a valuable customer whose order is not profitable but there is enough capacity to fulfill the order (case 4). If the customer is valuable but there is not enough production capacity, the order will be rejected by the GSD (case 5).

Till now there are three cases for which the seller shows its willingness to negotiate on order issues and waits for the response from the buyer agent. They are:

1. Profitable order from a valuable customer for which there is not enough capacity;

2. Profitable order from a not-valuable customer for which there is not enough capacity;

3. Not-profitable order from a valuable customer for which there is enough production capacity.

On the other side, when the customer is asked about his inclination for starting negotiation, it will check if its simultaneous order placement with another supplier is successful. If the order was not accepted, then the seller and the buyer start negotiation.

There remains another case in which price in the buyer's order does not satisfy the profit level and also the buyer agent does not belong to the valuable customers category. In that situation the order will be rejected (case 6).

Figure 4.7 summarizes different cases in the pre-negotiation phase.

Negotiation phase The second phase is negotiation. Those cases in the pre-negotiation phase set to enter to negotiation are dealt in this phase. In the negotiation phase, the agents take turn to make offers in order to reach an agreement on a specific value for each negotiation issues. These values should meet the constraints of the seller as well as those of the buyer. The procedure for preparing and exchanging offers in this research is mostly based on the work of Jonker and Treur (2001). First a brief description of what happens in the negotiation phase is presented then details are provided under "offer preparation". 
The first counter offer is made by the seller agent since the seller asked for starting negotiations in the previous phase. The seller agent sends the counter-offer to the buyer. The buyer agent assesses the offer from the seller using its utility function. If the counteroffer is acceptable in terms of utility and does not violate the buyer's constraints, then negotiation ends in agreement. If it is not acceptable, then the buyer agent decides whether it wants to continue negotiation with this seller or not. The buyer continues negotiation with this seller if:

1. its order was not accepted by an alternative supplier;

2. it does not reach its step limit.

If these conditions are satisfied, then the buyer makes an offer for the seller, otherwise, it quits negotiation. When an offer is sent to the seller, it will accept the offer if two conditions are met:

1. the value for issues fall within the acceptable range seller has set for each issue;

2. the difference between the utility of the received order and the utility the seller aims to achieve (target utility) is acceptable.

If the offer is acceptable, then negotiation ends in agreement. If it is not acceptable, the seller agent checks its constraints on step limit. If the step limit does not elapsed, it would ask the buyer whether it wants to negotiate on issues again or not. If it has intention to continue negotiation, the negotiation process explained in this section will start over.

The detailed description of how the offers are prepared is described below.

Offer preparation procedure In this procedure, to assess an offer from the counterparty, an evaluation method is required. Evaluation can be performed at two levels: the level of each issue and the level of the offer as a whole. The assessment is based on the utility function.

The idea in this procedure is that an offer in a certain point in time relates to the offer at the previous time points (Bosse and Jonker, 2005).

The procedure runs as follows:

- Each negotiation round (except the initial round) starts with the evaluation of issues in the previous offer. The issue values for the first offer come from the range the buyer has set for itself. The buyer starts negotiation by offering its shortest delivery time and the lowest price (an offer with utility value of 1 ).

- Then the evaluation values are aggregated into overall utility of the previous offer.

- Next, the amount of concession the party wants to make for the next offer is specified in terms of overall utility. This concession amount which is called concession step will be added to the utility value of the previous offer. This provides target utility for the next offer. 


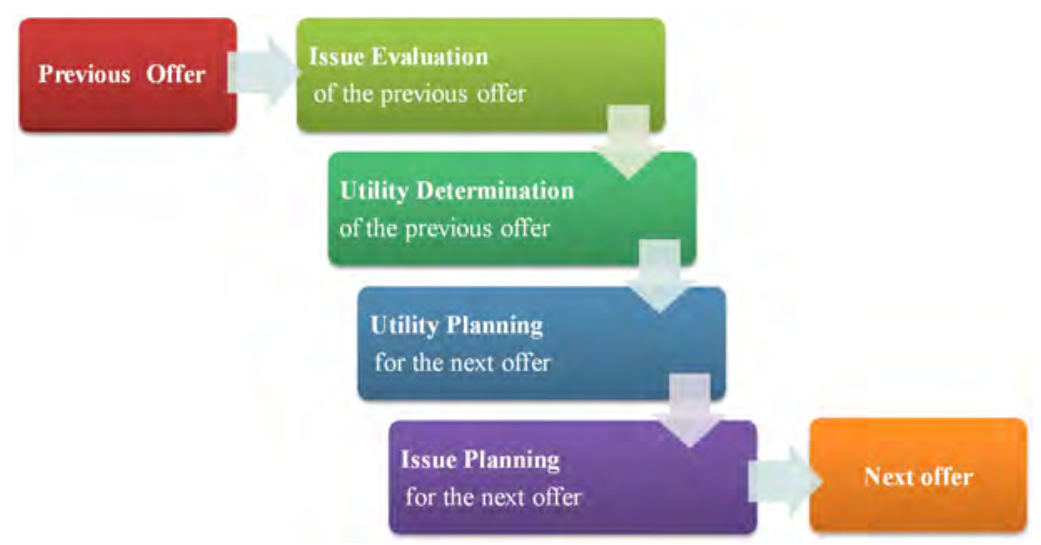

Figure 4.8: Offer preparation procedure

- To specify the values for issues in the next offer, given the target utility, first the value of discrete issues (e.g. delivery time) is specified, then the remaining utility is divided between continuous issues (e.g. price) in a way that issue values do not violate relevant constraints.

As mentioned in the last step, first the values for discrete issues are determined and then the remaining assigned to the continuous issues. If this would not be the case, it is quite possible that the target utility would not be reached. Specifying the value for the continuous issue can compensate the differences in the target utility that are created by assigning values for discrete issues. In our case, price is a continuous issue that is determined at the last step to compensate for possible differences. By following this approach, offers are prepared that exactly match the target utility.

Figure 4.8 sketches the steps mentioned above. The offer preparation procedure has 4 components: issue evaluation of the previous offer, utility determination of the previous offer, utility planning for the next offer, and issue planning for the next offer. When the agents are willing to negotiate, they follow the steps mentioned above to make offers and counter-offers. Each of these components is described in more detail.

\section{Issue evaluation}

Issues are assessed on the basis of evaluation functions that each party has for itself. For each value of the issue, the evaluation function assigns a number to shows its desirability. To make the research feasible, we have to make some design choices about evaluation functions that each party uses. The evaluation functions of each issue in the negotiations are part of the parties' profile and the ones used in the model are described in Chapter 5.

\section{Utility determination}

The utility (U) of an offer is a weighted sum of issue evaluation values (Ej) for different negotiation issues denoted by $\mathrm{j}$.

$$
U=\sum{ }_{j} w_{j} E_{j}
$$




\section{Utility planning}

Target utility (TU) for the next offer is determined by the following formula:

$$
T U=U_{s}+C S
$$

Where $\mathrm{U}_{s}$ is the utility of the last offer of the party, and CS is the concession step. Concession step is the amount in terms of utility that a party is willing to give up at each round of negotiation. It is determined by:

$$
C S=\beta\left(1-\mu / U_{s}\right)\left(U_{o}-U_{s}\right)
$$

In which $\mathrm{U}_{o}$ is the utility of the last offer of the other party (opponent). $U_{o}-U_{s}$ expresses the current utility gap between the last offers of parties. The factor $\left(1-\mu / U_{s}\right)$ implies that the concession step will decrease to 0 if $\mathrm{U}_{S}$ approximates the minimal utility $\mu$. This ensures that $U_{s} \geq \mu$. The minimal utility is taken as $\mu=1-\gamma$ where $\gamma$ is the concession factor, used to express how far concession can be made. The factor $\beta$ stands for negotiation speed, how fast concession can be made.

\section{Issue planning}

In the attribute planning component, target utility is the input and the outputs are target values for each issue in the next offer of the party.

To find a value for an issue, first the portion of utility (UP) for a discrete issue ( $\mathrm{j}$ ) is determined by the following formula:

$$
U P_{j}=\left(w_{j}\right)\left(T U-U_{s}\right)
$$

Where $\mathrm{w}_{j}$ is the weight of that issue in the party's profile. Then, given the portion of utility, issue value is determined with an evaluation that is as close as possible to the portion. When the values for discrete issues are determined, the same procedure is followed for continuous issues to compensate possible remaining utility.

Post-negotiation phase Based on the experience in the previous two phases, either ending up in a successful or failed negotiation, the parties form and update their history about each other. The history plays role in making decision for the next trades with the same counter-party. The trading experience could be completely positive (agreement) or completely negative (failed negotiation). This update is modeled by the following formula for the customers of the MPE.

$$
\text { History }_{t+1}= \begin{cases}\text { History }_{t}+d^{+} & \text {if the experience is positive } \\ \text { History }_{t}+d^{-} & \text {if the experience is negative }\end{cases}
$$

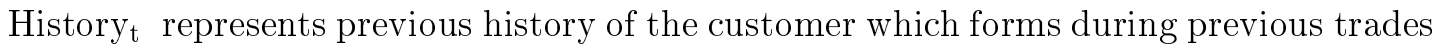
with the enterprise. In this formalization, there is a threshold for the history of customers 
which is constant for all the customers. The history is updated symmetrically with equal positive or negative values $\left(\mathrm{d}^{+}\right.$and $\left.\mathrm{d}^{-}\right)$.

Delivery performance of the enterprise, also, has a role in the history that customer keeps about the enterprise. It is possible that agreement is reached on the offer's issues but delivery of the order does not happen on the agreed time. This may happen because of late delivery of raw materials to the plants. The formalization for the delivery performance of the enterprise is similar to the history described above.

The history and history formation for the enterprise is also similar to that of the customer except that the initial history is not constant for all customers. The base model is run 100 times and the history threshold of the enterprise for customers is set based on the average of runs.

To get an overall review of the activities in each three phases, see Figure 4.9. 

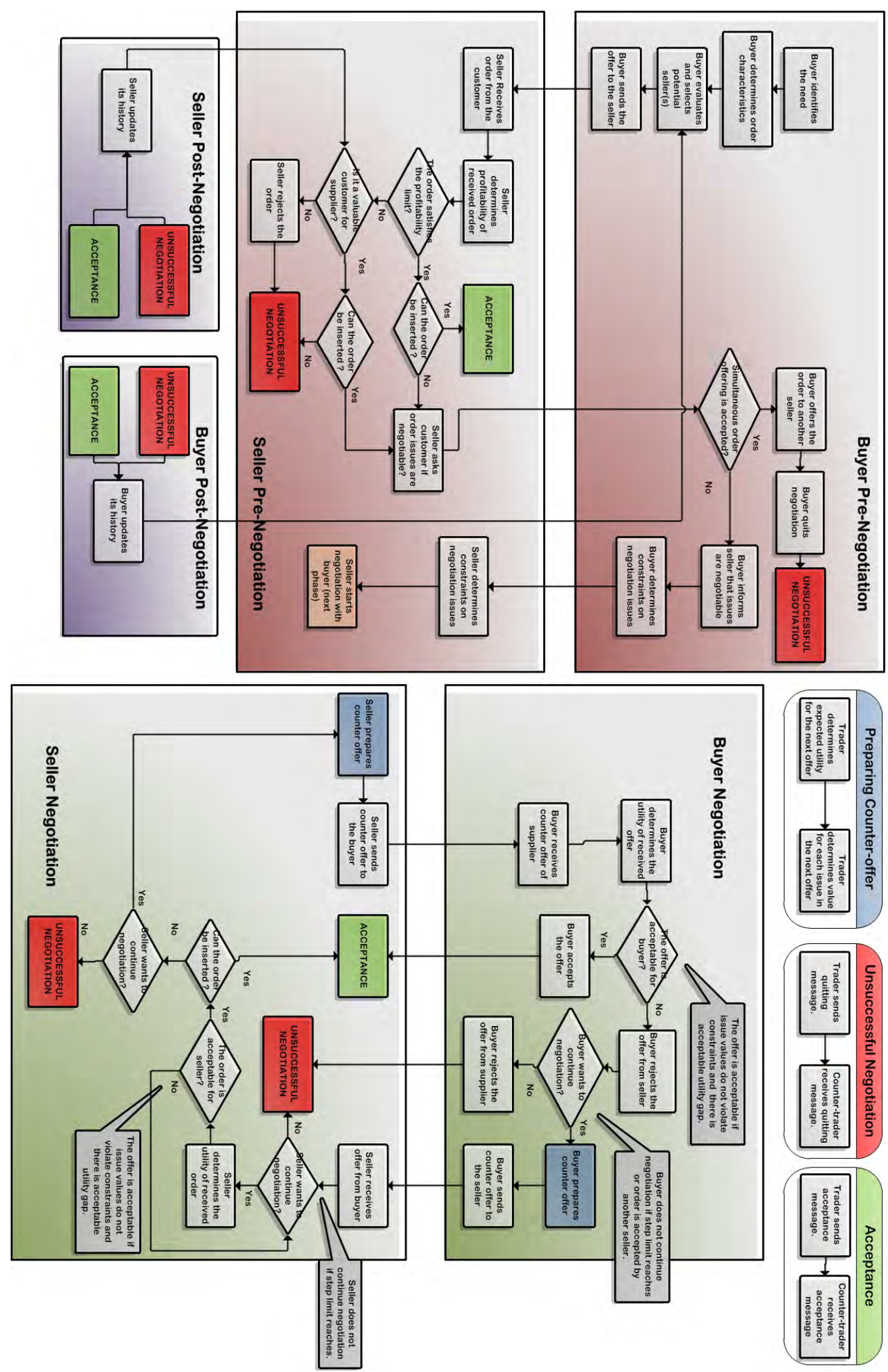

Figure 4.9: The agents' interaction diagram (three negotiation phases, decisions and activities) 


\subsection{Detailed design}

In this step, the concepts in the ontology are elaborated further for this case. Then the agents and their interaction (explained in the previous section) are put in computer codes.

Modeling and simulation toolkit used in this research to develop negotiation model is Recursive Porous Agent Simulation Toolkit (Repast). Repast is a widely used open-source toolkit which has multiple implementations in several languages (North et al., 2006). Java programming language used for model development.

The following paragraphs provide more information about each concept in the ontology. The negotiation concepts are represented as a class in the ontology. Each class visualized using Protégé ${ }^{1}$.

- Negotiation Process. The Negotiation process is the encounter in which Negotiation Parties persuade the goal of reaching a common agreement on Negotiation Issues. The Negotiation Process consists of Negotiation Phases. The Negotiation Protocol governs the Negotiation Process. Figure 4.10 shows the relations between Negotiation Process and other concepts. The properties (slots) of the Negotiation Process class are also shown in Figure 4.10.

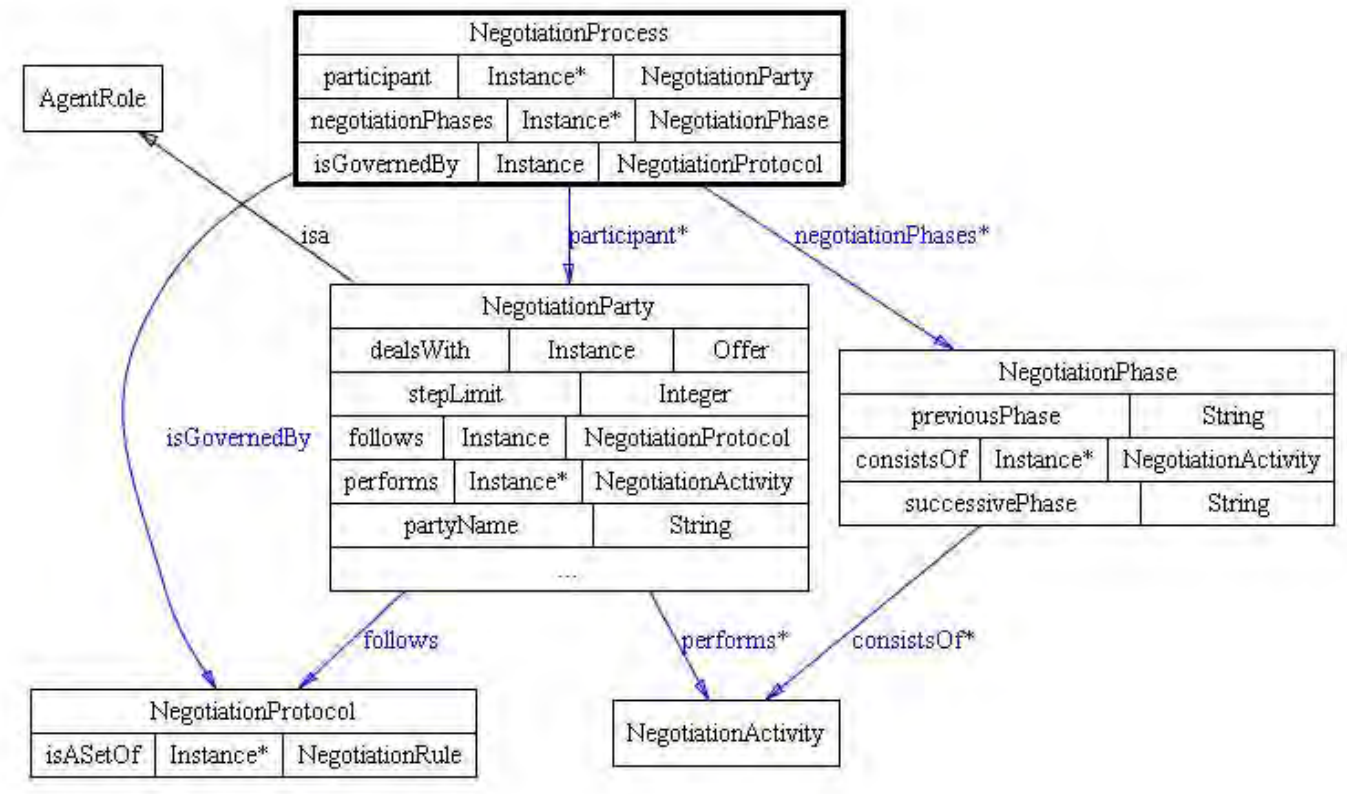

Figure 4.10: Negotiation Process class, its slots and relations in the ontology

- Negotiation Phases. Each Negotiation Phase is composed of several Negotiation Activities performed by the Negotiation Parties. The Negotiation Phases follow a se-

\footnotetext{
${ }^{1}$ Protégé is an open source ontology editor and knowledge-base framework developed in Stanford University School of Medicine. Protégé implements a rich set of knowledge-modeling structures and actions that support the creation, visualization, and manipulation of ontologies in various representation formats. For more information on Protégé visit http://protege.stanford.edu.
} 
quence of pre-negotiation, negotiation and post-negotiation. There is also a feedback from the post-negotiation phase to the pre-negotiation phase for the next round of negotiation. Figure 4.11 shows Negotiation Phases in the ontology.

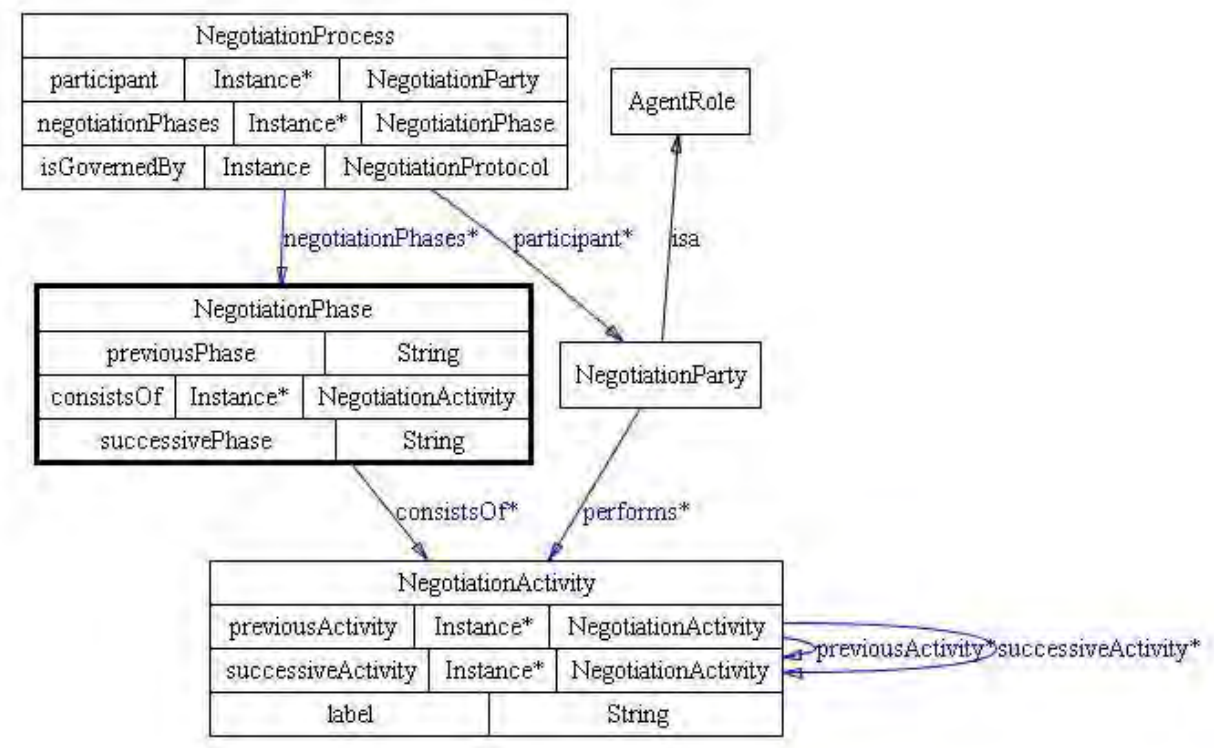

Figure 4.11: Negotiation Phase class, its slots and relations in the ontology

- Negotiation Activity. A Negotiation Activity is an action that is undertaken by Negotiation Parties in a Negotiation Process. The superclass of Negotiation Activity has eight subclasses of "continue negotiation", "quit negotiation", "accept offer", "reject offer", "prepare offer", "evaluate offer", "receive from counter-party", and "send to counter-party". Each Negotiation Activity could precede several Negotiation Activities and at the same time is followed by other Negotiation Activities. The sequence of activities in each phase is presented in the next section of this chapter.

- Negotiation Party. The Negotiation Parties are the participants of the Negotiation Process who performs Negotiation Activities. They deal with Offers and follow the Negotiation Protocol during the Negotiation Process. 


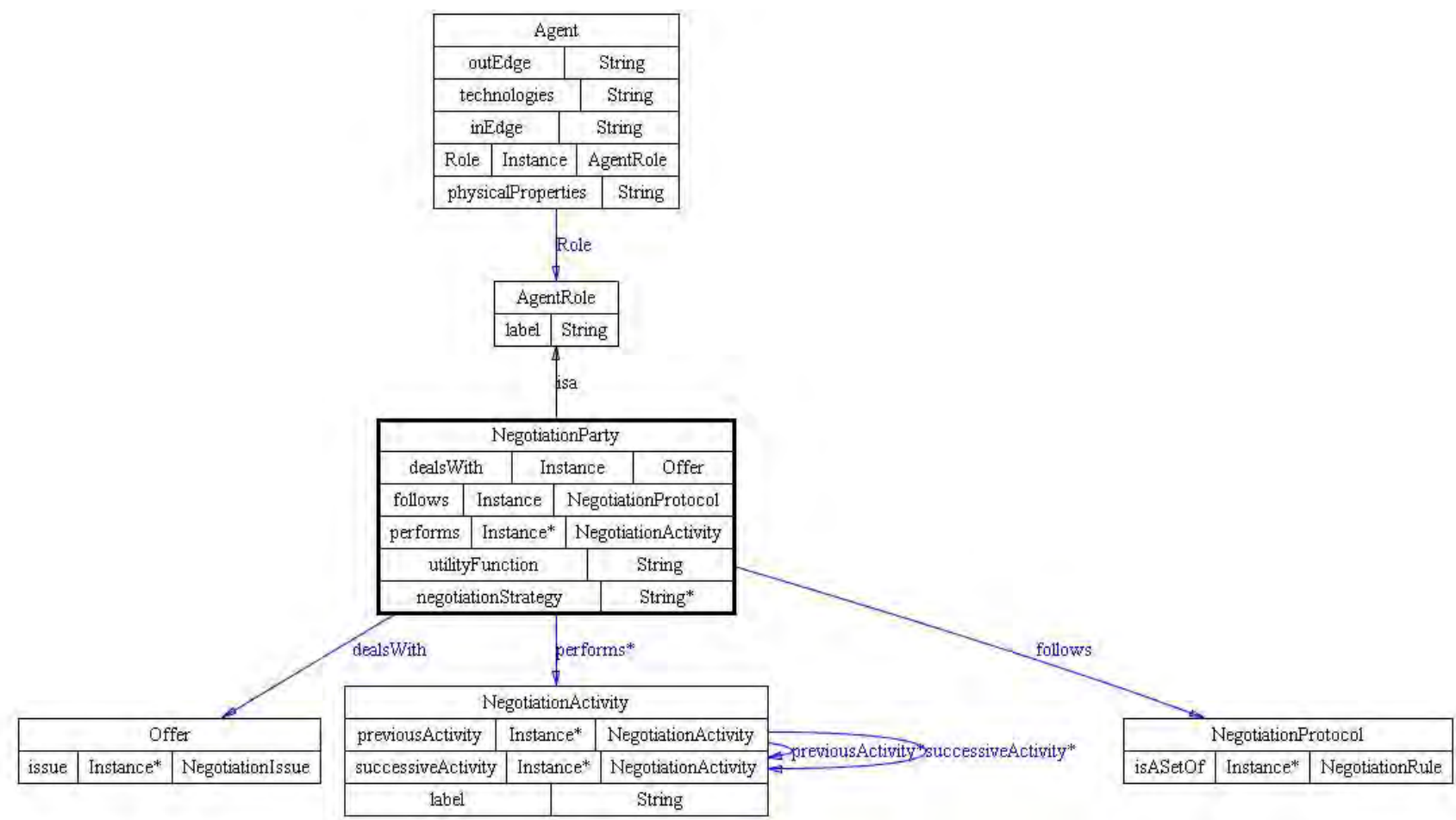

Figure 4.12: Negotiation Party class, its slots and relations in the ontology

The behavior towards the counter-party is characterized by the negotiation strategy adapted by a Negotiation Party.

As mentioned earlier, the Negotiation Party is a role that an agent can take. These relations are shown in Figure 4.12 .

- Offer. Each offer consists of a number of Negotiation Issues and an assigned value for each of them. Offers are exchanged during the Negotiation Process by the Negotiation Parties. Most of the Negotiation Activities are also dealt with Offers e.g. evaluating offer, accepting offer, preparing offer, etc.

- Negotiation Issues. A Negotiation Issue is an issue under negotiation between the Negotiation Parties during the Negotiation Process.

Some examples of Negotiation Issues could be price, delivery time, and quality. Figure 4.13 shows Negotiation Issue in the ontology.

In this work, price and delivery time have been taken as the issues for negotiation.

- Negotiation Protocol. A Negotiation Protocol is a set of Negotiation Rules. It defines the rules of encounter between Negotiation Parties during the Negotiation Process. 


\begin{tabular}{|l|l|l|}
\hline \multicolumn{3}{|c|}{ Offer } \\
\hline issue & Instance* & NegotiationIssue \\
\hline & \multicolumn{2}{|c|}{ issue* } \\
\hline \\
\begin{tabular}{|c|c|}
\hline \multicolumn{3}{|c|}{ NegotiationIssue } \\
\hline minAcceptedValue & Float \\
\hline maxAcceptedValue & Float \\
\hline issueValue & Any \\
\hline label & \multicolumn{2}{|c|}{ String } \\
\hline
\end{tabular}
\end{tabular}

Figure 4.13: Negotiation Issue class, its slots and relations

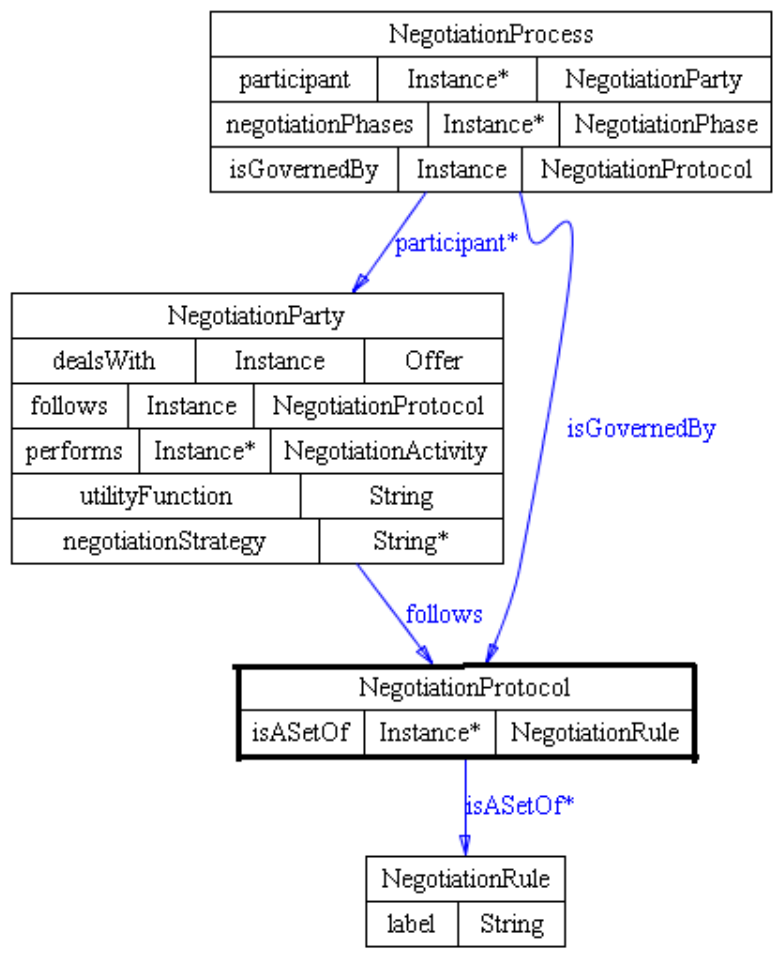

Figure 4.14: Negotiation Protocol class, its slots and relations in the ontology 


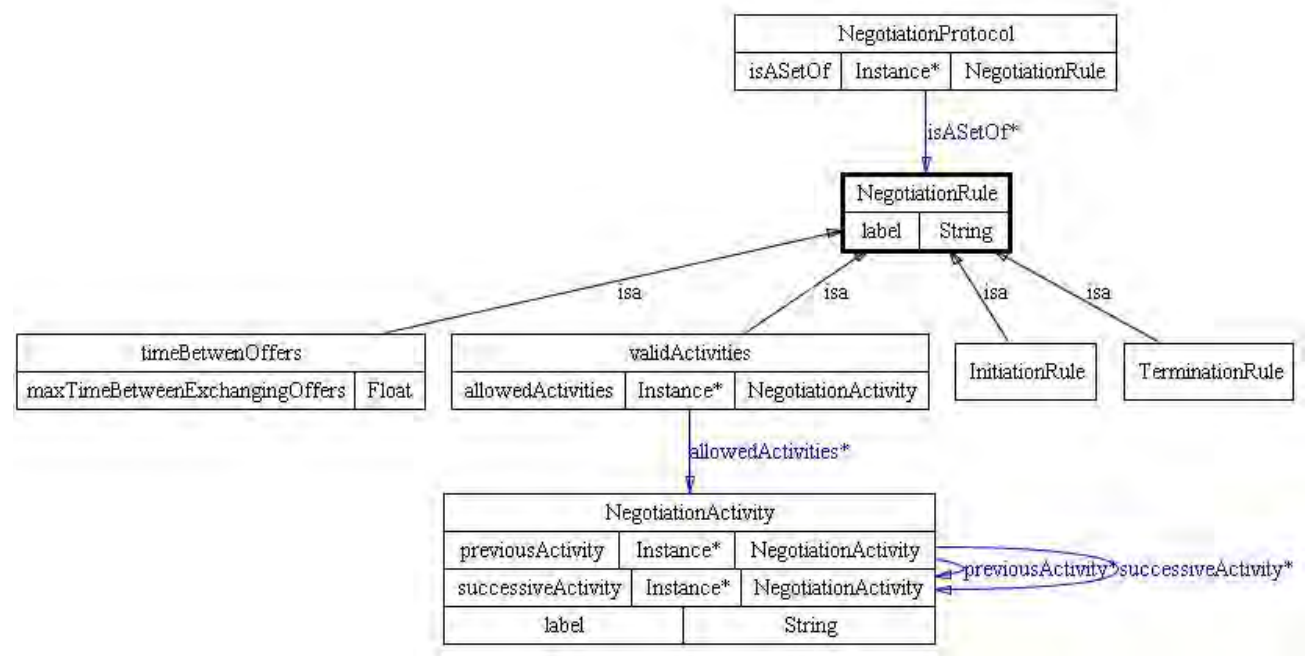

Figure 4.15: Negotiation Rule class, its subclasses, slots and relations

- Negotiation Rule. There are several rules that are followed by the Negotiation Parties. These rules regulate interactions between the Negotiation Parties. The subclasses of the Negotiation Rule class are "initiation rule", "termination rule", "maximum time between exchanging offers", and "valid activities". See Figure 4.15. "Initiation rule" implies that there should be two present parties to start negotiation. The negotiation is terminated when the parties end in agreement, disagreement or one of them quits negotiation ("termination rule"). Response time is the time each party has to respond to the offer of its counter-party. The maximum time is determined by "maximum time between exchanging offers". In the current work the response time is set to zero.

To codify the behavior and decision rules of the agents, several fields and methods are defined for the classes. It is not possible to explain all the fields and methods because of the large volume and complexity of the methods. Please refer to the Appendix $\mathrm{C}$ for the CD of the Repast model.

\subsection{Verification and validation}

The next step after detailed design and software implementation is verification and validation. In this stage multiple tests are performed on the model. The purpose of model testing is to build confidence in the model.

\subsubsection{Verification}

Verification of a model entails consistency check of the model: whether the concepts and relations are coded correctly. The attempt in verification is to answer "does the model do what it is intended to do". 
Verification is an iterative process. When a model is under development, the modeler most likely tests the model and iterates between developing and testing.

There could be different types of test in this stage. It is important to check if the model is

1. well-written and readable,

2. behaves properly in extreme conditions and

3. does what it is supposed to do.

The development of a readable model will make it easier for the modeler to check her work and forces a clear model structure. A well-written model is extremely helpful in finding the source of probable errors. Also, a readable model can be used easily either by others who may join the model development team later or by the client who is going to use the model. During the development of the model, it should always bear in mind to make clear, understandable documentation for each part of the code. Choosing proper names for the fields and methods is another way to make the model easily understandable.

Moreover, there should be a test to assure that the code performs well with a number of input parameters, e.g. zero, or very large values. The resulting values should be checked whether they are plausible compared to the knowledge or expectations of what would happen in the real situation.

Finally, to check if the model does what is intended to do, debugging should be performed. This could be done by using a simple System.out.println() method or using more advanced debuggers in Java.

During developing the negotiation model, all these tests were performed. The attempt was to choose clear names, make simple documentation for each method used and provide explanation for the complicated methods. Documentation also involves the purpose and assumptions used in the method.

For methods, also, extreme values were used as inputs and the output of methods was checked without model run. Some hypotheses were made, and the formulas and methods were checked whether they give the expected results. Table 4.3 shows some examples of extreme value test. For verification, formulas and methods are individually checked. The overall performance of the system is not considered.

Additionally, each line of a method and other relevant methods which were used in its body were checked by debugging mode in eclipse. Debugging allowed us to step through code, freeze output, and inspect variables. Figure 4.16 shows an example of debugging in eclipse. For the 79th order, the method of "determine profit contribution of order" is checked line by line. The return value of the method is the profit of the order which is calculated by reducing cost from the revenue of the order. 
Table 4.3: Some examples of extreme value test

\begin{tabular}{ll}
\hline Hypothesis & Result \\
\hline \hline $\begin{array}{l}\text { By increasing the lower bound of } \\
\text { profit to } 100 \%, \text { no order should be } \\
\text { accepted. }\end{array}$ & $\begin{array}{l}\text { The hypothesis is accepted; the profitability check } \\
\text { method does not allow a single order to be accepted. }\end{array}$ \\
\hline $\begin{array}{l}\text { By reducing the value of concession } \\
\text { factor to 0, there will be no }\end{array}$ & $\begin{array}{l}\text { The hypothesis is accepted; the agents remain on } \\
\text { their initial offer till the step limit reaches. }\end{array}$ \\
$\begin{array}{ll}\text { successful negotiation. } \\
\text { By increasing the step limit to 100, } \\
\text { should increase. }\end{array}$ & $\begin{array}{l}\text { The hypothesis is accepted; the effect of time is } \\
\text { reduced. Thus, the number of successful negotiations } \\
\text { increases. This is checked for several single session } \\
\text { negotiations. }\end{array}$ \\
\hline $\begin{array}{l}\text { If the weight factor of one of the } \\
\text { issues is set to 0, then concession } \\
\text { should be made only on the other } \\
\text { issues. }\end{array}$ & $\begin{array}{l}\text { The hypothesis is accepted; the price weight factor is } \\
\text { set to } 0 \text { for the buyer, and in the subsequent offers, } \\
\text { the buyer insisted on the initial price but made } \\
\text { concession on the delivery date. }\end{array}$ \\
\hline
\end{tabular}

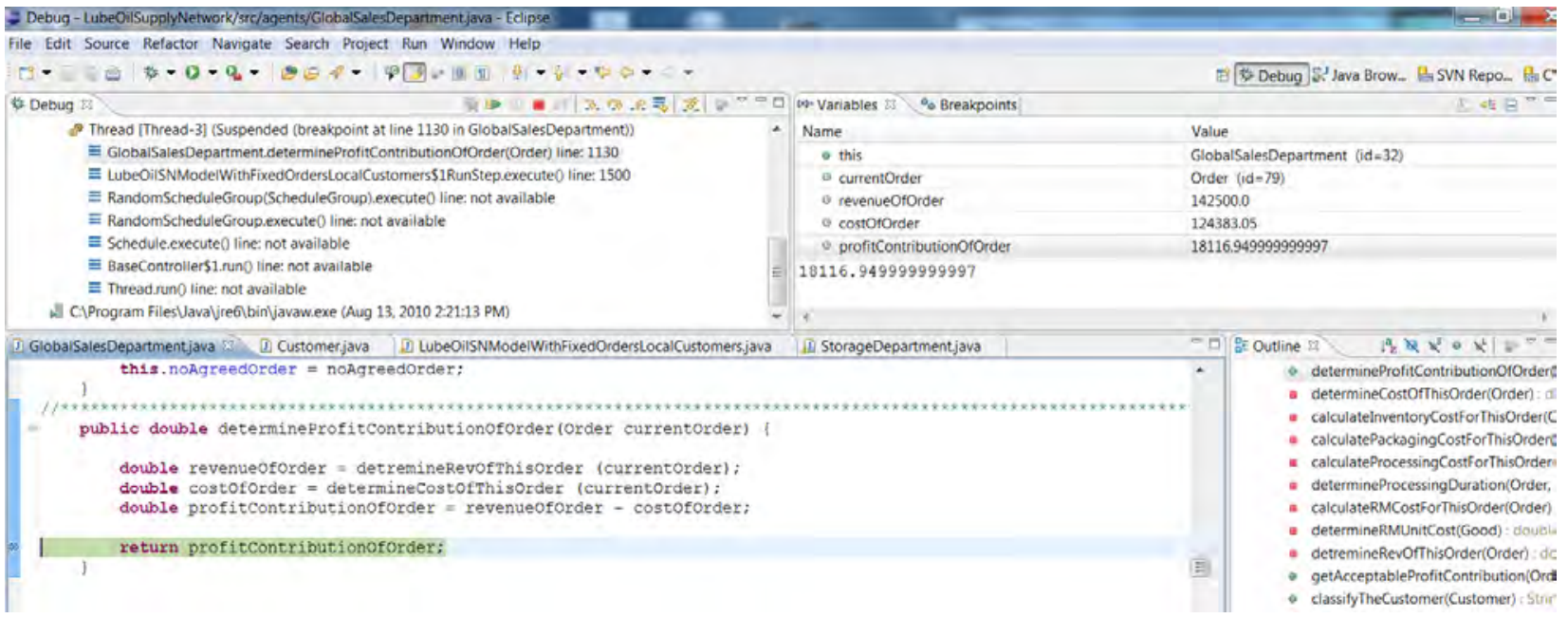

Figure 4.16: A debugging example in eclipse

\subsubsection{Validation}

After the model is checked in terms of consistency and we ensure that no errors have been made in representing the model in computer codes, a series of tests should be performed to validate the model. By validation, we mean a number of checks to ensure that the model meets the objective of the modeling study (the usability of the model).

There are different validation methods for different types of models. Validation of agentbased models is still in development (Moss, 2008). There is no single standard method for 
model validation. However, there are various types of validation tests that can be used in agent-based models as well.

It should be noted, first, that the current model is developed for the purpose of exploration of possibilities and it is not a prediction model. Therefore, comparison with real data is impossible as there is no real data.

Second, a major concern in validation is to ensure that the model is "fit for its purpose". According to Balci (1994), in our modeling effort, we must show the relevance of the model for the study objective that it was developed for. Hence, the main concern would be to become sure that the model is applicable for its domain and can help better understanding of the problem under study. This application relevance can be shown by different experiments performed with the model and getting insight about, e.g. the behavior of the system. A series of experiments in Chapter 5 shows that the developed model is fit for its purpose. Different OA settings can be designed and implemented in the model in order to evaluate the performance of the enterprise and get insight about different OA strategies.

Thirdly, to evaluate the validity of the negotiation model, a distinction is made between the results validation and process validation. The process in the negotiation phase is mainly based on the work of Jonker and Treur (2001) who asserted that the process is validated in several domains with human and computer agents. This process is also quite similar to the bidding behavior in the real life (Jonker et al., 2007). Therefore, we focus on the results validation of the model as a whole. To this end, extreme condition test and sensitivity analysis are performed.

\section{Extreme condition test}

For validation, the hypotheses in the verification stage are now checked by model runs so as to evaluate the performance of the whole system (instead of a single method) which should be corresponded with plausible expectations. An example of extreme value test is increasing the threshold for profitability check from the current value of 0.2 to 1 . This implies that only orders which their profit contribution is equal to their incurred cost will be accepted. The expectation here is that no order is accepted and the order history of customers decreases to its minimum level. These expectations were confirmed by model runs. Table 4.4 summarizes the output of model for the normal condition and the extreme case.

Table 4.4: An example of extreme value test

\begin{tabular}{|c|c|c|}
\hline & Profit Threshold $=20 \%$ & Profit Threshold $=100 \%$ \\
\hline Annual Profit & 11435869 & -2175540 \\
\hline Order History & 0.54 & 0.5 \\
\hline Delivery History & 0.91 & 0.8 \\
\hline
\end{tabular}

The negative profit in the extreme case shows the inventory holding cost of three plants. 
Table 4.6: Some examples of extreme value test (with model run)

\begin{tabular}{ll}
\hline Hypothesis & Result \\
\hline \hline $\begin{array}{l}\text { By reducing the value of concession factor to 0, there } \\
\text { will be no successful negotiation; profit and history } \\
\text { should decrease accordingly. }\end{array}$ & $\begin{array}{l}\text { The model is run } 100 \text { times, and all the orders set for } \\
\text { negotiation are rejected. The profit and order history } \\
\text { are also decreased. }\end{array}$ \\
\hline $\begin{array}{l}\text { By increasing the step limit to 100, number of } \\
\text { successful negotiations should increase; profit and }\end{array}$ & $\begin{array}{l}\text { The hypothesis is accepted; the effect of time is } \\
\text { reduced. Thus, the number of successful negotiations } \\
\text { history should increase subsequently (as the number } \\
\text { of rejected orders are reduced). }\end{array}$ \\
$\begin{array}{l}\text { negotiation increased by 20\% on average. The annual } \\
\text { profit and order history are also increased by about } \\
12 \% \text { on average. }\end{array}$ \\
\hline $\begin{array}{l}\text { If the reorder point is set to 0, the number of late } \\
\text { deliveries should increase (delivery history decreases) }\end{array}$ & $\begin{array}{l}\text { The hypothesis is accepted; the delivery history of } \\
\text { the customer reaches to its minimum value and the } \\
\text { and profit decreases because of tardiness penalty. }\end{array}$ \\
\hline
\end{tabular}

Since there is no order for production, the inventory level during the simulation period (one year) remains constant at its beginning level. Figure 4.17 shows the inventory level for this extreme case. This is one example of extreme value test. The test is also performed for three other parameters in the model (Table 4.6).

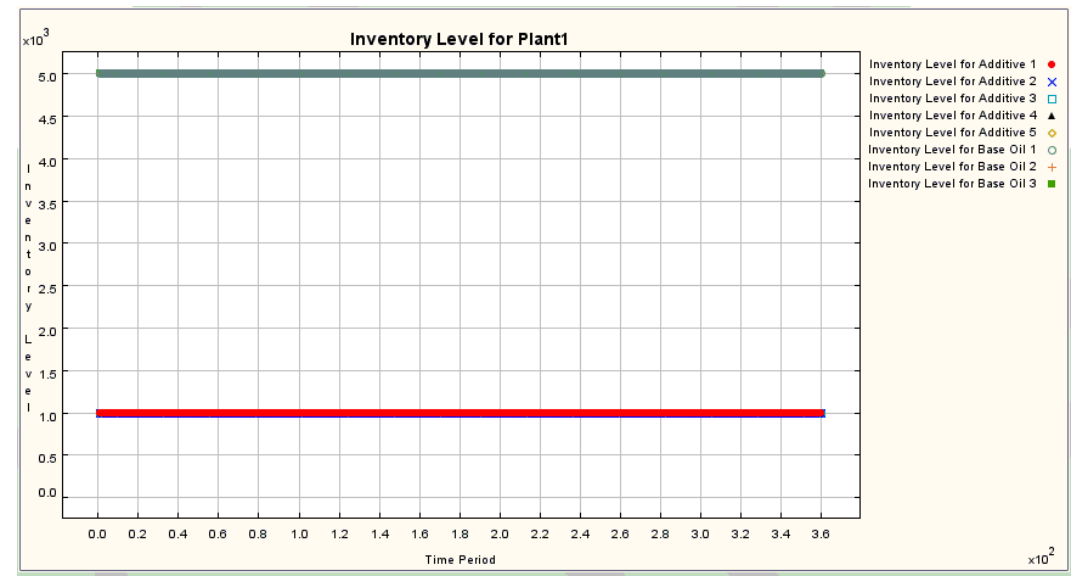

Figure 4.17: Inventory level for the extreme case

\section{Sensitivity analysis}

Sensitivity analysis is used to determine to which elements the model is sensitive; i.e. small changes in the value of which elements has major influence on the outcome of the model. Sensitivity analysis can be performed by increasing or decreasing model parameters a little bit (e.g. 10\%) and observing the effect of that change on the output of the model.

Table 4.7 shows the result of sensitivity analysis for 4 parameters: profitability check, 
history threshold for order placement, step limit for both customers and the enterprise, and negotiation speed for the enterprise. It can be observed that model outputs are sensitive to plausible changes in the parameters. These results can be used in designing of experiments with the model.

Table 4.7: Results of sensitivity analysis

\begin{tabular}{llll}
\cline { 2 - 4 } & Annual Profit & Order History & $\begin{array}{c}\text { Delivery } \\
\text { History }\end{array}$ \\
\hline \hline Profitability check $=0.1$ & 16330363 & 0.5101 & 0.9092 \\
\hline Profitability check $=0.2$ & 14623276 & 0.5738 & 0.9372 \\
\hline Profitability check $=0.3$ & 10028288 & 0.5407 & 0.8834 \\
\hline \hline History threshold $=0.48$ & 15277027 & 0.5774 & 0.9452 \\
\hline History threshold $=0.5$ & 14623276 & 0.5738 & 0.9372 \\
\hline History threshold $=0.52$ & 12336404 & 0.5732 & 0.926 \\
\hline \hline Step limit $=5$ & 12084371 & 0.5674 & 0.9256 \\
\hline Step limit $=7$ & 14623276 & 0.5738 & 0.9372 \\
\hline Step limit $=10$ & 16202698 & 0.5952 & 0.9548 \\
\hline \hline Negotiation speed $=0.5$ & 13045895 & 0.5856 & 0.9442 \\
\hline Negotiation speed $=1$ & 14623276 & 0.5738 & 0.9372 \\
\hline Negotiation speed $=1.5$ & 14198272 & 0.5786 & 0.9424 \\
\hline
\end{tabular}

Sensitivity analysis can be performed for other parameters to increase confidence in the model.

An alternative way for validation is expert validation in which the behavior of agents (micro-level), the system's patterns of behavior (macro-level) and also the application of model for its designed purposes are discussed with domain experts. For the developed model, the domain expert validation was performed especially for the negotiation process.

It should be noted that a good way to validate the model is to compare the results of this model with a similar model. This comparison could be on the basis of some graphs that depicts the outcome of the models over time or the final conclusion and recommendations of the models. We could not find such a model that considers some similar variables like the performance of the enterprise. Therefore, this remains as an idea for better evaluating the validity of the developed model.

\subsection{Chapter conclusion}

In this chapter, an agent-based model for negotiation process in MPE was developed. For this purpose, first, the problem was defined. Then, the system for which the model should 
be developed was defined. This was followed by design of a negotiation ontology and agent architecture. The behavior of the actors in the system was captured using some attributes, states, and decisions for the computer agents. Next, the behavior of agents in the system was delineated in the agent interaction section. To this end, the concepts introduced in Chapter 2 were incorporated in the agent behaviors. Also, a validated procedure for offer preparation was considered for the negotiation phase. At this stage, the design was implemented in Repast simulation platform using Java programming language. Verification was also initiated along with software implementation to ensure that the developed design was implemented correctly. After consistency check, the usability of the model was evaluated.

The model at hand enables us to perform experiments, learn from these experiments and subsequently help the problem owner to design settings and strategies that will result in improved performance of the enterprise. This is the subject for the next part of this research. 


\section{Part III}

\section{Results and Reflections}




\section{Chapter 5}

\section{Experimental Set-up and Simulation Results}

This research extends the previously constructed model for the make-to-order multi-plant enterprise (Behdani et al, 2010) by incorporating negotiation in the order acceptance procedure of the enterprise. To study the effect of negotiation on the performance of the enterprise, some experiments are designed and implemented in the simulation model.

In this chapter, first some model assumptions are described in 5.1. Next, to evaluate the performance of the enterprise in different experiments, some indicators are introduced in 5.2. Three sets of experiment are designed and implemented in 5.3, 5.4 and 5.5.

\section{$5.1 \quad$ Model assumptions}

As mentioned in Chapter 4, to evaluate the offers and to prepare offers, evaluation functions for the issues and utility functions for the offer as a whole are used. Table 5.1 shows the evaluation functions of the enterprise (the seller agent) and customers (the buyer agents). The utility function for both agents has a linear form without issue dependencies.

There are also some assumptions regarding the seller agent (GSD) and the enterprise:

- The environment for the enterprise consists of customers who has stochastic demand pattern and suppliers who may deliver raw materials with delay.

- The model considers one-off negotiations; i.e. at a certain point in time, only one order is considered for decision-making.

- Requested products in the customer orders are standard products, therefore, it is possible for the enterprise to estimate the processing time and relevant costs.

- The enterprise and its customers are negotiators of equal power.

- The production capacity is fixed during the time that the OA decision is made.

It is also assumed that the demand pattern of customers follows a Poisson distribution with the average arrival rate of 1.75 order per day. The Poisson distribution expresses the 
Table 5.1: Evaluation functions of the agents

Enterprise

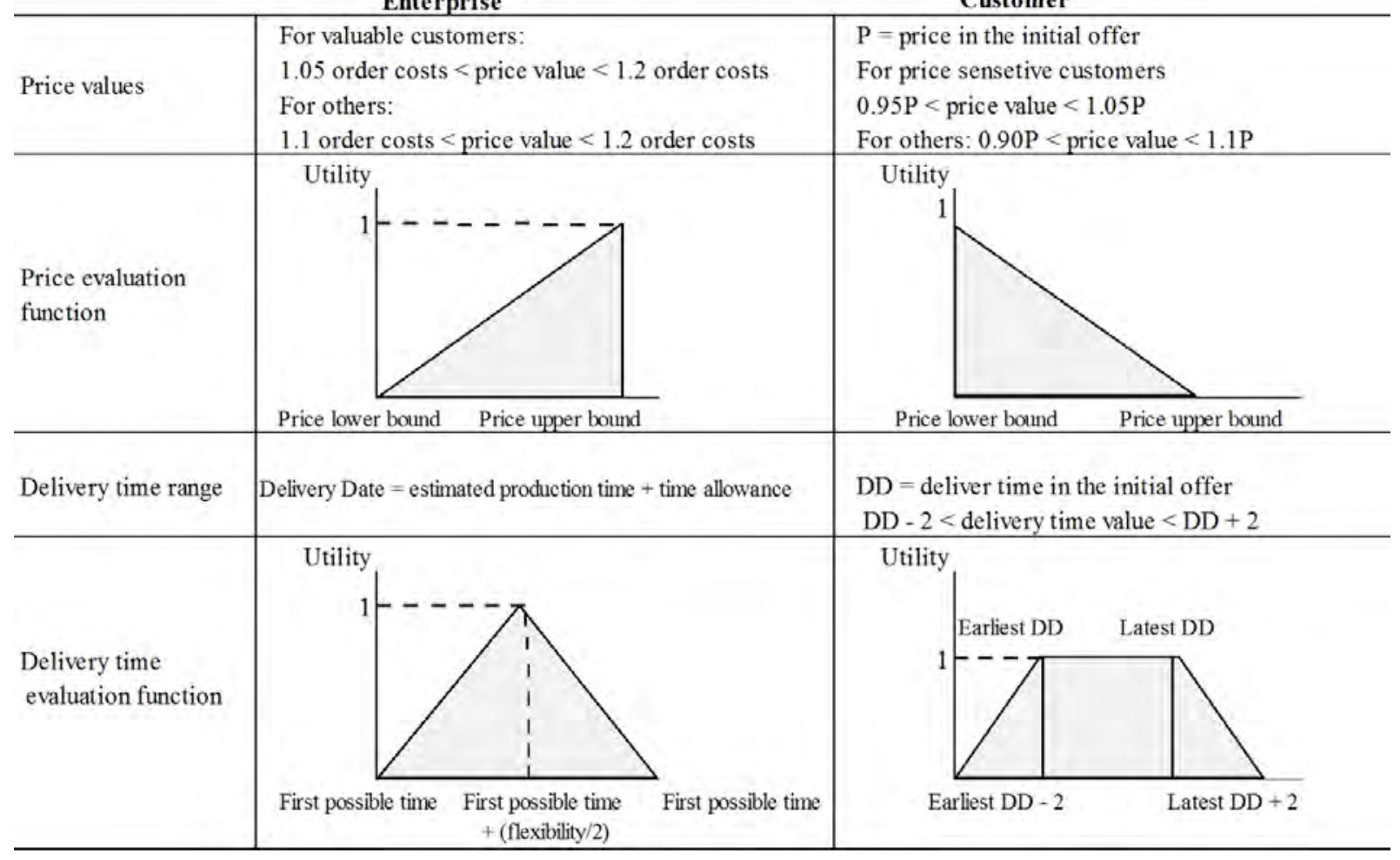


probability of a number of events (order arrivals) occurring in a fixed period of time (a day) if these events occur independently. Therefore, the demand pattern can be described by Poisson distribution. This is also in line with a number of studies in the literature (Carr and Duenys, 2000; Missbauer, 2003). 1.75 is determined by exploratory experiments in a way that the utilization rate of the production plants is about $90 \%$ on average. As in the high-loaded demand environment, making OA decisions becomes more important and has larger effect on the performance of the enterprise.

\subsection{Performance indicators}

To compare the performance of the enterprise under different order acceptance experiments, two categories are considered. One is to evaluate the performance by measuring financial factors (e.g. operational costs, daily profit, and overall profit in a year) and the other is to consider non-financial factors (customer satisfaction, customer order frequency, customer intention to repurchase).

With regard to the model outputs, overall profit in a year, order acceptance history and order delivery history of the enterprise that the customer keeps for itself are chosen as the performance indicators.

The overall profit is as a measure of financial aspects in the short-term. The other two are utilized to measure the customer evaluation of the enterprise and therefore the relation between customers and the enterprise.

It is also possible to define other performance measures if future analysis asks for it.

\subsection{Experimental set-up 1:important OA viewpoints}

Several experiments can be designed and implemented in the simulation model to evaluate different settings for order acceptance of the enterprise. The basic idea for designing experiments in this section is to incorporate important viewpoints in making OA decisions explained in Chapter 2 (see Figure 5.1).

Sales/production integration In this perspective, an order is accepted if the production plan of one of the plants can accommodate the order and it can be delivered before the requested time.

Order selectivity based on profit In this viewpoint, the fulfillment cost of an order is calculated and if the price offered in the order leads to a profit that exceeds a specific lower bound, then order will be accepted. The basic idea here is to allocate valuable production capacity to the profitable orders.

Customer segmentation The idea in this point of view is that customers differ in their importance which may go beyond immediate costs and revenues they bring for the enterprise. Different priority rules can be applied to segment customers in various classes. In this research, a customer is valuable if:

1. The frequency multiplied by the value of previous purchases of the customer exceeds the average for all the customers; 


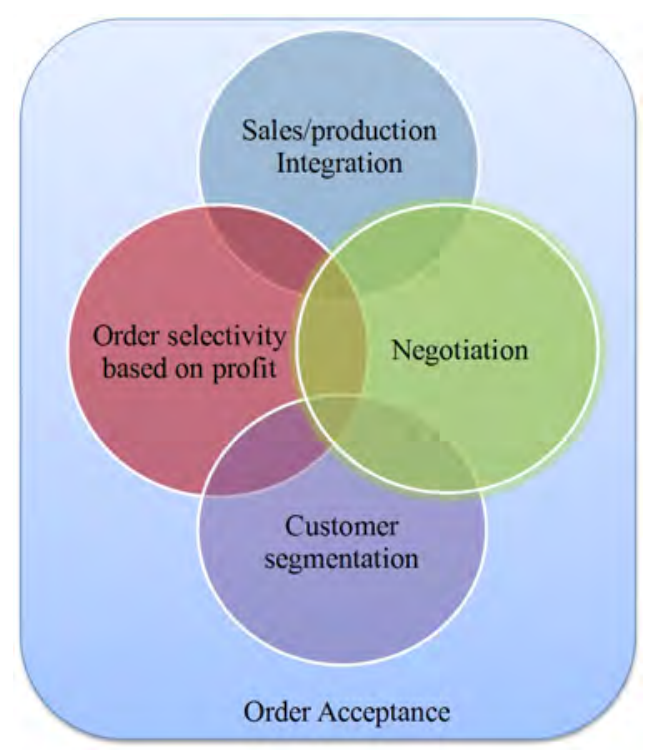

Figure 5.1: Important viewpoints on making OA decisions

2. The order placement history (a value between 0 and 1 ) of the customer (whether finally there was an agreement or not) is larger than the average value.

Negotiation on order terms Negotiation enables the enterprise (seller) to keep its customer (buyer) satisfied, have more flexibility in the order delivery due date and improve its profit as well. In other words, without negotiation, the due date specified by the customer must be met and the unit price that he suggested is the basis for profit calculation. The buyer and the seller reach agreement by negotiation on the order terms. In this research the negotiation parties follow the Rubinstein bargaining model (Osborne and Rubinstein, 1994) i.e. exchange offer respectively to find satisfactory values for the issues under negotiation. In each negotiation round, one of the parties makes concession in preparing the counter-offer if he is willing to continue negotiation.

\subsubsection{Base case}

In the base case (Behdani et al., 2010), when orders are received from the customers, the global sales department sends the order specifications to the plants and asks them to announce their first possible time for delivery of the order. If the first possible time for the order fulfillment is earlier than the requested delivery time by the customer, then order will be accepted and inserted into the production plan of the plant with earliest completion date. Otherwise, the order will be rejected.

In this setting, only the integration of sales and production functions is taken into account for making OA decisions. 


\subsubsection{Order selectivity}

In the second case, the profit contribution of orders received from customers is checked first. Only if the order meets the profitability requirement the feasibility of the plants' production schedules will be checked. This implies that profitable orders for which production before the requested delivery time is feasible are accepted and all others are rejected.

In this case, the focus is on the short-term goal of making profit by employing the policy of order selectivity based on profit.

It should be mentioned that the threshold for profitability level is set to $20 \%$ of the incurred cost of the order. $20 \%$ is the first value for which the annual profit exceeds the profit in the base case.

\subsubsection{Negotiation}

In the third setting, both short- and long-term goals are considered. To accept an offer, three factors of order selectivity based on profit, integration of sales and production, and customer segmentation are considered as the initiation conditions of negotiation between the buyer and the seller.

If an order does not meet the profitability requirement (short-term goal), it will not be rejected immediately. But the value of the customer plays role in making the order acceptance decision. To maintain a relationship with a valuable customer (long-term goal), a negotiation session will be started to reach an agreement on issue values that are satisfactory for both the customer and the enterprise. The enterprise expands the acceptable range of issue values and decreases the profitability lower bound for a valuable customer in order to maintain a good relationship.

The negotiation settings in this experiment are the ones described in Chapter 4. The whole interaction of the GSD and the customer is depicted in Figure 4.9.

\subsubsection{Simulation results and discussion}

In this research, the simulation model time step is set to "day", that is, the unit time to produce products and the deadline of orders are counted by day. Each setting is run for 10800 days. 10800 days is determined by exploratory experiments in a way that the model outputs (e.g. profit behavior) show a stable pattern with similar values (less than $3 \%$ difference in the values).

Figures 5.2, 5.3, and 5.4 respectively show annual profit, order acceptance history and delivery history in three settings described in this section. As demonstrated, the negotiation setting outperforms the other two in two performance measures (profit and delivery history).

In the base case, the total number of accepted orders by the enterprise is considerably larger than the other two cases (Table 5.2), as the only criterion for order acceptance is availability of production capacity. In this case, a probable late arrival of raw materials can considerably affect the delivery performance of the enterprise (Figure 5.4). Large number of accepted orders makes the production plan tight and inflexible. Also, the lateness penalty that the enterprise should pay for delayed deliveries is high. 


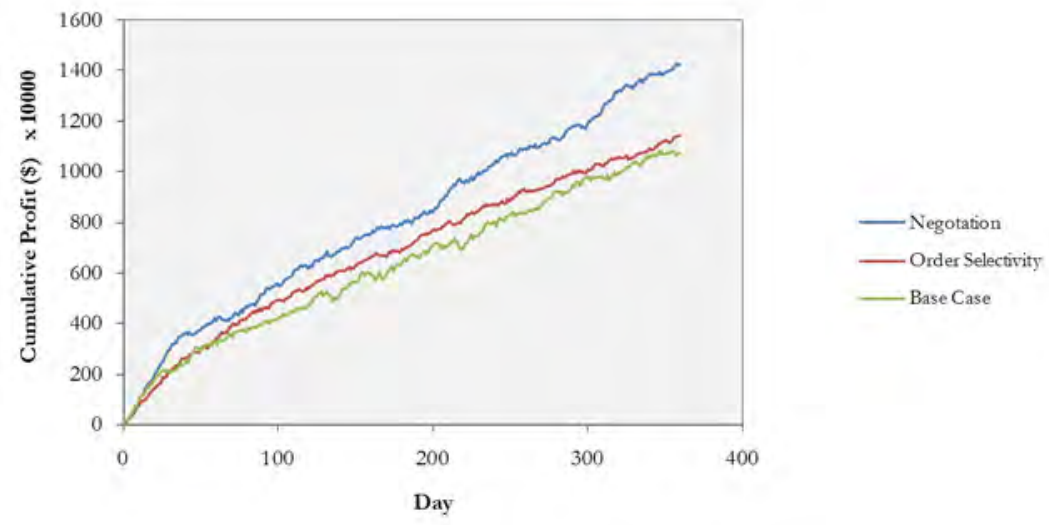

Figure 5.2: Annual profit in the first set of experiments

Since in this case, orders are accepted easily, the order acceptance history of customers is good (Figure 5.3), but this good history will be compromised later when customers receive their orders with considerable delay.

Accepting every incoming order as long as capacity allows does not seem to be a logical policy in a competitive business environment. Adopting this policy for order acceptance leads to commitment of production capacity in a way that accepting more profitable orders in the near future is no longer feasible. The situation for enterprise becomes worse when delayed deliveries also harm the reputation of the enterprise. The enterprise loses potential profitable customers on the one side and current customers who face late deliveries on the other side.

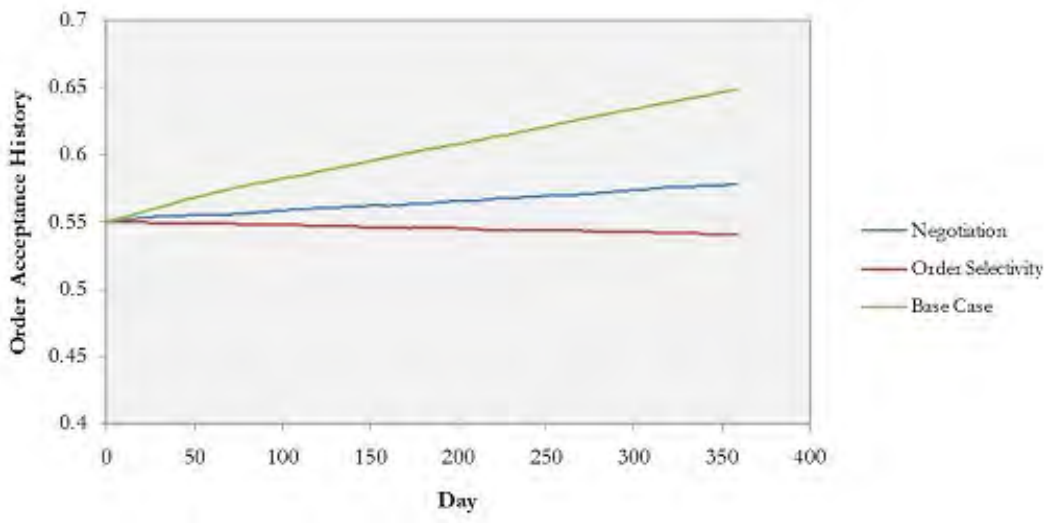

Figure 5.3: Order acceptance history in the first set of experiments

To address this situation, the enterprise may choose which orders worth accepting by checking the profit contribution of each order (the second setting). In this case, the enterprise seeks to maximize its profit by only accepting those orders for which their revenue is at least $20 \%$ greater than the cost of the requested resources. With this strategy, the number of accepted orders will decrease considerably but at the same time the annual profit 
increases. There are two main factors in this case, reducing the number of accepted orders: the first one is the profitability check of the enterprise and the second is the order acceptance history of the customers. However, as production capacity of the plants is assigned to more profitable orders, and because there is no lateness penalty for the enterprise, the profit will be higher compared to the base case. This clearly shows the effectiveness of selecting orders in terms of annual profit. Also there is no late delivery anymore (Table 5.2). Thus, the delivery history of the enterprise is improved significantly. However, given the increase in the number of rejected orders, the value of the order acceptance history of customers, forming on the basis of acceptance or rejection of their orders, will decrease.

In other words, in this case, the enterprise mainly focuses on its short-term goal of making immediate profit and does not consider the long-term goal of building relationship with customers.

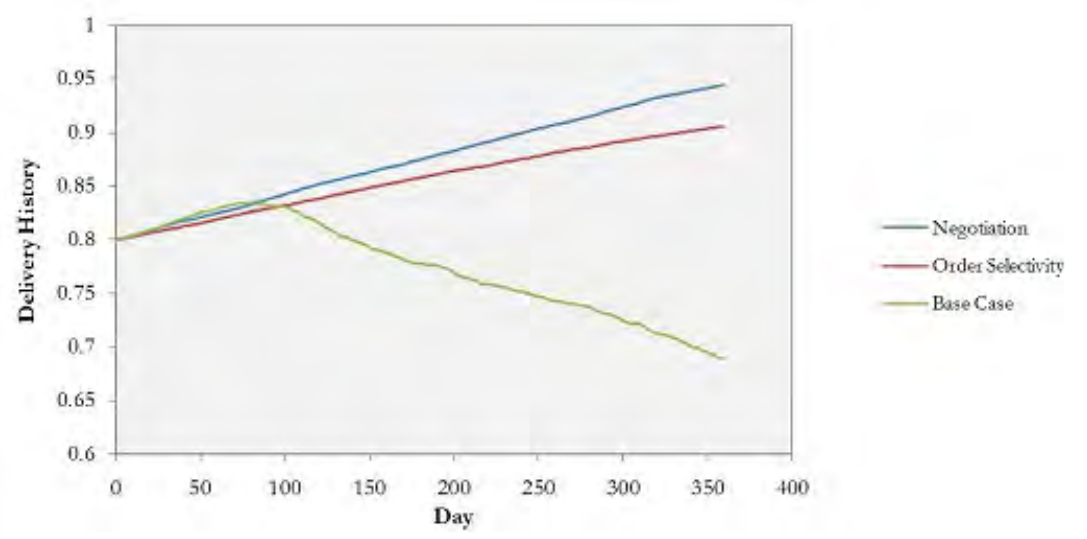

Figure 5.4: Delivery history in the first set of experiments

To consider the relationship with customers, in the third setting, the enterprise does not reject orders that fail to meet the profitability criterion, but instead begins negotiation with the customer in order to maintain relationships with its valuable customers. Thus, customer's value is another criterion for order acceptance in this setting.

As it can be observed in Figure 5.3, the order acceptance history is improved in the negotiation setting relative to the order selectivity setting. This can be attributed to consideration of customer's value and negotiation with the customers.

Table 5.2: Comparison of the number of orders in the first set

\begin{tabular}{lccc}
\cline { 2 - 4 } & Base case & Order selectivity & Negotiation \\
\hline \hline Number of finished orders & 549 & 285 & 391 \\
\hline Number of late orders & 142 & 0 & 0 \\
\hline Annual profit & 11319167 & 12961501 & 14400688 \\
\hline
\end{tabular}

In addition, negotiation on order terms results in flexibility in delivery time, and the number of late orders is reduced accordingly. Meanwhile, because of negotiation on price 
value, the final agreed price for orders is higher than the first offered price by the customers, also an important factor in the enterprise's profit improvement in this setting.

\subsection{Experimental set-up 2: effect of demand load}

In the previous set of experiments, the arrival pattern of orders follows a Poisson distribution with the average of 1.75 orders per day. In this condition, the utilization rate of each production plant in approximately $90 \%$ which is a high load.

To evaluate the effect of demand load in the previous set of experiments, the arrival rate of orders is set to 1.25 orders per day. In this case the utilization rate of the production plants is roughly reduced to $65 \%$.

In this lower-loaded environment, employing the previous profitability lower bound of $20 \%$ leads to rejection of a high number of orders and weak performance in all dimensions as compared to other policies (Figure 5.5, 5.6, and 5.7).

In the previous section, considering negotiation simultaneously with order selectivity based on profit improves the performance, however, in the lower-loaded demand situation, negotiation with the same threshold for profit (20\%) outperforms order selectivity alone. Still performance is poorer than the base case in which every incoming order is accepted as long as there is enough capacity. To adjust the lower bound of profitability in a way that the three performance indicators improve, some exploratory experiments have been conducted and the result for the first possible lower bound (10\%) which leads to the performance improvement (in three dimensions) are illustrated in Figure 5.5, 5.6, 5.7.

As observed, in a negotiation setting in which the seller uses the lower bound of $10 \%$ for the profitability check, the performance improves in all the three dimensions.

This experiment clearly shows the capability of the developed model for the fine-tuning model parameters under different situations.

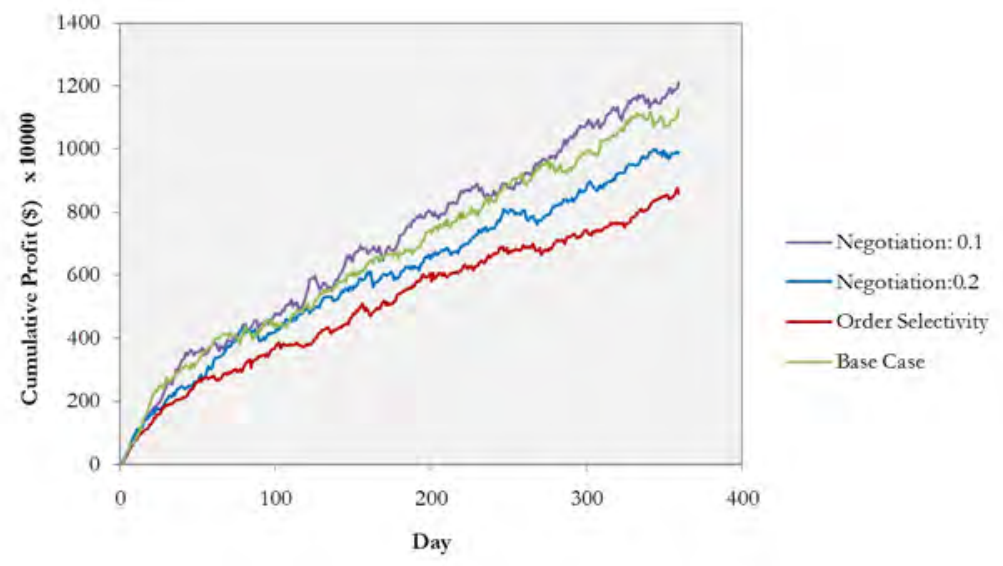

Figure 5.5: Annual profit in the lower-loaded demand situation 


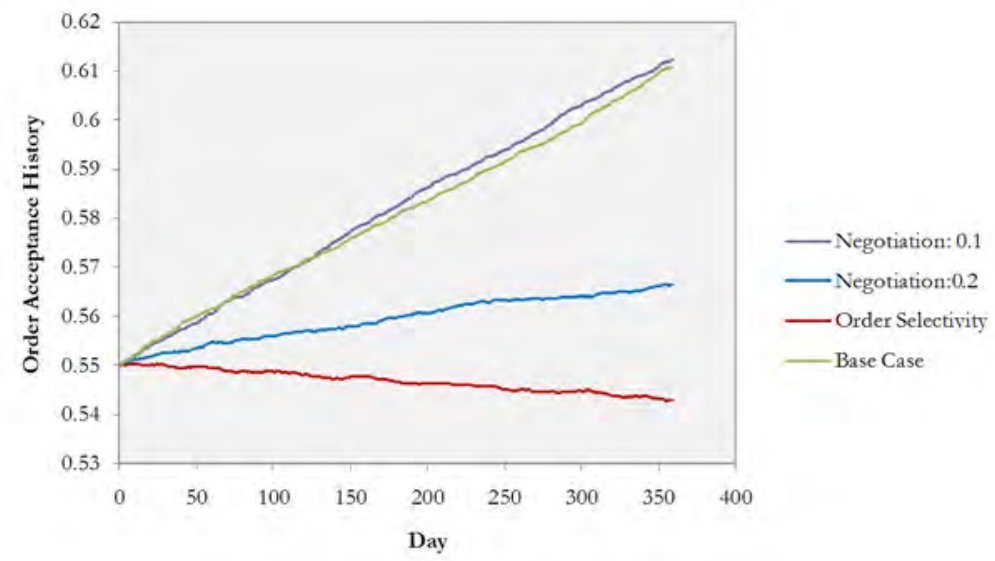

Figure 5.6: Order acceptance history in the lower-loaded demand situation

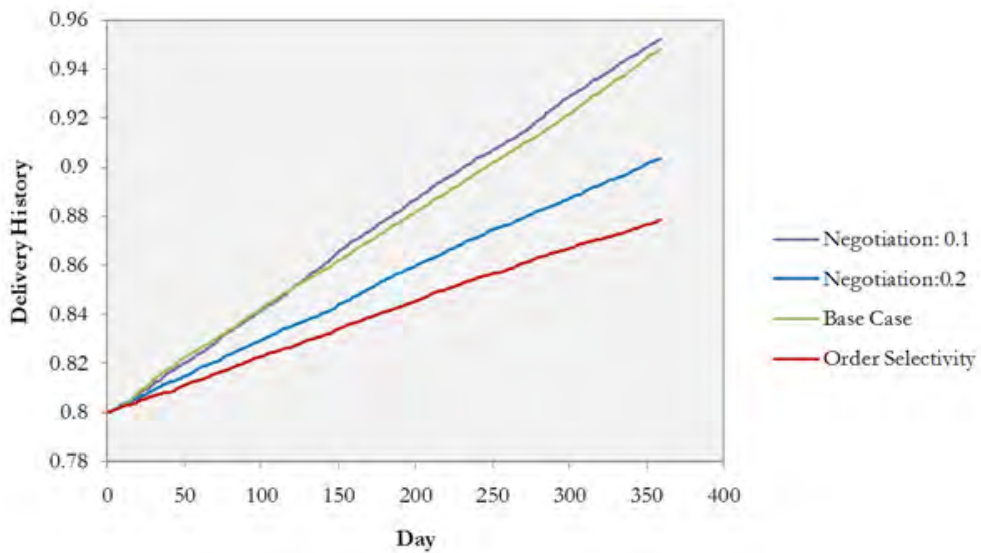

Figure 5.7: Delivery history in the lower-loaded demand situation

\subsection{Experimental set-up 3: different approaches in preparing the counter-offer}

The model developed in this research can be used to experiment with different possible settings and negotiation policies as well. Two of these experiments defined on the basis of different approaches for concession making by the enterprise. These experiments are implemented in the model and results are discussed in this section.

In the developed model in Chapter 4 and also the first set of experiments in this chapter, the seller makes concession in every round of negotiation by a constant amount. However, the enterprise may make concessions, in preparing the counter-offer for the next round, in much more intelligent ways. Two settings are introduced in this section: time-dependent concession and customer-dependent concession. 


\subsubsection{Time-dependent concession}

In the first experiment, the seller considers the effect of time in its concession-making behavior, for it is quite plausible that the buyer breaks off negotiations as time proceeds either because of its limitation on the maximum number of negotiation rounds (step limit) or acceptance of its order by an alternative supplier.

To take into account the effect of time on its concession-making behavior, the seller increases its negotiation speed (the measure of how fast concession can be made) in a linear proportion to the number of negotiation rounds, i.e. the seller concedes more rapidly as the maximum step limit approaches. Of course, the average negotiation speed equals to 1 (the value set for previous cases), hence, the formalization for the negotiation speed in this setting is a linear function of negotiation round between 0.5 and 1.5:

Negotiation Speed $=0.5+\frac{1}{\text { Step Limit-1 }} \times($ Number of rounds -1$)$

\subsubsection{Customer-dependent concession}

In the second experiment, the seller considers the sensitivity of its customer to price or delivery time in making concessions and preparing the next offer.

If the customer is price-sensitive (i.e. the enterprise knows that it is a retailer), the larger portion of the target utility (the integrated evaluation of issues in the previous offer added to the concession factor) that the seller aims to achieve is allocated to the price. The same is true for customers who are sensitive to delivery time; for due-date sensitive customers (i.e. the industrial customers), in preparing the next offer, more concession is made on the due date.

The performance of these strategies is only slightly different considering the defined performance indicators. A more interesting measure to look at is the percentage of successful negotiations in each setting. Table 5.3 compares the percentage of successful negotiations in the three settings.

Table 5.3: Comparison of successful negotiations in different concession-making approaches

\begin{tabular}{lc}
\hline Concession-making approach & Successful Negotiation (\%) \\
\hline \hline Constant concession & 0.7496 \\
\hline Time-dependent concession & 0.7530 \\
\hline Customer-dependent concession & 0.7628 \\
\hline
\end{tabular}

As it can be observed, both intelligent concession settings result in more successful negotiations; however, in this case, the concession in which the customer's sensitivity is taken into account outperforms the other two. 


\subsection{Chapter conclusion}

Three different sets of experiments have been designed and implemented in this chapter. In the first set, important perspectives on making order acceptance decisions, introduced in Chapter 2, were borrowed for designing the experiments. From the simulation results, it was concluded that employing four perspectives of integration of sales and production activities, order selectivity based on order profit, customer segmentation and negotiation with the customers for making order acceptance decisions improved financial performance of the enterprise in terms of annual profit. Also, this approach for order acceptance led to improvement in the delivery performance of the enterprise.

The chapter then has examined the effect of the demand load on the order acceptance performance of the enterprise. The simulation results showed that under a lower demand load, it was necessary to adjust the value of profit threshold in order to achieve better performance compared to the base case. Consequently, the model can be effectively used for the adjustment of parameters if it is needed.

The last set of experiments has dealt with different approaches in preparing the counteroffer. The time-dependent and customer-dependent concession-making approaches for preparing the offer for the next round were explained and compared with the constant concession-making approach. The percentage of successful negotiations in the customerdependent concession was higher compared to the other two approaches.

These experiments are clearly showed the capability of the developed simulation model in handling various experiments and can help the decision-makers in the multi-plant enterprise gain insight of their order acceptance procedure. The model also can be utilized in the order acceptance strategy development for the managers of the enterprise. 


\section{Chapter 6}

\section{Conclusion and Reflection}

This final chapter aims to draw conclusions from the research and reflects on the performed work. Section 6.1 provides an overview of the research, followed in 6.2 by answers to the research questions. Contributions of this research and some recommendations for further research are explained in 6.3 and 6.4 respectively. Section 6.5 reflects on the methodology used.

\subsection{Research overview}

The thesis started with the general problem of order acceptance (OA). OA is a critical decision in the order-driven production environments as the decisions have significant effects on the short- and long-term performance of a firm. Therefore, it is crucial for firms to carefully choose between orders worth accepting and orders that should be rejected from the viewpoint of making progress towards short- and long-term organizational goals (e.g. making profit and satisfying customers).

The objective of this research was to improve the order acceptance performance of a make-to-order multi-plant enterprise by incorporating buyer-seller negotiations in the OA procedure with the main question of "How can the buyer-seller negotiation process contribute to the improvement of order acceptance performance in the multi-plant enterprise?"

To answer this question, the research started with the literature review on order acceptance in general and negotiation in particular. A gap was identified in the OA literature: major perspectives on the OA procedure rest on the underlying assumption that order terms are already determined, which is not always tenable. In fact, order terms are usually specified by negotiations between the buyer and the seller. A negotiation-based order acceptance procedure was consequently suggested in order to consider the whole activities in a negotiation process with three phases. The proposed process involves the initiation conditions for negotiation (pre-negotiation phase), the main interaction (negotiation phase) and the consequences of negotiation on the future decisions of the involved actors (post-negotiation phase). This negotiation process is a part of more general negotiation framework which was then extended into the negotiation ontology. The ontology introduces main concepts and their relations in a negotiation problem.

Next, the conceptualization of the order negotiation process in OA and the negotiation 
ontology were used in developing an agent-based model for the buyer-seller negotiations in a case of multi-plant enterprise. The general assumptions and settings for model development came from a model previously has been presented by Behdani et al. (2010) for a lube oil multi-plant case study motivated by a real supply chain. In this research, the previous model was extended by incorporating negotiations between the enterprise and its customers in the OA context.

To illustrate the applicability of the developed model to support OA decision-making, some experiments were designed and implemented in the model. The experiments were used to evaluate the performance of several OA strategies and gain insight of the OA procedure in the MPE.

The research addressed several sub-questions. Following paragraphs provide answer to the questions.

\subsection{Addressing research questions}

\section{Negotiation framework and negotiation ontology}

To answer the question of "what are important concepts in negotiations and how the relation between them can be described?", a negotiation framework introducing the main concepts of a negotiation problem has been developed. The concepts are considered to be negotiation parties, negotiation subjects, negotiation process, negotiation context and negotiation outcome. The negotiation framework is elaborated further in the ontology for negotiation in which some new concepts are incorporated and relations between the concepts are determined. In the ontology, the interaction between the Negotiation Parties is called the Negotiation Process. The Negotiation Process has several Negotiation Phases which in turn are made up of Negotiation Activities. Negotiation Activities are performed by Negotiation Parties during the Negotiation Process. The Negotiation Parties deal with Offers to one another. There could be several Negotiation Issues in each Offer exchanged between the Negotiation Parties. The whole Negotiation Process is governed by a Negotiation Protocol which consists of several Negotiation Rules.

The ontology provides a formal presentation of the concepts and relations between them. In fact, the negotiation ontology is a conceptual model of the negotiation situation which must be shared between actors in order to understand the main concepts and get effective communication. The negotiation ontology is a basis for developing an agent-based model for the multi-plant enterprise supply chain.

The developed ontology is generic; it does not involve any problem specific details. The ontology consequently can be utilized by experts in other domains to share and annotate information for their own negotiation problem and/or use it as a basis for model development. Should a specific application require it, the negotiation ontology may be easily extended in accordance. 


\section{Agent-based modeling approach for the negotiation process in the multi plant enterprise}

Three factors lead us to choose the computer-based simulation modeling approach for this research:

1. The aim of the research is to provide insight for the MPE about its order acceptance decisions and to examine various OA policies so as to improve the performance of the enterprise. To this end, design and implementation of several experiments are required and simulation enables us to do so.

2. The complex, dynamic, adaptive and path-dependent characteristics of the system require a modeling approach which can capture (a) various stochastic behavior of several system elements (e.g. stochastic demand pattern and order attributes), and (b) changing states and relations in the system and their relevance to the previous states and decisions.

3. The capabilities of the simulation modeling approach includes allowing incorporation of many variables and parameters, manipulation of the parameters' values, obtaining the effects of these modifications very fast, and analysis of the system's behavior in different time steps which were required for our purpose.

From a range of simulation modeling techniques, agent-based modeling is chosen because its bottom-up approach is able to consider individual buyer and seller along with their heterogeneous characteristics (e.g. various objectives, needs and decision-making behaviors) and autonomous decision-making. ABM thus can perfectly capture the decentralized nature of the supply chain in this research.

Additionally, the execution of the buyer and the seller agents along with suppliers and various departments in agent-based modeling is based on internal decision rules of the agents, and not on the external and global rules. ABM, therefore, effectively enables us to analyze the collective behavior of the system, emerging from interactions of individual agents (e.g. the buyer and the seller).

ABM furthermore makes it possible to model the adaptive behavior of the buyer and seller agents that arises from their interactions during different negotiation sessions.

Agent-based modeling hence is well-suited for the objective of the study and is able to capture the characteristics of the multi-level, complex adaptive system of the MPE supply

chain. As a result, agent-based modeling is the answer to the research question of "What is an appropriate approach to model buyer-seller negotiations?"

\section{Negotiation process}

The whole interaction between the buyer and the seller in this research is divided into three phases. In the first phase (pre-negotiation phase), each party evaluates his counterparty and decides whether he wants to begin negotiations with the opponent or not. The negotiation phase is the main interaction in which the buyer and the seller try to reach an agreement on issue values. The result of this phase could be a successful negotiation (agreement on order terms) or a failed one (disagreement or a broken-off negotiation). On 
the basis of the results in the negotiation phase, the buyer and the seller update their history (perception) about each other in the post-negotiation phase. The parties' history plays role in making decision for future trades with the same counter-party.

These three phases are defined to describe the interaction between the negotiation parties and therefore, provide the answer to the second question of "What is the process in negotiation?".

To develop this conceptualization of the negotiation process in order acceptance context, the negotiation process has been approached by incorporating important viewpoints on making OA decisions. The conceptualization can be generalized in other different manufacturing situations for making OA decisions.

\section{Pre-negotiation phase}

In this phase, the buyer and the seller separately decide whether to enter negotiation with their adversary or not.

The buyer (customer) makes decision based upon its previous ordering experiences and delivery reliability of the enterprise.

The decision of the enterprise (seller) for the initiation of negotiations with the customer depends on several factors. The factors are driven from the OA literature and chosen in a way to realize the short-term goal of making immediate profit and at the same time focus on the long-term relation with customers and long-term profitability accordingly.

The first condition is the profit contribution of the customer's order; i.e. the firm assigns production capacity to only valuable orders (in terms of profit) and reserves capacity for future orders with higher profit margins. This is referred to revenue-based capacity management in the literature.

The second condition is the order's production feasibility; i.e. the enterprise makes its OA decisions with regard to the limited capacity of the production plants (this is referred to integration of sales and production functions in the literature). Only orders which can be produced and delivered before the requested due time are accepted.

The last condition is the value of the customer who places an order (customer segmentation). The value determination goes beyond immediate revenues that the customer brings to the firm. The underlying idea in the customer segmentation is to keep satisfied valuable customers and increase the probability of repeat purchase and long-term profitability accordingly.

The history that the enterprise keeps on each customer plays role in determining the customer's value. The history is based upon the frequency and value of the customer's previous purchases from the enterprise. Valuable customers are treated differently; the profit that the enterprise seeks to achieve is reduced for valuable customers in order to keep them satisfied and therefore increase the long-term profitability.

Taking into account the three factors of order selectivity based on order's profit margin, capacity of the production functions and customer segmentation in making order acceptance decisions ensures reaching profitability in the short- and long-term. This is also the answer to the research question of "Which conditions can be considered before initiating negotiations?". 


\section{Negotiation phase}

Exchanging successive offers by negotiation parties (or dance of offers in the vocabulary of Raiffa et al. (2002)) will determine the outcome of negotiation in the negotiation phase. A concession-oriented negotiation strategy which is claimed to be quite similar to the bidding behavior in the real life is used in this research to show the way that offers are exchanged. This strategy is validated in several experiments with human as well as computer negotiators in different domains (Jonker and Treur, 2001).

In this type of negotiation, an offer in a certain point in time relates to the offer at the previous time points. The offers are prepared as follows in this type of negotiation strategy: for every round, evaluations of the negotiation issues of the previous offer are determined. These evaluations are aggregated into the overall utility of the previous offer. Next, the target utility for the next offer will be determined considering a proper concession step. Finally, the target utility is divided between issues on the basis of their weights to specify the value for each issue in the new offer.

Following this procedure for preparing offers and exchanging them will determine the negotiation outcome (i.e. agreement or disagreement) and consequently provides the answer to the research question of "How the outcome of negotiations will be determined?".

\section{Post-negotiation phase}

On the basis of the outcome in the negotiation phase, whether an agreement has been reached, negotiation is broken off (because of e.g. time limitation of one party) or the seller and the buyer end in disagreement, the negotiation parties in the post-negotiation phase update the negotiation history (perception) they have about one another. There is a threshold for the negotiation history at the beginning of the simulation period which will be updated by a completely positive or negative value based on the negotiations' outcome. The positive and negative values represent successful and unsuccessful negotiations respectively.

There is also the delivery history for the customer. If the negotiation ends in an agreement but the order is delivered later than the agreed-upon delivery date, the customer updates the delivery history that it keeps on the delivery reliability of the enterprise.

The history, representing the adaptive decision-making behavior of agents, plays a role in future decisions regarding trade with the same counter-party. This provides the answer to the question of "How the negotiation outcome may influence the future behavior of actors?"

\section{Agent-based model for the negotiation process in MPE}

The negotiation ontology is used as a basis to develop an agent-based model for the negotiation process in MPE.

To implement the described negotiation process for the agent interactions in the MPE, for the focal agents in the negotiation process; i.e. the seller (global sales department) and buyers (customers), different attributes and rules are defined. These attributes and rules capture the agent's behavior in computer-based agents. This provides the answer to the question of "How the behavior of actors and the negotiation process can be reflected in a model?". In summary: 
- Each agent has the history in which it keeps its perception about the other agent and updates it on the basis of its interaction with the counterpart. The history is used in the evaluation of the counterpart for the future trades.

- Each agent also has a utility function, evaluation functions for negotiation issues, weight factors for issues, concession factor, acceptable utility gap size, step limit which are used in preparing offers and evaluating offers of its counterpart following the procedure described in the negotiation phase.

- The other aspects of agents' behaviors are based on the case description previously has been presented by Behdani et al. (2010).

The ontology concepts, agent attributes and rules are implemented in the Repast simulation toolkit using Java codes as different fields and methods. It should be noted that although the agents are developed for this chemical multi-plant enterprise, the nature of the designed structure is so that they can be customized for other cases in various industrial domains.

\section{Order acceptance experiments}

To answer the research question of "How the developed model can be used to improve understanding of decision makers about the negotiation process in the order acceptance procedure of MPE?", three sets of experiments mostly based upon salient perspectives in OA have been designed and implemented in the simulation model so as to evaluate the MPE performance under different settings.

The integration of sales and production activities, order selectivity based on the order's profit contribution, customer segmentation and negotiation with the customers are the main focus in the first set of experiments.

The performance of different settings of order acceptance in high and low-loaded demand situation is investigated in the second set of experiments.

In the third set of experiments, the emphasis is on the value and sensitivity of the customers to order attributes and effect of each on the offer preparation for the next negotiation round.

Although the experiment sets provide valuable insights for the decision makers in the enterprise (usually managers) into the nature of negotiation in the MPE supply chain and can contribute to the understanding of strategy development for order acceptance, they are only some of the possible experiments that can be performed. The model is quite flexible in designing and analyzing other experiments in order to evaluate the enterprise performance under different OA settings.

\subsection{Research contribution}

The main contribution of this work is to conceptualize and develop an agent-based model for the buyer-seller negotiation process to improve the order acceptance performance of a multi-plant enterprise. For conceptualization, the issue of order acceptance has been investigated in the relevant literature. It is then concluded that several significant points of view in OA (i.e. integration of sales/marketing and production activities, order selectivity 
based on profit, and customer segmentation) rest on the underlying assumption that the value of issues in the customers' orders (e.g. price and delivery time) are already agreed upon, which is not always the case in reality. Order terms are often specified by negotiations between the buyer and the seller. There is, however, scant literature that directly addresses the buyer-seller negotiations in the OA context, and those which incorporate negotiation merely emphasize negotiation per se in a single session. Little attention has been paid to the initiative conditions for negotiation and repercussions of the negotiation outcome on the future decision-making behavior of the involved parties.

To address this void, we develop a negotiation-based order acceptance approach in which negotiation is considered simultaneously with other mentioned concepts in the OA literature. In other words, to have a model which can capture the performance of the enterprise, we consider all the steps of a negotiation process:

1. conditions in which a firm initiates negotiation with its customers,

2. how the negotiation takes place, and

3. how the negotiation outcome, directly or indirectly, influences the counterpart behavior for future interactions.

On the basis of these steps, the whole encounter between the seller and the buyer is conceptualized in three phases to show the initiation conditions for negotiation (pre-negotiation phase), the main interaction (negotiation phase) and the consequences of negotiation on the future decisions of the involved actors (post-negotiation phase). Considering all these steps in one conceptualization for the negotiation-based order acceptance is one of the main contributions of this work.

Furthermore, important aspects and their relations in a negotiation problem are conceptualized in a negotiation ontology that can be used in various socio-technical settings. Domain experts can share the ontology and annotate information for their own negotiation problem. The developed ontology can provide a modeler with a sound conceptualization for developing agent-based models on negotiation.

To show the applicability of the negotiation ontology and the conceptualization, an agent-based model for the interaction of buyers and a seller in the order acceptance context for the specific case of a multi-plant enterprise has been developed.

In contrast to most of previous works on negotiation in the order fulfillment process which mainly focus on a single session of negotiation, the developed model in this research is able to evaluate the short- and long-term effects of different negotiation settings on the performance of an enterprise. In the model, the negotiation between the enterprise (the seller) and each of its customers (the buyers) would happen several times during the simulation time. This allows evaluating the effect of negotiation on the parties' behavior and the performance of the multi-plant enterprise at the end of simulation time.

Several experiments in the model have been also performed. Decision makers in the multi-plant enterprise can use the model to gain understanding of their order acceptance decisions and effectively develop strategies that can help realizing their organizational goals.

Moreover, the agents developed in this research can also be reused in developing other models for other industrial supply chains as described by van Dam (2009). 


\subsection{Recommendation for further research}

The purpose in this research is to conceptualize the negotiation process and apply it in an agent-based model for a specific problem setting of a multi-plant enterprise. It is worthwhile to apply this conceptualization in other cases after fine-tuning it to the problem-specific parameters. This could further show the merits of the developed conceptualization.

In addition, the negotiation parties in this research do not reveal their preferences to each other (close negotiation); only the offers are exchanged. This may affect the efficiency of the negotiation outcome. Therefore, a suggestion for further development of the model could be implementing some learning methods in the model to allow the parties to gain insight about each other's preferences (e.g. utility function and weight factors for issues) and as a result make more efficient concessions to reach an agreement without utility waste. A good example of a learning algorithm is suggested by Tykhonov (2010).

Another possible direction for further development is extending the model by considering information sharing between the negotiation parties. This is especially interesting if the negotiation conceptualization and the ontology developed in this work will be used for the negotiation between the production plants and their suppliers in the supply chain; as there are several interesting topics in the operation management literature on the information sharing with suppliers (e.g., vendor managed inventory (VMI)) that can significantly improve the performance of the supply chain as a whole.

In this research, the utility functions of the parties belong to the linear additive class of utility functions; i.e. there is no dependency between the negotiation issues. Although there are some approximation methods to eliminate the dependencies between the negotiation issues in the utility functions of parties (Hindriks et al., 2006) and use the linear function instead, it is worthwhile to explicitly consider issue dependencies in the utility functions and explore the behavior of the system under these conditions.

Other areas for future research could be considering different evaluation functions and various response times when the offers are exchanged.

\subsection{Reflection}

In this research we used agent-based modeling to explore the possible outcomes of our developed conceptualization. We chose this modeling tool based on the characteristics of the specific problem we faced. In other words, the nature of the buyer-seller negotiation context we encountered seemed to match the individual bottom-up approach of agent-based modeling.

With the agent-based model, we could develop a valuable model that captured the characteristics of our actors and their interactions in the order acceptance context. We performed some experiments that provided insight about the nature of negotiation in a supply chain setting and could help the manager in MPE to gain insight about the OA procedure in the enterprise. The model could also be used for strategy development in the OA context as AB modeling approach provided us with a decentralized flexible model that can be used and extended if it is necessary.

Nonetheless, other simulation approaches could have also been used to tackle this prob- 
lem. It would have been interesting to find out how we would model this system with other approaches. After all, it is never impossible to simulate systems which were approached by ABM with other methods such as system dynamics, but the process of simulation might be more difficult and time consuming.

One other reflection regarding this research pertains to the implementation tool we used. Although we implemented our model in Repast platform and used some of its libraries, it would have been more helpful if we had used the full potential of this platform. Due to time limitations, there was only the chance to learn the Java programming language, the overall structure of Repast and some of the many libraries existing in this platform. We could have also used the tools for making charts and diagrams from the model runs without having to use an external spreadsheet (Excel).

Also, it would be more efficient in terms of time and effort to use Excel macros or other statistical software for analysis of the model's results instead of using readily available functions that limit the options for analysis.

Additionally, in this research we designed and implemented some experiments to show the effect of negotiation on the performance of the enterprise on one hand and the capabilities of the developed model on the other hand. These experiments were among the many that could be performed to gain insight of the problem. In this research, we chose the ones that directly consider the effect of different OA concepts and some various behaviors of the seller agent in negotiations. Several other experiments can be performed in order to gain better understanding of the research issue. The relevant literature could be consulted in designing new experiments. This may be also helpful in the validation process if some similar results with the ones in the literature could be obtained (under similar conditions, of course).

Consulting the relevant literature could be extremely helpful in all stages of research from the beginning to the end. It is always possible to gain insight to others' works and develop your own ideas for the problem at hand. 


\section{Bibliography}

Akkan, C. (1997). Finite-capacity scheduling-based planning for revenue-based capacity management. European Journal of Operational Research, 100(1):170 - 179.

Arredondo, F. and Martinez, E. (2010). Learning and adaptation of a policy for dynamic order acceptance in make-to-order manufacturing. Computers $\&$ Industrial Engineering, $58(1): 70-83$.

Babaioff, M. and Walsh, W. E. (2005). Incentive-compatible, budget-balanced, yet highly efficient auctions for supply chain formation. Decision Support Systems, 39(1):123 - 149.

Balci, O. (1994). Validation, verification, and testing techniques throughout the life cycle of a simulation study. Annals of Operations Research, 53(1):121-173.

Banerjee, A. (1986). A joint economic-lot-size model for purchaser and vendor. Decision Sciences, 17:292-311.

Barut, M. and Sridharan, V. (2005). Revenue management in order-driven production systems. Decision Sciences, 36(2):287-316.

Bazerman, M., Curhan, J., and Moore, D. (2007). The Death and Rebirth of the Social Psychology of Negotiation in Blackwell Handbook of Social Psychology: Interpersonal Processes. Blackwell Publishers Ltd, Malden, MA, USA.

Behdani, B., Lukszo, Z., Adhitya, A., and Srinivasan, R. (2009). Agent-based modeling to support operations management in a multi-plant enterprise. In International Conference on Networking, Sensing and Control, 2009. ICNSC '09., pages 323-328.

Behdani, B., Lukszo, Z., Adhitya, A., and Srinivasan, R. (2010). Performance analysis of a multi-plant specialty chemical manufacturing enterprise using an agent-based model. Computers \&6 Chemical Engineering, 34(5):793 - 801.

Bobashev, G. V., Goedecke, D. M., Yu, F., and Epstein, J. M. (2007). A hybrid epidemic model: combining the advantages of agent-based and equation-based approaches. In WSC '07: Proceedings of the 39th conference on Winter simulation, pages 1532-1537.

Bonabeau, E. (2002). Predicting the unpredictable. Harvard Business Review, 80(3):109117. 
Borshchev, A. and Filippov, A. (2004). From system dynamics and discrete event to practical agent based modeling: Reasons, techniques, tools. In Proceedings of the 22nd International Conference of the System Dynamics Society, pages 25-29.

Bosse, T. and Jonker, C. (2005). Human vs. computer behavior in multi-issue negotiation. Rational, Robust, and Secure Negotiation Mechanisms in Multi-Agent Systems, pages $11-24$.

Cakravastia, A. and Nakamura, N. (2002). Model for negotiating the price and due date for a single order with multiple suppliers in a make-to-order environment. International journal of production research, 40(14):3425-3440.

Calosso, T., Cantamessa, M., and Gualano, M. (2004). Negotiation support for make-toorder operations in business-to-business electronic commerce. Robotics and ComputerIntegrated Manufacturing, 20(5):405 - 416 .

Calosso, T., Cantamessa, M., Vu, D., and Villa, A. (2003). Production planning and order acceptance in business to business electronic commerce. International Journal of Production Economics, 85(2):233 - 249.

Cannon, J. and Perreault, W. (1999). Buyer-seller relationships in business markets. Journal of Marketing Research, 36(4):439-460.

Carnevale, P. J. D. and Isen, A. M. (1986). The influence of positive affect and visual access on the discovery of integrative solutions in bilateral negotiation. Organizational Behavior and Human Decision Processes, 37(1):1-13.

Carr, S. and Duenyas, I. (2000). Optimal Admission Control and Sequencing in a Maketo-Stock/Make-to-Order Production System. Operations Research, 48(5):709-720.

Chamodrakas, I., Alexopoulou, N., and Martakos, D. (2009). Customer evaluation for order acceptance using a novel class of fuzzy methods based on topsis. Expert Systems with Applications, 36(4):7409 - 7415 .

Charnsirisakskul, K., Griffin, P., and Keskinocak, P. (2004). Order selection and scheduling with leadtime flexibility. IIE transactions, 36(7):697-707.

Chen, Y., Peng, Y., Finin, T., Labrou, Y., Cost, S., Chu, B., Yao, J., Sun, R., and Wilhelm, B. (1999). A negotiation-based multi-agent system for supply chain management. Working Notes of the agents, 99.

Chen, Y.-M. and Huang, P.-N. (2007). Bi-negotiation integrated ahp in suppliers selection. Benchmarking: An International Journal, 15(5):575 - 593.

Choi, T., Dooley, K., and Rungtusanatham, M. (2001). Supply networks and complex adaptive systems: control versus emergence. Journal of Operations Management, 19(3):351366 .

Chung, C. (2004). Simulation modeling handbook: a practical approach. CRC Press, New York, USA. 
Cicirello, V. and Smith, S. (2004). Wasp-like agents for distributed factory coordination. Autonomous Agents and Multi-agent systems, 8(3):237-266.

Cohen, M. and Stathis, K. (2001). Strategic change stemming from e-commerce: implications of multi-agent systems on the supply chain. Strategic change, 10(3):139-149.

Cooper, W., Seiford, L., and Tone, K. (2007). Data envelopment analysis: a comprehensive text with models, applications, references and DEA-solver software. Springer Verlag.

Cramton, P. C. (1991). Dynamic bargaining with transaction costs. Management Science, $37: 1221-1233$.

Defregger, F. and Kuhn, H. (2007). Revenue management for a make-to-order company with limited inventory capacity. OR Spectrum, 29:137-156.

Docherty, J. (2003). Culture and Negotiation: Symmetrical Anthropology for Negotiators. Marq. L. Rev., 87:711.

Ebadian, M., Rabbani, M., Jolai, F., Torabi, S., and Tavakkoli-Moghaddam, R. (2008). A new decision-making structure for the order entry stage in make-to-order environments. International Journal of Production Economics, 111(2):351 - 367.

Ebben, M. J. R., Hans, E. W., and Olde Weghuis, F. M. (2005). Workload based order acceptance in job shop environments. OR Spectrum, 27:107-122.

Ervolina, T., Ettl, M., Lee, Y., and Peters, D. (2009). Managing product availability in an assemble-to-order supply chain with multiple customer segments. OR spectrum, $31(1): 257-280$.

Fan, L. and Chen, X. (2008). Order acceptance and capacity allocation policies based on revenue management. In International Conference on Information Management, Innovation Management and Industrial Engineering ICIII'08, volume 3, pages 248 -251.

Fang, F., Xin, Y., Yun, X., and Haitao, X. (2008). An Opponent's Negotiation Behavior Model to Facilitate Buyer-seller Negotiations in Supply Chain Management. In Proceedings of the 2008 International Symposium on Electronic Commerce and Security-Volume 00, pages 582-587. IEEE Computer Society.

Fisher, R., Ury, W., and Patton, B. (1991). Getting to yes: Negotiating agreement without giving in. Penguin Group USA.

Francis, D. (2008). Some structures of negotiation talk. Language in Society, 15(01):53-79.

Garcia, R. (2005). Uses of Agent-Based Modeling in Innovation/New Product Development Research. Journal of Product Innovation Management, 22(5):380-398.

Garcia-Flores, R. and Wang, X. Z. (2002). A multi-agent system for chemical supply chain simulation and management support. OR Spectrum, 24:343-370. 
Gordon, G. (1961). A general purpose systems simulation program. In AFIPS '61 (Eastern): Proceedings of the December 12-14, 1961, eastern joint computer conference: computers - key to total systems control, pages 87-104, NY, USA.

Goyal, S. K. (1988). "a joint economic-lot-size model for purchaser and vendor": A comment. Decision Sciences, 19:236-241.

Guillen, G., Pina, C., Espua, A., and Puigjaner, L. (2005). Optimal offer proposal policy in an integrated supply chain management environment. Industrial 63 Engineering Chemistry Research, 44(19):7405-7419.

Guttman, R. and Maes, P. (1998). Cooperative vs. competitive multi-agent negotiations in retail electronic commerce. In Klusch, M. and Weib, G., editors, Cooperative Information Agents II Learning, Mobility and Electronic Commerce for Information Discovery on the Internet, volume 1435 of Lecture Notes in Computer Science, pages 135-147. Springer Berlin / Heidelberg.

Harris, F. and Pinder, J. (1995). A revenue-management approach to demand management and order booking in assemble-to-order manufacturing. Journal of Operations Management, 13(4):299-309.

Hill, T. (2000). Manufacturing strategy: text and cases. Irwin McGraw-Hill, New York.

Hindriks, K., Jonker, C., and Tykhonov, D. (2006). Eliminating interdependencies between issues for multi-issue negotiation. In Klusch, M., Rovatsos, M., and Payne, T., editors, Cooperative Information Agents X, volume 4149 of Lecture Notes in Computer Science, pages 301-316. Springer Berlin / Heidelberg.

Hing, M. M., Harten, A. V., and Schuur, P. C. (2007). Reinforcement learning versus heuristics for order acceptance on a single resource. Journal of Heuristics, 13(2):167187.

Homburg, C., Droll, M., and Totzek, D. (2008). Customer prioritization: Does it pay off, and how should it be implemented? Journal of Marketing, 72(5):110-130.

Huang, S., Lu, M., and Wan, G. (2010). Integrated order selection and production scheduling under mto strategy. International Journal of Production Research, iFirst:1-17.

Ito, T. and Rizal Salleh, M. (2000). A blackboard-based negotiation for collaborative supply chain system. Journal of Materials Processing Technology, 107(1-3):398-403.

Jalora, A. (2006). Order acceptance and scheduling at a make-to-order system using revenue management. PhD thesis, Texas A\&M University.

Jansen, D. R., van Weert, A., Beulens, A. J. M., and Huirne, R. B. M. (2001). Simulation model of multi-compartment distribution in the catering supply chain. European Journal of Operational Research, 133(1):210 - 224 .

Jennings, N. (2001). An agent-based approach for building complex software systems. Communications of the ACM, 44(4):35-41. 
Jennings, N. R., Sycara, K., and Wooldridge, M. (1998). A roadmap of agent research and development. Autonomous Agents and Multi-Agent Systems, 1:7-38.

Ji, G. and Yang, C. (2010). Uni-objective negotiating mechanism of supply chain management based on multi-agent. In 7 th International Conference on Service Systems and Service Management (ICSSSM), pages $1-5$.

Jonker, C., Robu, V., and Treur, J. (2007). An agent architecture for multi-attribute negotiation using incomplete preference information. Autonomous Agents and MultiAgent Systems, 15:221-252.

Jonker, C. and Treur, J. (2001). An agent architecture for multi-attribute negotiation. In International joint conference on artificial intelligence, volume 17, pages 1195-1201.

Jung, H., Jeong, B., and Lee, C.-G. (2008). An order quantity negotiation model for distributor-driven supply chains. International Journal of Production Economics, 111(1):147 - 158 .

Kaihara, T. (2003). Multi-agent based supply chain modelling with dynamic environment. International Journal of Production Economics, 85(2):263 - 269. Supply Chain Management.

Keeney, R. and Raiffa, H. (1993). Decisions with multiple objectives. Cambridge University Press.

Kelle, P., Transchel, S., and Minner, S. (2009). Buyer-supplier cooperation and negotiation support with random yield consideration. International Journal of Production Economics, 118(1):152 - 159.

Keskinocak, P., Ravi, R., and Tayur, S. (2001). Scheduling and Reliable Lead-Time Quotation for Orders with Availability Intervals and Lead-Time Sensitive Revenues. Management Science, 47(2):264-279.

Kolisch, R. (2001). Make-to-order assembly management. Springer Verlag.

Korpela, J., Kylaheiko, K., Lehmusvaara, A., and Tuominen, M. (2002). An analytic approach to production capacity allocation and supply chain design. International Journal of Production Economics, 78(2):187 - 195.

Kremenyuk, V. and Sjostedt, G. (2000). International economic negotiation: models versus reality. Edward Elgar Pub.

Lim, M. and Zhang, Z. (2003). A multi-agent based manufacturing control strategy for responsive manufacturing. Journal of Materials Processing Technology, 139(1-3):379384 .

Lin, F. and Lin, Y. (2006). Integrating multi-agent negotiation to resolve constraints in fulfilling supply chain orders. Electronic Commerce Research and Applications, 5(4):313322. 
Macal, C. and North, M. (2010). Tutorial on agent-based modelling and simulation. Journal of Simulation, 4(3):151-162.

Manzini, R., Ferrari, E., Gamberi, M., Persona, A., and Regattieri, A. (2005). Simulation performance in the optimisation of the supply chain. Journal of Manufacturing Technology Management, 16(2):127-144.

McCarthy, I. (2003). Technology management-a complex adaptive systems approach. International Journal of Technology Management, 25(8):728-745.

McMains, M. and Mullins, W. (2006). Crisis negotiations: Managing critical incidents and hostage situations in law enforcement and corrections. No.: ISBN 1-59345-323-X, page 603.

Meyr, H. (2009). Customer segmentation, allocation planning and order promising in maketo-stock production. OR Spectrum, 31:229-256.

Missbauer, H. (2003). Optimal lower bounds on the contribution margin in the case of stochastic order arrival. OR Spectrum, 25:497-519.

Moodie, D. (1999). Due date demand management: negotiating the trade-off between price and delivery. International journal of production research, 37(5):997-1021.

Moss, S. (2008). Alternative approaches to the empirical validation of agent-based models. Journal of Artificial Societies and Social Simulation, 11(1):5.

Muthoo, A. (1999). Bargaining theory with applications. Cambridge University Press.

Nandi, A. and Rogers, P. (2006). Optimal control of make-to-order manufacturing systems via selected order acceptance. Winter Simulation Conference, 0:2003-2011.

Nguyen, T. D. and Jennings, N. R. (2005). Managing commitments in multiple concurrent negotiations. Electronic Commerce Research and Applications, 4(4):362 - 376.

Nie, L., Xu, X., and Zhan, D. (2006). Model for negotiating prices and due dates with suppliers in Make-To-Order supply chains. Agent Computing and Multi-Agent Systems, 4088:315-326.

Nikolic, I. (2009). Co-evolutionary Method for Modeling Large-Scale Socio-Technical Systems Evolution. PhD thesis, Delft University of Technology.

Nilsson, F. and Darley, V. (2006). On complex adaptive systems and agent-based modeling for improving decision-making in manufacturing and logistics settings. International Journal of Operations $\&$ Production Management, 26(12):1351-1373.

North, M. J., Collier, N. T., and Vos, J. R. (2006). Experiences creating three implementations of the repast agent modeling toolkit. ACM Trans. Model. Comput. Simul., $16(1): 1-25$.

Noy, N. and McGuinness, D. (2001). Ontology development 101: A guide to creating your first ontology. 
Oguz, C., Salman, F. S., and Yalcin, Z. B. (2010). Order acceptance and scheduling decisions in make-to-order systems. International Journal of Production Economics, 125(1):200 - 211.

Osborne, M. and Rubinstein, A. (1994). A course in game theory. The MIT press.

Padgham, L. and Winikoff, M. (2003). Prometheus: a methodology for developing intelligent agents. In AOSE'02: Proceedings of the 3rd international conference on Agentoriented software engineering III, pages 174-185, Berlin, Heidelberg. Springer-Verlag.

Parry, G. and Graves, A. (2008). Build to order: the road to the 5-day car. Springer.

Praca, I., Viamonte, M., Ramos, C., and Vale, Z. (2006). A Multi-Agent Market Simulator to Support Negotiation Decision Making. Exploiting the Knowledge Economy: Issues, Applications and Case Studies, page 149.

Quante, R., Meyr, H., and Fleischmann, M. (2009). Revenue management and demand fulfillment: matching applications, models, and software. OR Spectrum, 31:31-62.

Raaymakers, W. H. M., Bertrand, J. M., and Fransoo, J. C. (2000). The performance of workload rules for order acceptance in batch chemical manufacturing. Journal of Intelligent Manufacturing, 11:217-228. 10.1023/A:1008999002145.

Rahmandad, H. and Sterman, J. (2008). Heterogeneity and network structure in the dynamics of diffusion: Comparing agent-based and differential equation models. Management Science, 54(5):998-1014.

Rahwan, I., Kowalczyk, R., and Pham, H. H. (2002). Intelligent agents for automated one-to-many e-commerce negotiation. In ACSC '02: Proceedings of the twenty-fifth Australasian conference on Computer science, pages 197-204, Darlinghurst, Australia.

Raiffa, H., Richardson, J., and Metcalfe, D. (2002). Negotiation analysis: The science and art of collaborative decision making. Belknap Press.

Rapoport, A., Erev, I., and Zwick, R. (1995). An Experimental Study of Buyer-Seller Negotiation with One-Sided Incomplete Information and Time Discounting. Management Science, 41(3):377-394.

Renna, P. and Argoneto, P. (2010). Production planning and automated negotiation for smes: An agent based e-procurement application. International Journal of Production Economics, 127(1):73 - 84.

Robinson, S. (2004). Simulation: The practice of model development and use. John Wiley \& Sons.

Rosenschein, J. S. and Zlotkin, G. (1994). Rules of encounter: designing conventions for automated negotiation among computers. MIT Press, Cambridge, MA, USA.

Roundy, R., Chen, D., Chen, P., Cakanyildirim, M., Freimer, M. B., and Melkonian, V. (2005). Capacity-driven acceptance of customer orders for a multi-stage batch manufacturing system: models and algorithms. IIE Transactions, 37(12):1093-1105. 
Rubin, P. and Carter, J. (1990). Joint optimality in buyer-supplier negotiations. Journal of Purchasing and Materials Management, 26:20-25.

Russ, C. and Walz, A. (2009). Macsima: On the effects of adaptive negotiation behavior in agent-based supply networks. In Braubach, L., van der Hoek, W., Petta, P., and Pokahr, A., editors, Multiagent System Technologies, volume 5774 of Lecture Notes in Computer Science, pages 128-140. Springer Berlin / Heidelberg.

Russell, S. and Norvig, P. (2002). Artificial intelligence: a modern approach. Prentice hall.

Sebenius, J. K. (1992). Negotiation Analysis: A Characterization and Review. Management Science, 38(1):18-38.

Shoham, Y. and Leyton-Brown, K. (2009). Multiagent systems: algorithmic, game-theoretic, and logical foundations. Cambridge University Press.

Slantchev, B. (2004). The principle of convergence in wartime negotiations. American Political Science Review, 97(04):621-632.

Slikker, M. and Van den Nouweland, A. (2001). Social and economic networks in cooperative game theory. Springer Netherlands.

Stacey, R. (2000). The Emergence of Knowledge in Organization. Emergence, 2(4):23-39.

Sutton, R. and Barto, A. (1998). Reinforcement learning: An introduction. The MIT press.

Talluri, S. (2002). Enhancing supply decisions through the use of efficient marginal costs models. Journal of Supply Chain Management, 38(4):4-10.

Talluri, S., Vickery, S. K., and Narayanan, S. (2008). Optimization models for buyersupplier negotiations. International Journal of Physical Distribution 63 Logistics Management, 38(7):551 - 561 .

ten Kate, H. A. (1994). Towards a better understanding of order acceptance. International Journal of Production Economics, 37(1):139 - 152.

Tollison, R. and Willett, T. (2009). An economic theory of mutually advantageous issue linkages in international negotiations. International Organization, 33(04):425-449.

Tykhonov, D. (2010). Designing Generic and Efficient Negotiation Strategies. PhD thesis, Delft University of Technology.

Umeda, S. and Zhang, F. (2006). Supply chain simulation: generic models and application examples. Production Planning $\&$ Control: The Management of Operations, 17(2):155166.

Valluri, A. and Croson, D. C. (2005). Agent learning in supplier selection models. Decision Support Systems, 39(2):219 - 240.

van Dam, K. H. (2009). Capturing socio-technical systems with agent-based modelling. $\mathrm{PhD}$ thesis, Delft University of Technology. 
van der Vorst, J. G. A. J., Beulens, A. J. M., and van Beek, P. (2000). Modelling and simulating multi-echelon food systems. European Journal of Operational Research, 122(2):354 -366 .

van Foreest, N., Wijngaard, J., and van der Vaart, T. (2010). Scheduling and order acceptance for the customised stochastic lot scheduling problem. International Journal of Production Research, 48(12):3561-3578.

Weber, C., Current, J., and Desai, A. (1998). Non-cooperative negotiation strategies for vendor selection. European Journal of Operational Research, 108(1):208-223.

Weber, C. and Desai, A. (1996). Determination of paths to vendor market efficiency using parallel coordinates representation: a negotiation tool for buyers. European Journal of Operational Research, 90(1):142-155.

Wester, F. A. W., Wijngaard, J., and Zijm, W. R. M. (1992). Order acceptance strategies in a production-to-order environment with setup times and due-dates. International Journal of Production Research, 30(6):1313 -1326.

Wong, T. N. and Fang, F. (2010). A multi-agent protocol for multilateral negotiations in supply chain management. International Journal of Production Research, 48(1):271-299.

Yokoo, M., Durfee, E., Ishida, T., and Kuwabara, K. (1998). The distributed constraint satisfaction problem: Formalization and algorithms. IEEE Transactions on Knowledge and Data Engineering, 10(5):673-685.

Young, H. (1991). Negotiation analysis. University of Michigan Press.

Zartman, I. and Rubin, J. (2002). Power and negotiation. University of Michigan Press.

Zeigler, B., Praehofer, H., and Kim, T. (2000). Theory of modeling and simulation. Academic press New York, NY.

Zhu, J. (2004). A buyer-seller game model for selection and negotiation of purchasing bids: extensions and new models. European Journal of Operational Research, 154(1):150-156.

Zorzini, M., Corti, D., and Pozzetti, A. (2008). Due date (dd) quotation and capacity planning in make-to-order companies: Results from an empirical analysis. International Journal of Production Economics, 112(2):919 - 933. 


\section{Appendix A}

\section{Overview of the MPE Supply Chain}

The main actors in the multi-plant enterprise supply chain and their interactions are depicted in Figure A.1. The solid arrows show the material flow while dash arrows show information flow among the actors. 


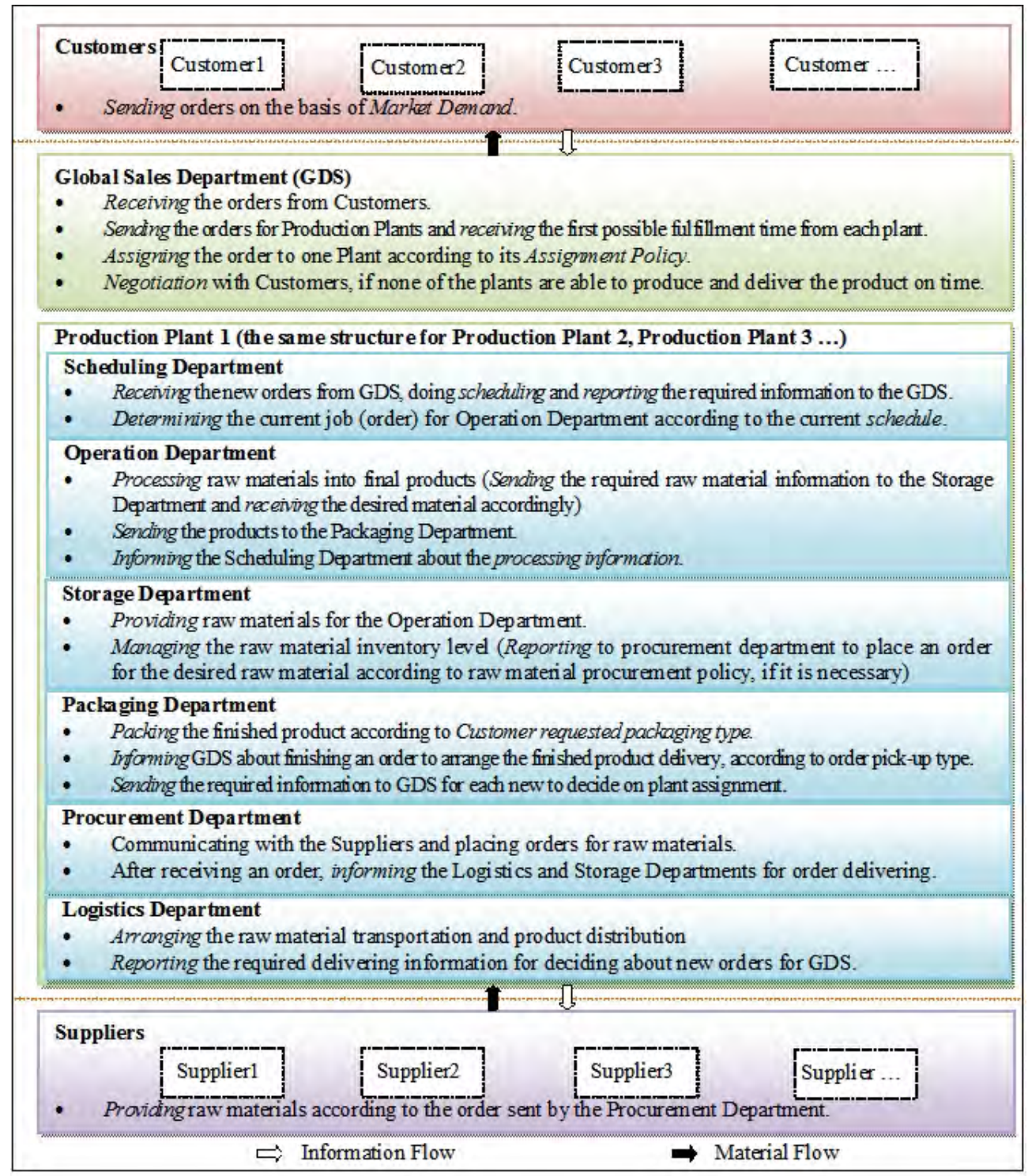

Figure A.1: Main actors and their interactions in the MPE supply chain from (Behdani et al., 2009) 


\section{Appendix B}

\section{Order Costs and Revenue}

Each order incurs some costs that are explained below.

Total cost of each order is calculated by:

Total Cost $=$ Fixed Cost + Raw Material Costs + Inventory Costs + Processing Costs + Packaging Costs + Transportation Costs

\section{Fixed Cost}

Fixed Cost is the cost incurred by the plant such as labor, infrastructure and sunk costs. This is calculated as 10 percent of the sum of other costs.

\section{Raw Material Costs}

There are three types of Lubricant products (i.e. A, B \& C) and 5 grades for each type. Each product is manufactured based on a particular ratio of raw materials and base oils as shown in the table below.

Table B.1: Product A, its grades and raw materials

\begin{tabular}{ccccccc}
\hline Grade & Base Oil 1 & ZDDP & Dispersants & MMA & Anti-Oxidants & Mental Sulfonate \\
\hline A & 0.8 & 0.1 & - & - & - & 0.1 \\
\hline B & 0.75 & - & 0.15 & - & - & 0.1 \\
\hline C & 0.8 & 0.05 & - & - & 0.15 & - \\
\hline D & 0.7 & - & 0.15 & 0.15 & - & - \\
\hline E & 0.7 & - & - & 0.2 & - & 0.1 \\
\hline
\end{tabular}


Table B.2: Product B, its grades and raw materials

\begin{tabular}{ccccccc}
\hline Grade & Base Oil 2 & ZDDP & Dispersants & MMA & Anti-Oxidants & Mental Sulfonate \\
\hline \hline A & 0.7 & 0.15 & - & - & - & 0.15 \\
\hline B & 0.8 & - & 0.1 & - & - & 0.1 \\
\hline C & 0.7 & 0.2 & - & 0.1 & - & - \\
\hline D & 0.8 & - & 0.05 & - & 0.15 & - \\
\hline E & 0.75 & - & - & 0.15 & - & 0.1 \\
\hline
\end{tabular}

Table B.3: Product C, its grades and raw materials

\begin{tabular}{ccccccc}
\hline Grade & Base Oil 3 & ZDDP & Dispersants & MMA & Anti-Oxidants & Mental Sulfonate \\
\hline \hline A & 0.75 & 0.1 & - & - & - & 0.15 \\
\hline B & 0.8 & - & - & 0.15 & - & 0.05 \\
\hline C & 0.7 & - & 0.2 & - & 0.1 & - \\
\hline D & 0.8 & 0.1 & - & - & 0.1 & - \\
\hline E & 0.7 & - & 0.15 & - & - & 0.15 \\
\hline
\end{tabular}

The cost of raw materials is considered as follows:

Table B.4: Raw material costs

\begin{tabular}{lc}
\hline Grade & Price (\$/unit) \\
\hline \hline Base Oil 1 & 35 \\
\hline Base Oil 2 & 130 \\
\hline Base Oil 3 & 255 \\
\hline ZDDP & 30 \\
\hline Dispersants & 60 \\
\hline MMA & 90 \\
\hline Anti-Oxidants & 70 \\
\hline Mental Sulfonate & 50 \\
\hline
\end{tabular}

\section{Inventory Costs}

Inventory costs are the cost of storing the raw materials at the production plants. This is calculated based on the following formula: 
Inventory Cost $=$ Total Amount of Raw Material $\times \$ 0.001 /$ Unit

\section{Processing Costs}

Processing cost is the cost of blending and processing the raw material into the lubricant products. This is calculated as $\$ 12,000 /$ day of processing.

The processing time of a job is calculated based on the following formula:

Processing Time $=$ Processing Factor $\times$ Product Quantity C.

where Processing Factor $=0.005$ for Product A; 0.002 for Product B; 0.003 for Product

\section{Packaging Costs}

Packaging costs depend on the packaging type as specified by the customer. The formula is as follows:

Packaging Cost $=$ Packaging Cost Factor $\times \frac{\text { Quantity }}{\text { PackageCapacity }}$

where

Packaging Cost Factor $=\$ 100 /$ drum; $\$ 200 /$ isotank

Package Capacity $=100$ units for drums; 500 units for isotank.

\section{Product Delivery Costs}

Product delivery costs also depend on the packaging type and are calculated as follows:

Product Delivery Costs $=$ Product Delivery Cost Factor $\times \frac{\text { Quantity }}{\text { PackageCapacity }} \times$ Delivery Time where

Product Delivery Cost Factor $=500 /$ day for each drum; 750/day for each isotank

Package capacity $=100$ units for drums; 500 units for isotank.

\section{Revenue}

Revenue is calculated when the lubricant products reach the customer's location and upon acceptance by the customer. The amount received depends on the type and the grade of the product. Revenue is calculated by:

$$
\text { Revenue }=\text { Product Revenue Factor } \times \text { Product Quantity }
$$

The product revenue factor is in the $\$ /$ unit of the product and is documented in the table below: 
Table B.5: Products revenue (\$/unit)

\begin{tabular}{cccccc} 
& Grade1 & Grade2 & Grade3 & Grade4 & Grade5 \\
\hline Type A & 100 & 110 & 120 & 130 & 140 \\
\hline Type B & 200 & 210 & 220 & 230 & 240 \\
\hline Type C & 300 & 310 & 320 & 330 & 340 \\
\hline
\end{tabular}

\section{Lateness penalty}

For each day delay in the delivery of the order, the enterprise has to pay a penalty which is equal to $5 \%$ of the value of the order. The value is the agreed price multiplied by the order quantity. 


\section{Appendix C}

\section{The Repast Model}

Below you can find the negotiation model for the multi-plant enterprise, integrated with the previously developed model. 
